Illinois State University

ISU ReD: Research and eData

Theses and Dissertations

$4-4-2014$

\title{
Location, Location, Location, The Impact Of Registered Sex Offenders On Home Sale Prices: A Case Study Of Mclean County, Illinois
}

John C. Navarro

Illinois State University, drpeppernavarro@gmail.com

Follow this and additional works at: https://ir.library.illinoisstate.edu/etd

Part of the Criminology Commons, Criminology and Criminal Justice Commons, Economics

Commons, and the Law Commons

\section{Recommended Citation}

Navarro, John C., "Location, Location, Location, The Impact Of Registered Sex Offenders On Home Sale Prices: A Case Study Of Mclean County, Illinois" (2014). Theses and Dissertations. 120.

https://ir.library.illinoisstate.edu/etd/120

This Thesis is brought to you for free and open access by ISU ReD: Research and eData. It has been accepted for inclusion in Theses and Dissertations by an authorized administrator of ISU ReD: Research and eData. For more information, please contact ISUReD@ilstu.edu. 
LOCATION, LOCATION, LOCATION, THE IMPACT OF REGISTERED SEX OFFENDERS ON HOME SALE PRICES: A CASE STUDY OF MCLEAN COUNTY, ILLINOIS

John C. Navarro

140 Pages

May 2014

Borrowing from broken windows theory, this paper addresses the impact of sex offenders' residences on neighborhood's property values in McLean County, Illinois. Three data sets were combined to explore the relationship: the addresses of registered sex offenders (RSOs) in McLean County, Illinois, the location and property characteristics of homes sold in McLean County between December 2012 to December 2013, and variables from the 2010 U.S. Census. ArcGIS was utilized to create buffers up to 0.2 of a mile around a sold home to measure the concentrations of RSOs and sexual predators (SPs) and to calculate the distance from the nearest RSO and SP. The results indicate that as registered sex offender and sexual predator concentrations increased, home selling prices decreased by $\$ 6,586$ for each registered sex offender and $\$ 9,098$ for each sexual predator within the buffer. In regards of distance, registered sex offenders and sexual predators negatively impacted home selling prices the closer they were to a home sale transaction. These findings inform the debate surrounding the requirements placed on sexual offender registration, community notification, and residency restrictions. 

LOCATION, LOCATION, LOCATION, THE IMPACT OF REGISTERED SEX OFFENDERS ON HOME SALE

PRICES: A CASE STUDY OF MCLEAN COUNTY, ILLINOIS

JOHN C. NAVARRO

\author{
A Thesis Submitted in Partial \\ Fulfillment of the Requirements \\ for the Degree of \\ MASTER OF SCIENCE \\ Department of Criminal Justice Sciences \\ ILLINOIS STATE UNIVERSITY
}


All rights reserved

INFORMATION TO ALL USERS

The quality of this reproduction is dependent upon the quality of the copy submitted.

In the unlikely event that the author did not send a complete manuscript and there are missing pages, these will be noted. Also, if material had to be removed, a note will indicate the deletion.

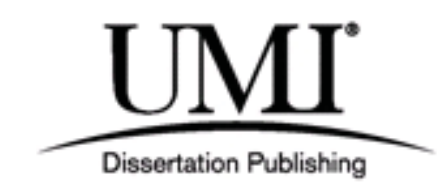

UMI 1562487

Published by ProQuest LLC (2014). Copyright in the Dissertation held by the Author.

Microform Edition () ProQuest LLC.

All rights reserved. This work is protected against unauthorized copying under Title 17, United States Code

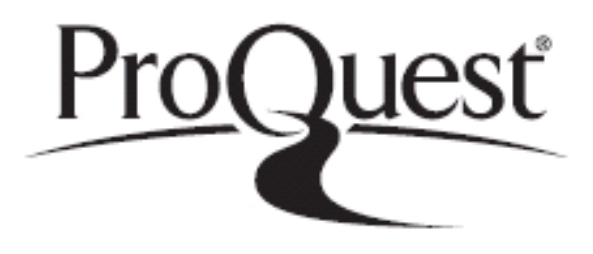

ProQuest LLC.

789 East Eisenhower Parkway

P.O. Box 1346

Ann Arbor, MI 48106 - 1346 
C2014 John C. Navarro 
LOCATION, LOCATION, LOCATION, THE IMPACT OF REGISTERED SEX OFFENDERS ON HOME SALE PRICES: A CASE STUDY OF MCLEAN COUNTY, ILLINOIS

JOHN C. NAVARRO

COMMITTEE MEMBERS:

Cara Rabe-Hemp, Chair Jason Ingram

Shelly Clevenger 


\section{ACKNOWLEDGEMENTS}

Bright minds have collaborated and assisted me in order to complete this monumental undertaking of a thesis at Illinois State University. Under the tutelage of Dr. Rabe-Hemp, this thesis has gone beyond what I believed was possible. Her kind words positioned me onto the turf of academics. I am forever indebted for her guidance and mentorship. Praise must be given for the genius-like abilities of Dr. Ingram and for tolerating my constant questions about the ugliness of what is called SPSS. For the last committee member, I thank Dr. Clevenger for her constant reinforcement. Within the Criminal Justice department, I would like to thank the kookiest chair of a department, Dr. Schneider, for knowingly distracting me from my thesis. Acknowledgment is also expressed for Dr. Beichner for allowing me to continue my studies in school under strained life moments. Assistance from the geography department enhanced my learning of ArcGIS. Individuals from the geography department tolerated my presence and offered their assistance. To Dr. Kostenick, I am grateful for the ArcGIS subscription that allowed the geocoding of my data. Lastly, as promised to Crystal Williams, who made available of her help and endured my constant presence at her office. Rest in peace, Dr. Wells.

J.C.N. 


\section{CONTENTS}

Page

ACKNOWLEDGEMENTS

CONTENTS

TABLES $\quad v$

FIGURES $\quad$ vi

CHAPTER

$\begin{array}{ll}\text { I. INTRODUCTION } & 1\end{array}$

Statement of the Problem 3

Legislation $\quad 4$

Socially Disorganization Neighborhoods 4

Housing Issues 5

$\begin{array}{ll}\text { Purpose of the Study } & 6\end{array}$

Purpose Statement $\quad 6$

Description of the Study $\quad 8$

$\begin{array}{ll}\text { Contributions to the Field } & 10\end{array}$

$\begin{array}{ll}\text { II. LITERATURE REVIEW } & 17\end{array}$

$\begin{array}{ll}\text { Introduction } & 17\end{array}$

Sex Offender Legislation $\quad 19$

Registry 19

Residency Restrictions 26

Community Notification $\quad 30$

Social Disorganization $\quad 34$

Housing $\quad 37$ 
III. METHODS

$\begin{array}{ll}\text { Introduction } & 64\end{array}$

Setting $\quad 66$

$\begin{array}{ll}\text { Data Collection } & 68\end{array}$

Registered Sex Offender List 68

Sample/Home Sale Transaction and Property Characteristics $\quad 72$

2010 Decennial U.S. Census Bureau Variables 74

ArcGIS 78

Measurement Instruments/Variables $\quad 80$

Sexual Predators $\quad 80$

Dependent Variable $\quad 81$

Independent Variables $\quad 81$

Distance $\quad 82$

Control Variables $\quad 83$

Descriptives $\quad 84$

$\begin{array}{llr}\text { IV. } & \text { RESULTS } & 87\end{array}$

$\begin{array}{lr}\text { Introduction } & 87\end{array}$

$\begin{array}{ll}\text { Concentration } & 87\end{array}$

Correlation between Dependent and Independent Variables $\quad 89$

Correlation of the Dependent Variable and Independent Variables between the Control Variables 90

Regression between Dependent and Independent Variables 92

$\begin{array}{ll}\text { Distance } & 96\end{array}$

Correlation between Dependent and Independent Variables $\quad 97$

Correlation of the Dependent Variable and Independent Variables between the Control Variables 99

Regression between Dependent and Independent Variables $\quad 100$

$\begin{array}{ll}\text { V. DISCUSSION } & 105\end{array}$

$\begin{array}{ll}\text { Introduction } & 105\end{array}$ 
Concentrations of Registered Sex Offenders Within 0.2 of a Mile 107 Concentrations of Sexual Predators Within 0.2 of a Mile

Distance to the Nearest Registered Sex Offender Within 0.2 of a Mile

Implications

Change of Population and Setting

Different Residency Restrictions

Different Reactions between Registered Sex Offenders and Sexual Predators

Concentrations of Registered Sex Offenders and Sexual Predators 
1. Summary Results of Larsen et al. (2003), Linden and Rockoff (2008), and Pope (2008) 42

2. Summary Results of Wentland et al. (2013)

3. Summary Results of Bian et al. (2013) Registered Sex Offenders Within $\leq .25$

4. Descriptive Statistics

5. Correlations Among Concentrations of Registered Sex Offenders (RSOs) and Sexual Predators (SPs) and Variables

6. Concentrations of Registered Sex Offenders (RSOs) and Sexual Predators (SPs) Within 0.2 of a Mile Predicting Sold Homes' Selling Prices

7. Calculated Isolated Financial Effect Onto Selling Price Produced by the Concentrations of Registered Sex Offenders (RSOs) and Sexual Predators (SPs) Within 0.2 of a Mile

8. Correlations Among Distance of the Nearest Registered Sex Offender (RSO) and Nearest Sexual Predator (SP) and Variables

9. Distance of the Nearest Registered Sex Offender (RSO) and Nearest Sexual Predator (SP) Within 0.2 of a Mile Predicting Sold Homes' Selling Prices

10. Calculated Isolated Financial Effect Onto Selling Price Produced by the Nearest Registered Sex Offender (RSO) and the Nearest Sexual Predator (SP) Within 0.2 of a Mile 


\section{FIGURES}

Figure

Page

1. Registered Sex Offenders and Sexual Predators Within 0.2 of a Mile From Home Sales in McLean County, Illinois 
CHAPTER I

INTRODUCTION

The massive surge of legislation written with the purpose of protecting the public from persons convicted for sexual crimes in the 1990s has produced complex, and multi-faceted issues not only for neighborhoods, but also for registered sex offenders. Sex offender legislation sets out to protect vulnerable members of society from potential sexual assaults by offenders convicted previously for these types of crimes (Sex offender registration, 2012). Various pieces of legislation were created as a result of public reactions to registered sex offenders presence in their neighborhoods (Zevitz, 2004). This principle of public protection resulted in the establishment of the sex offender registry, residency restrictions, and community notification laws. There are major controversies in how effective these registries and laws are in achieving their stated purposes (Levenson \& Cotter, 2005; Tewksbury, 2002; Tewksbury \& Higgins, 2005).

Detrimental repercussions have been inadvertently created as a result of sex offender legislation, which have stressed communities (Prentky, 1996) and forced registered sex offenders to neighborhoods with or pre-existing unfavorable conditions (Suresh, Mustaine, Tewksbury, \& Higgins, 2010; Tewksbury \& Mustaine, 2006). Neighborhoods that appear to be rampant with social and physical problems and social disadvantages are generally populated by criminals, specifically registered sex offenders (Suresh et al., 2010). As a neighborhood begins to experience ominous conditions, such as the known presence of a registered sex offender, 
community members have chosen to move because of their unwillingness to reside near a registered sex offender (Zevitz, 2003, 2004).

Their presence can produce unintentional social and financial consequences, for example, decreases in home value (Bian, Brastow, Stoll, Waller \& Wentland, 2013; Larsen, Lowrey, \& Coleman, 2003; Linden \& Rockoff, 2008; Pope, 2008; Wentland, Waller, \& Brastow, 2013), increases in house sales surrounding the recent residence of a registered sex offender (Linden \& Rockoff, 2008), and lengthens the period of time the house is on the market (Bian et al., 2013; Wentland et al., 2013). However, communities that are not socially disadvantaged have the ability to prevent registered sex offenders from establishing residency in their neighborhood, thus protecting their neighborhood and investments from potential decline (Socia \& Stamatel, 2012). The presence of registered sex offenders in three U.S. counties have exhibited a decrease in nearby house prices (Larsen et al., 2003; Linden \& Rockoff, 2008; Pope, 2008) with an enormous estimated financial loss for the county (Linden \& Rockoff, 2008). This phenomenon of depreciated home sale value extended itself outside of a county to a larger area in central Virginia (Bian et al., 2013; Wentland et al., 2013). It is important to note that while sex offender laws do not cause them to live in communities that are already socially crippled but instead registered sex offenders are forced to populate these neighborhoods due to the constraints mandated by law (Mustaine, Tewksbury, \& Stengel, 2006b). A spiral of decline results whereby, communities give the impression that they are a designated area for registered sex offenders, consequently, further depressing community members' ability to gain control of situation (Zevitz, 2003). Legislation has created the fortuitous effect that registered sex offender can compromise a community's environment and stability. 


\section{Statement of the Problem}

There is an abundance of empirical research that has discovered how registered sex offenders have affected a neighborhood's environment and the issues that sex offender legislation inadvertently created. Sex offender law has created tools to monitor and deter those convicted of sexual crimes (Sex offender registration, 2012), but have been followed with criticism, in particular with forcing offenders into areas generally found with socially disorganized features (Burchfield \& Mingus, 2008; Mustaine \& Tewksbury, 2008; Mustaine, Tewksbury, \& Stengel, 2006a; Mustaine et al., 2006b; Socia \& Stamatel, 2012; Suresh et al., 2010; Tewksbury \& Lees, 2006), profound types of physical and social disorder (Suresh et al., 2010; Tewksbury \& Mustaine, 2006), and limited housing options (Grubesic, Murray, \& Mack, 2011; Zevitz \& Farkas, 2000b). The types of communities where registered sex offenders reside contain a lack of social and/or economic investment by residents' in their neighborhood (Tewksbury \& Mustaine, 2008). Unfortunately, communities with high levels of social disorganization offer the only available housing for registered sex offenders (Mustaine et al., 2006b; Zandbergen \& Hart, 2006). In return, housing in these communities have manufactured tense feelings amongst the residents, with the fear more registered sex offenders will follow to mark their territory into their community (Cowan, Pantazis, \& Gilroy, 2001; Davey, 2006; Parks, 2001; Zevitz, 2004). An option some residents have taken is to move, and that some are concerned about their property value (Zevitz, 2004). Counties located in the Midwest and South regions of the U.S. have revealed financial losses for housing values (Larsen et al., 2003; Linden \& Rockoff, 2008; Pope, 2008), as well as areas in the Eastern region of the U.S. (Bian et al., 2013; Wentland et al., 2013). The following is an explanation of how sex offender legislation has compounded major social issues to socially disadvantaged communities. The three main areas of 
importance include: sex offender legislation, socially disorganized neighborhoods, and housing issues.

Legislation

Infamous sexual crimes against children have encouraged the establishment of laws that have created the sex offender registry (Jacob Wetterling Crimes Against Children and Sexually Violent Offender Registration Program of 1994; Megan's Law of 1996), community notification laws (Megan's Law of 1996), and residency restrictions. These laws are enforced differently by jurisdictions across the U.S. (Adam Walsh Child Protection and Safety Act, 2013; Grubesic et al., 2011; Levenson, Brannon, Fortney, \& Baker, 2007; Meloy, Miller, \& Curtis, 2008; Zandbergen \& Hart, 2009). Illinois has carried out these three tools with slight variation from national sex offender requirements (720 ILCS § 5/11-9.3 (LexisNexis 2014); 730 ILCS § 152/120 (LexisNexis 2013); Guide, 2006; Sex, 2003). Unfortunately, the implementation of these laws has led to several unintended consequences, especially for nonurban areas from residency restrictions, which created one consequence, the availability of housing (Chajewski \& Mercado, 2009; Grubesic et al., 2011; Norman-Eady, 2007; U.S. Department of Justice, 2008; Zandbergen \& Hart, 2006; Zevitz \& Farkas, 2000b).

Socially Disorganized Neighborhoods

Areas that contain markers of neglect (Kelling \& Wilson, 1982; Skogan, 1990) convey the message that they are disadvantaged and inevitably invite crime and criminals (Mustaine et al., 2006a). Not an exhaustive list, but areas with lower house values (Mustaine \& Tewksbury, 2008; Mustaine et al., 2006a; Tewksbury \& Lees, 2006, Zevitz, 2004), higher rates of unemployment (Burchfield \& Mingus, 2008; Mustaine et al., 2006a; Suresh et al., 2010), and higher rates of 
poverty (Mustaine \& Tewksbury, 2008; Mustaine et al., 2006a; Suresh et al., 2010) are indicators of a socially disorganized community. These markers carry with them expectations that criminals are present, specifically registered sex offenders (Suresh et al., 2010). There is evidence that social and physical disorder have a much stronger effect than crime to residents' perception of their community (Price-Spratlen \& Santoro, 2011). Elements of social disorganization that are considered social and physical disorder include: homeless people (Perkins \& Taylor, 1996), female-headed households (Mustaine \& Tewksbury, 2011; Tewksbury \& Mustaine, 2008), unkempt yards (Perkins, Florin, Rich, Wandersman, \& Chavis, 1990; Perkins, Meeks, \& Taylor, 1992; Perkins \& Taylor, 1996; Price-Spratlen \& Santoro, 2011; Seo \& Rabenau, 2011; Taylor, 1999a), and building neglect (Perkins et al., 1992; Perkins \& Taylor, 1996; Price-Spratlen \& Santoro, 2011; Seo \& Rabenau, 2011; Skogan \& Maxfield, 1981; Taylor, 1999a). All of these elements are commonly found in the neighborhoods of registered sex offenders (Suresh et al., 2010; Tewksbury \& Mustaine, 2006). According to Burchfield and Mingus (2008), concentrations of registered sex offenders in a neighborhood can potentially be an additional layer of social disadvantage. This finding confirms Zevitz's (2003) assertion that the mere presence of only one registered sex offender can destabilize the essence of a community.

\section{Housing Issues}

Housing has shown to be a quandary for registered sex offenders (Mustaine et al., 2006b; Turley \& Hutzel, 2001; Zandbergen \& Hart, 2006; Zevitz, 2004; Zevitz \& Farkas, 2000b), which is generally located in socially disorganized areas (Burchfield \& Mingus, 2008; Mustaine \& Tewksbury, 2008; Mustaine et al., 2006a; Mustaine et al., 2006b; Socia \& Stamatel, 2012; Suresh et al., 2010; Tewksbury \& Lees, 2006) frequently resided in by neighbors who no longer have a stake in their neighborhood (Tewksbury \& Lees, 2006). Those who still do, are worried that their 
neighborhood will eventually be known as an area for registered sex offender placement (Cowan et al., 2001; Davey, 2006; Parks, 2001; Zevitz, 2004), and will attempt to utilize sex offender legislation to their benefit (Lovett, 2013). With current law, it is now easier to identify the residences of registered sex offenders versus any other type of criminal (Larsen et al., 2003; Wentland et al., 2013). Residents are concerned that the settlement of registered sex offenders in their neighborhoods will deteriorate the culture of their environment (Zevitz, 2003), as well as the property value of their home (Zevitz, 2004), which some areas have experienced an increase in posted house sales (Linden \& Rockoff, 2008). Research has demonstrated that counties home to large metropolitan cities have experienced depreciated property values due to the residence of a nearby registered sex offender (Larsen et al., 2003; Linden \& Rockoff, 2008; Pope, 2008).

\section{Purpose of the Study}

\section{Purpose Statement}

The purpose of this study is to explore the relationship between the presence of registered sex offenders and property values in McLean County, Illinois with the utilization of the broken windows theory proposed by Kelling and Wilson (1982). The literature has shown that sex offender legislation has created unintentional consequences that have compromised communities socially and financially. In order to be in compliance with sex offender legislation, which includes the sex offender registry, residency restrictions, and community notification laws, registered sex offenders are often forced to reside in communities that are socially disorganized (Suresh et al., 2010) because these communities are the only one with available housing options (Burchfield \& Mingus, 2008; Mustaine \& Tewksbury, 2008; Mustaine et al., 2006a; Mustaine et al., 2006b; Socia \& Stamatel, 2012; Suresh et al., 2010; Tewksbury \& Lees, 
2006). Additionally, the placement of registered sex offenders in communities has exhibited the potential to destabilize their sense of community (Zevitz, 2003) and aggravate pre-existing social issues in disadvantaged communities (Suresh et al., 2010). Unfavorable conditions of a neighborhood have encouraged residents to move because it impacted them financially (Zevitz, 2004) and socially (Zevitz, 2003, 2004). A financial phenomenon upon homes' prices has been affected as a result of a nearby residence to a registered sex offender in three metropolitan U.S. counties located in Florida, North Carolina, and Ohio (Larsen et al., 2003; Linden \& Rockoff, 2008; Pope, 2008) and a large area in central Virginia (Bian et al., 2013; Wentland et al., 2013). This financial impact onto non-offenders homes loses strength the further they are from the residence of a registered sex offender (Larsen et al., 2003; Linden \& Rockoff, 2008; Pope, 2008; Wentland et al., 2013). In two studies, a more dangerous sex offender produced a stronger financial impact than those labeled as less dangerous (Larsen et al., 2003; Wentland et al., 2013). One study discovered that the greater the concentrations of registered sex offenders, specifically four or more, the greater the reduction in sale price (Bian et al., 2013). Additionally, the estimated financial loss for one of the counties in property values was $\$ 60$ million (Linden \& Rockoff, 2008). Seemingly, the residence of a registered sex offender is a contributing factor upon home prices when once they departed the neighborhood prices rebounded (Pope, 2008; Wentland et al., 2013). The broken windows theory will provide a framework to demonstrate how this sequence of deterioration created by the presence of registered sex offenders to comply with sex offender legislation, which have forced this population to reside in socially disadvantaged communities, and due to the unwillingness to reside near a registered sex offender it has the potential to produce a harmful downward financial and social progression, specifically sold homes' property values in McLean County, Illinois. 
Description of the Study

What is lacking in the literature is an investigation of the financial effects upon home sale transactions by the nearby presence of registered sex offenders and sexual predators ${ }^{1}$ in a Midwest U.S. county. The present study examined the household financial reactions to registered sex offenders and sexual predators in a largely rural U.S. county, McLean County, Illinois. In order to achieve the research purpose, two primary research questions and two secondary research questions explored these effects that included:

1. Does the concentration of registered sex offenders within 0.2 of a mile affect home sale value after controlling for disorder and property characteristics?

a. Does the concentration of sexual predators within 0.2 of a mile affect home sale value after controlling for disorder and property characteristics?

2. Does the distance of the nearest registered sex offender within 0.2 of a mile affect home sale value after controlling for disorder and property characteristics?

a. Does the distance of the nearest sexual predator within 0.2 of a mile affect home sale value after controlling for disorder and property characteristics?

To explore the research questions, four publicly available databases were accessed, combined, and inserted into a mapping software program, ArcGIS, to obtain the distance information in order to conduct a proper analysis. The data involved Illinois sex offender

\footnotetext{
${ }^{1}$ Sexually violent persons were combined with sexual predators as there were too few of sexually violent persons to produce a significant effect, and will be referred from here on out as sexual predators.

Furthermore, the distinct difference between a sexual predator and sexually violent person within Illinois sex offender legislation is that those with a sexually violent person label suffer from a mental disorder.
} 
information, characteristics of home properties in McLean County, a property sales report from December 2012 to December 2013, and 2010 decennial U.S. Census Bureau information of McLean County. First, the list of registered sex offenders was downloaded from the Illinois Sex Offender Registry on December 12 $2^{\text {th }}, 2012$ and compiled into an Excel spreadsheet. A total of 302 registered sex offenders have been found in McLean County, Illinois, and after the elimination process ${ }^{2} 146$ registered sex offenders were left. Of these 146 registered sex offenders, 99 reside in Bloomington, 26 in Normal, and 21 live in smaller cities and towns that are considered rural (besides Heyworth) in McLean County. A subset of these registered sex offenders are labeled as sexual predators $(n=64)$ and sexually violent $(n=5)$ with the remaining 77 being registered sex offenders. Second, housing transactions and property characteristics was collected from three assessor's offices' that serve McLean County. Third, a sales report delivered by the McLean County Assessor's office observed home sale transactions from December 2012, the same time period the registered sex offender data was pulled, to the end of the 2013 year. A total of 3,053 residential home sale transactions occurred in McLean County from December 2012 - December 2013, of which 2,547 were applicable to the present study. The bulk of the home sale transactions occurred in the City of Bloomington $(n=1,299)$ and the town of Normal ( $n=691$ ) with the remaining 557 transactions in the other townships. Fourth,

\footnotetext{
${ }^{2}$ Those eliminated from the McLean County sex offender group included those incarcerated in the Illinois Department of Corrections (IDOC) $(n=119)$ and the Illinois Department of Human Services (IDHS) $(n=11)$. A total of seven McLean County registered sex offenders were incarcerated in other U.S. states or counties: Kansas, Kentucky, Mexico, Minnesota, Missouri, New Hampshire, and Oregon with five registered sex offenders being eliminated from the city of Bloomington, as a result of two of them with a listed residence coincidentally from Bloomington, Indiana and three from Bloomington, Minnesota. Additionally, registered sex offenders excluded from the sample included those without known addresses/unknown location, non-compliant sex offenders, and a homeless status or in jail. At times, the McLean County Jail may be listed with the street address instead of indicating jail. As a whole, those who were eliminated were those who did not have a valid address and were not compliant.
} 
data similar to social disorganization variables and elements of disorder were collected by the information provided by the 2010 decennial U.S. Census Bureau for McLean County, Illinois through a U.S. Census Bureau operated entity, American FactFinder. The appropriate 2010 decennial U.S. Census variables was compiled and used to create an indicator of disorder for each census block in McLean County. ArcGIS was utilized to determine the concentration of registered sex offenders $(n=896)$ and sexual predators $(n=467)$ within 0.2 of a mile of a home sale and the distance to the nearest registered sex offender $(n=553)$ and nearest sexual predator $(n=376)$ within 0.2 of a mile of a home sale.

By utilizing these data sources, the effect registered sex offenders on home sales in McLean County, Illinois can be explored. The results of the present study can yield and fill the missing gaps in sex offender literature, particularly, the financial consequences of sex offender legislation. More specifically, the financial phenomenon registered sex offenders may produce upon home sale transactions in a rural U.S. county.

\section{Contributions to the Field}

Previous studies conducted by Larsen et al. (2003), Linden and Rockoff (2008), and Pope (2008) were in heavily populated counties with major metropolitan cities. The population at the time of each researchers study's for their respective counties: Montgomery County was 558,427 (Larsen et al., 2003), Mecklenburg County was 769,369 (U.S. Census Bureau, 2007b), and Hillsborough County was 1,772,745 (U.S. Census Bureau, 2007a). A contribution that this present study will make is reinforcing the household reactions via property value by the residence of a registered sex offender, amongst a county largely defined as a rural and agricultural community (Qualifying Urban Areas for the 2010 Census, 2012). Research has shown 
that registered sex offenders are generally relocated into rural, agricultural, or county areas in order to remain in compliance to residency restrictions (Chajewski \& Mercado, 2009; Turley \& Hutzel, 2001; Zandbergen \& Hart, 2006). Although McLean County is the largest county in the state of Illinois by size, which is comprised of $1,183.38$ square miles $^{3}$, it pales in comparison to the previously mentioned studies by population with an estimated 302,281 residents in 2012 (U.S. Census Bureau State \& County QuickFacts, 2012). Therefore, this present study may yield novel information for communities similar to McLean County.

A major disparity between the previous studies that have examined this real estate market phenomenon in their communities compared to the present study's area is the persons per square mile. A checkup of the 2010 decennial U.S. Census Bureau's results for persons per square mile in the three examined U.S. counties and independent city reported much higher numbers in density than McLean County, Illinois. Granted these are statistics from the 2010 U.S. decennial Census Bureau, it still stands as a marker that these locations are drastically different when matched with present study's U.S. county. In the 2010 decennial U.S. Census Bureau, the reported persons per square mile in Mecklenburg County $(1,755.5)$ (U.S. Census Bureau State \& County QuickFacts, 2013b), Hillsborough County $(1,204.9)$ (U.S. Census Bureau State \& County QuickFacts, 2013a), Montgomery County $(1,159.5)$ (U.S. Census Bureau State \& County QuickFacts, 2013c) ${ }^{4}$, and the independent city of Lynchburg, Virginia $(1,538.2)$ (U.S. Census

\footnotetext{
${ }^{3}$ To give a better representation of the enormous size of McLean County, Illinois, the 2010 U.S. Census reported the land area of Rhode Island, a U.S. state, to be $1,033.81$ square miles (U.S. Census Bureau State \& County QuickFacts, 2014).

${ }^{4}$ An examination was conducted to determine whether or not it was fair to use the 2010 decennial U.S. Census Bureau's reported number of persons per square mile for Montgomery County, Ohio when taken in consideration that study was conducted in 2000. It was determined it was fair. Montgomery County, Ohio has experienced a slow decline in population when compared to the reported results of the decennial U.S. Census Bureau in 2000 and 2010. Furthermore, the 2012 population estimate was slightly
} 
Bureau State \& County QuickFacts, 2013d) were exceedingly higher than McLean County, Illinois (143.3) (U.S. Census Bureau State \& County QuickFacts, 2012). The reason for this examination is due to the fact Bian et al. (2013) and Wentland et al. (2013) examined Lynchburg and its surrounding areas to uncover whether or not this phenomenon exists, but the 2010 decennial U.S. Census Bureau population of Lynchburg, Virginia $(75,568)$ (U.S. Census Bureau State \& County QuickFacts, 2013d) is lower than estimated 2012 decennial U.S. Census Bureau population of McLean County $(302,281)$. The disparities between the previous studies examined areas in regard to persons per square mile compared to the present study's setting indicated that the current study will unveil newfound findings. All five of these previous studies observed this real estate phenomenon in densely populated areas, whereas McLean County, Illinois is dissimilar in the matter of persons per square mile.

In accordance to the residency restrictions applied to registered sex offenders, such legislation for the state of Illinois differs from the other four pieces by Larsen et al. (2003), Linden and Rockoff (2008), Pope (2008), Bian et al. (2013) and Wentland et al. (2013), who observed the U.S. states of Ohio, North Carolina, Florida, and Virginia, respectively. Three of those U.S. states administer a 1,000 foot residential restriction upon the registered sex offenders (Fla. Stat. Ann. § 947.1405 (LexisNexis 2013); N.C. Gen. Stat. § 14-208.16 (2013); Ohio Rev. Code Ann. § 1950.034 (LexisNexis 2013)), a much wider buffer compared to Illinois legislation that enforced a 500 foot residency restriction to registered child sex offenders (720 ILCS § 5/11-9.3 (LexisNexis 2014)) and a 500 foot loitering restriction to sexual predators (720 ILCS § 5/11-9.4-1 (LexisNexis 2014)). The state of Virginia has not yet enforced a state-wide lower than the reported population in the 2010 decennial U.S. Census Bureau, thereby lowering the persons per square mile. 
residency restriction onto those convicted of sexual crimes, but those with such convictions are restricted from a school, school bus, and school sponsored area (Va. Code Ann. § 18.2-370.5, 2013). No one study explored the financial implications of the nearby residence of registered sex offenders in the state of Illinois. Additionally, Burchfield and Mingus (2008) stated that registered sex offenders located in Chicago, Illinois will have different experiences with the state's residency restriction compared to a rural area. The differing lengths of the residency restriction with the previous studies who examined three other U.S. states with 1,000 foot and the lack of such a restriction in Virginia might differ from Illinois' 500 foot residency restriction and therefore potentially produce a differential financial impact. In whole, the present study will be the first to examine household financial reactions of the U.S. state, Illinois, together with the lowest required residency restriction of 500 feet.

Further, is the financial effect placed upon the nearby neighbor's residences exacerbated by registered sex offenders who are labeled as a sexual predator or sexually violent? With the literature at hand, Larsen et al. (2003), Pope (2008), and Wentland et al. (2013) are the only studies to investigate whether or not the impact of those registered sex offenders labeled as more dangerous or with violent offenses on property values is stronger than those without the label. Larsen et al. (2003) found a significant difference when registered sex offenders from their Ohioan County were separated by level of dangerousness, as well as in Wentland's et al. (2013) study when separated into violent and non-violent registered sex offenders, which violent registered sex offenders produced a significant effect upon selling price and length of sale. On the other hand, Pope (2008) resulted in no differences between registered sex offenders and registered sexual predators and their effect on neighboring properties values. One would reason that a more dangerous offender would produce a greater 
impact upon house prices than the less dangerous offenders, and if there is no such impact, the public is not able to discern the difference in the notification systems of registered sex offenders (Larsen et al., 2003). Would the financial loss be greater if the registered sex offender was a sexual predator, sexually violent, or sexually dangerous in accordance with the categories in Illinois sex offender legislation? The financial impact upon an Illinois county's residential home if a nearby registered sex offender differed by their label is unknown. Taken in consideration the lesser population, community background, and weaker residency restrictions, the present study may yield newfound findings of the impact the residence of a registered sex offender in the state of Illinois and the influence on home prices.

Concentrated areas of registered sex offenders could add another layer of disadvantage (Burchfield \& Mingus, 2008) and have exhibited a correlation between the number of registered sex offenders in a community and the level of social disorganization (Hughes \& Burchfield, 2008; Hughes \& Kadleck, 2008; Linden \& Rockoff, 2008; Mustaine \& Tewksbury, 2008; Mustaine et al., 2006a; Mustaine et al., 2006b; Suresh et al., 2010; Tewksbury \& Mustaine, 2008; Tewksbury, Mustaine, \& Stengel, 2007). What is known in the state of Illinois, concentrations of registered sex offenders in Chicago, an urban area, exhibited a correlation between concentrations of registered sex offenders and social disorganization (Suresh et al., 2010). Additionally, registered sex offenders located in rural areas in an adjacent U.S. state, Kentucky, were more likely to reside in socially disorganized areas when compared to the nation (Tewksbury et al., 2007). If clusters of registered sex offenders can influence a community on a social aspect, taken in consideration their presence in socially disorganized neighborhoods with lower house values (Mustaine \& Tewksbury, 2008; Mustaine et al., 2006a; Tewksbury \& Lees, 2006; Zevitz, 2004), would a cluster of registered sex offenders yield a greater financial loss than just a single 
registered sex offender? In central Virginia, Bian et al. (2013) discovered that a cluster of four or more registered sex offenders within or less than a quarter mile of the examined properties produced the greatest financial impact upon home sale prices. Pope's (2008) findings suggested that clusters of registered sex offenders generally resided in areas with lower housing prices. In regards to rural settings, the risk of exposure to clusters of registered sex offenders via zip code boundaries in Illinois after the population is controlled is much more prevalent in rural areas than in urban areas (Grubesic, 2010). It is unknown that a concentration of registered sex offenders in McLean County, a much less urban area, will influence the property value, and if they do, produce a greater impact upon home sale prices than a single registered sex offender. This will add to the research by indicating whether or not concentrations of registered sex offenders in a much less populated county, one that is also not as urbanized, can influence property values at a greater impact.

To date, no study has utilized the broken windows theory to examine the effect the presence of a registered sex offender has on a neighborhood, specifically, sold homes' prices. Broken windows theory has been largely applied to urban areas (Kelling \& Wilson, 1982), and the present study is set in a rural and agricultural community. Gau and Pratt (2008) have indicated that Kelling and Wilson (1982) assumed the broken windows theory would be able to be applied to rural or small- and mid-city surroundings. Therefore, crime and disorder in such surroundings should be just as distinct as if they were in urban environments. The assumption for rural towns and mid-sized cities is that disorder and crime follow similar patterns as they do in urban areas. Unfortunately, disorder has rarely been studied in other areas except dense, urban environments. An examination of the effect registered sex offenders have on McLean County homes will be conducted, in order to confirm similar financial impacts on real estate 
value of past research studies that focused on major metropolitan areas (Bian et al., 2013;

Larsen et al., 2003; Linden \& Rockoff, 2008; Pope, 2008; Wentland et al., 2013). The present study can determine whether or not Kelling and Wilson's (1982) assumption is correct, which is that their theory is not only applicable to urban areas, but also to rural or small-and mid-city areas such as McLean County, Illinois. This gap in research can be addressed through the utilization of the broken windows theory. 


\section{CHAPTER II}

\section{LITERATURE REVIEW}

Introduction

In this chapter, a review of major national sex offender legislation is discussed that assisted in the movement for public protection from sex offenders, which is incorporated with current Illinois sex offender law. The Jacob Wetterling Crimes Against Children and Sexually Violent Offender registration Act of 1994, Megan's Law of 1996, and the Adam Walsh Child Protection and Safety Act of 2006 all played roles in the establishment of three forms of public protection: sex offender registry, residency restrictions, and community notification laws. Each of these tools set standards to abide by for those convicted of sexual crimes, but have created unintended repercussions onto communities where this population relocated, such as the migration from urban areas to rural areas after their conviction (Chajewski \& Mercado, 2009; Grubesic et al., 2011; Norman-Eady, 2007; U.S. Department of Justice, 2008; Zandbergen \& Hart, 2006).

Two of the major unintentional issues in neighborhoods created by sex offender legislation are discussed. One section addressed research related to socially disorganized communities and elements of social and physical disorder. Registered sex offenders frequently resided in disadvantaged communities after their conviction (Mustaine et al., 2006b) into smaller homes that sold for less (Linden \& Rockoff, 2008), and have been found to 
aggravate social problems especially if concentrations of registered sex offenders existed (Hughes \& Burchfield, 2008; Hughes \& Kadleck, 2008; Linden \& Rockoff, 2008; Mustaine \& Tewksbury, 2008; Mustaine et al., 2006a; Mustaine et al., 2006b; Suresh et al., 2010; Tewksbury \& Mustaine, 2008; Tewksbury et al., 2007). Following the discussion of unfavorable neighborhood conditions is a section that discussed research related to housing issues for registered sex offenders and community members as a result of sex offender legislation. Registered sex offenders face the hardship of finding housing due to such legislation (Mustaine et al., 2006b; Turley \& Hutzel, 2001; Zandbergen \& Hart, 2006; Zevitz, 2004; Zevitz \& Farkas, 2000b) while neighborhood residents have raised concerns that their community will be viewed as a dumping zone for registered sex offenders (Cowan et al., 2001; Davey, 2006; Parks, 2001; Zevitz, 2004). Their presence alone has exhibited a financial phenomenon for nearby homes (Bian et al., 2013; Larsen et al., 2003; Linden \& Rockoff, 2008; Pope, 2008; Wentland et al., 2013) possibly due to the unwillingness to reside near a registered sex offender (Suresh et al., 2010; Zevitz, 2003, 2004).

Lastly, the theoretical framework established by Kelling and Wilson (1982) that explained the relationship between crime and disorder on urban communities is used to explore the effect registered sex offenders have on communities, followed by a discussion of the similarities between the influence of crime and disorder and registered sex offenders have on communities. The beginnings of the broken windows theory began with the Newark foot patrol experiment and Zimbardo's car field experiment, which the concept was held in Skogan's (1990) research. His research on urban U.S. communities and the presence disorders, which he divided into social and physical, and its ability to influence neighbor's perspectives of their surroundings, supported Kelling and Wilson's (1982) broken windows theory. 


\section{Sex Offender Legislation}

A number of the major national legislative movements were enacted in the mid-1990s that established and enforced stricter regulations upon individuals convicted for a sexual crime. A public outcry encouraged the passage of these laws (Sample \& Kadleck, 2008), and compounded with the rapid evolution and amendments in the sex offender legislation it has created unintended repercussions amongst three main tools, the registry, residency restrictions, and community notification laws utilized to manage registered sex offenders. These laws that created massive sex offender registries to mainly deter future sexual crimes (Sex offender registration, 2012) have also restricted housing availability (Zevitz \& Farkas, 2000b) and relocated registered sex offender into rural areas (Chajewski \& Mercado, 2009; Grubesic et al., 2011; Norman-Eady, 2007; U.S. Department of Justice, 2008; Zandbergen \& Hart, 2006).

Registry

Sex offender registries made their official appearance in the mid-1990s ${ }^{5}$ (Jacob Wetterling Crimes Against Children and Sexually Violent Offender Registration Program of 1994; Megan's Law of 1996), eventually becoming fully accessible to the public (Megan's Law of 1996) in every U.S. state (Tewksbury \& Higgins, 2005; Sex offender registration, 2012). All 50 U.S. states require registered sex offenders to provide certain types of personal information (Grubesic et al., 2011; Sample \& Bray, 2003; Sex offender registration, 2012). The basic idea of sex offender registries is public protection (Megan's Law of 1996; Sex offender registration,

\footnotetext{
${ }^{5}$ California became the first state to have enacted the first sex offender registration statute in 1947 (Norman-Eady, 2007; Sex offender registration, 2012).
} 
2012), for communities and to those most vulnerable, foremost children (Mustaine et al., 2006b; Sample \& Kadleck, 2008; Zevitz, 2003).

The Jacob Wetterling Crimes Against Children and Sexually Violent Offender Registration Act was passed in 1994 by Congress that established the standards for sex offender registries, which was later amended by Megan's Law of 1996. All U.S. states were mandated to maintain a registry that included all sex offenders. The Act required sex offenders' addresses to be identified by local law enforcement agencies and to inform such agencies when they change addresses'. Verification of addresses by the state must be conducted up to ten years on an annual basis from their initial registration date. Those with a mental disorder and a previous sexual conviction are labeled as a sexually violent person and are required to register quarterly for natural life instead of yearly. U.S. states were penalized with a $10 \%$ reduction in federal block grants (Edward Byrne Memorial Justice Assistance Grant Program of 1968 (LexisNexis 2013)) if they failed to meet the minimum requirements of the Act (Jacob Wetterling Crimes Against Children and Sexually Violent Offender Registration Program of 1994). Prior to Megan's Law of 1996 amendment, sex offender registries were not accessible to the public, which after its authorization allowed the public to access registered sex offender's information (Megan's Law of 1996), and for Illinois, the sex offender registry became available on the internet on November 15, 1999 (Guide, 2006; Sex, 2003).

After some growth and development and the passage of the Jacob Wetterling Crimes Against Children and Sexually Violent Offender Registration Program of 1994 and Megan's Law of 1996, the sex offender registry became a multi-purposed tool. According to the Center for Sex Offender Management (Sex offender registration, 2012), the registry provides a sex offender's information that is accessible online to deter them from future sexual offending. The registry 
also offers the police with an investigation tool, which can assist law enforcement sexual investigations. Illinois police officers have been known to utilize sex offender registries during traffic stops to inspect whether or not the driver is a registered sex offender through a criminal history check, and if they are in compliance. Additionally, it encourages awareness in the community, thereby offers public protection.

The Adam Walsh Child Protection and Safety Act of 2006 also played a role in the development of sex offender registries. Efforts by John and Revé Walsh—parents of Adam Walsh who was abducted and murdered on July $27^{\text {th }}, 1981$-assisted the establishment of the Adam Walsh Act, also known as the Sex Offender Registration and Notification Act (SORNA), a federal statute enacted in 2006 to protect and prevent sexual attacks on children and bring those child predators in front of the criminal justice system (s. 103). Personal identifying information of the registered sex offender must be provided to the state's registry, which included their name, social security name, address of residence, name and address of employment, name and address of education, license, and car description. U.S. states that enforce the registry requirements of the Act Walsh Act must provide their physical description, their offense, criminal history, photograph, finger/palm prints, DNA sample, and identification card (s. 114).

The Adam Walsh Act was unique in that it discussed the demarcation of persons with a sex offense conviction by their committed sexual offense. Under the Adam Walsh Act was the SORNA that listed three tier levels, tier I, tier II, and tier III, which all three differ in registration period, how often to register, and offense type. Their registration period can be shortened by a clean record, which involves no convictions that comprise of one or more years of imprisonment, additional sex conviction, successful completion of supervised release, parole, 
parole, and/or treatment. An individual who is considered to be a tier I sex offender is required to register for 15 years, but with a clean record only 10 years of registration is needed. They are to register in their jurisdiction every year. There is no apparent reduction for tier II sex offenders, but they are required to register for 25 years. They are to register in their jurisdiction every six months. Tier III sex offenders register for life with the possibility of no more than a year of imprisonment, but those who are an adjudicated delinquent with a clean record can be reduced to register for 25 years. They are to register in their jurisdiction every three months (s. 111).

According to the National Conference of State Legislatures (2013) subject on Adam Walsh Child Protection Safety Act only 16 U.S. states have implemented the requirements of the Adam Walsh Act as of January 2013. U.S. states that do not comply with the Adam Walsh Act experience a $10 \%$ reduction in federal assistant grants for law enforcements (s. 125), a punitive measure similar to the U.S. states that did not enforce the Jacob Wetterling Crimes Against Children and Sexually Violent Offender Registration Program of 1994. Illinois is not amongst the U.S. states to have enacted the Adam Walsh Act (Adam Walsh Child Protection and Safety Act, 2013). The Adam Walsh Act reimbursed each U.S. state $\$ 1$ million that has implemented their stipulations, but would cost the state of Illinois $\$ 21$ million to do so. As of the date of the article, 35 U.S. states have chosen not to fulfill Adam Walsh Act's requirements because it is not cost efficient (Yeagle, 2012).

Instead, the state of Illinois formed their own classification of registered sex offenders within their registry, which include a criminal sex offender, sexual predator, sexually violent or sexually dangerous person. These four labels of Illinois registered sex offenders differ in length and frequency of registration, types of convicted sexual crimes, mental stability, and propensity 
to commit sexual crimes. As of 2012, the majority of the total population of Illinois sex offenders are almost evenly split between being a criminal sex offenders or sexual predators with a small portion of other offenders that are sexually violent or sexually dangerous (Illinois Voices for Reform, Inc., 2012). Previously, a sex offender was required to complete registration within 10 days of discharge, release on probation, or parole to their residence's jurisdiction - this was changed on January $1^{\text {st }}, 2006$ to five days (Guide, 2006), current law now has established the duty to register within three days (730 ILCS § 150/ (LexisNexis 2013)). Additionally, every annual registration requires an updated photo of the sex offender. On July $1^{\text {st }}, 1999$, the sexual predator label was added and required registration once a year for natural life, which was amended on July $1^{\text {st }} 2005$ to a registration period for natural life every 90 days (Guide, 2006). A sexual predator label is given to those with a second or subsequent conviction that is a registerable offense or a conviction of an offense or attempt of various sexual offenses ${ }^{6}$, such as the crime of juvenile pimping or traveling to meet a minor (730 ILCS § 150/2 (LexisNexis 2013)).

\footnotetext{
${ }^{6}$ According to the Illinois Sex Offender Information (Frequently Asked Questions; 2014), a conviction or a conviction of an attempt of any of the following sexual offenses will determine the individual a sexual predator: "keeping a place of juvenile prostitution; juvenile pimping; exploitation of a child; child pornography; aggravated child pornography; criminal sexual assault, if the victim is under 12; criminal sexual assault, regardless of the victim's age (if convicted on or after January 1, 2006); aggravated criminal sexual assault; predatory criminal sexual assault; aggravated criminal sexual abuse; ritualized abuse of a child; sexual misconduct with a person with a disability (if convicted on or after January 1, 2011); kidnapping (if convicted on or after January 1, 2011); aggravated kidnapping (if convicted on or after January 1, 2011); unlawful restraint (if convicted on or after January 1, 2011); aggravated unlawful restrained (if convicted on or after January 1, 2011); children abduction (if convicted on or after January 1 , 2011); conviction of first degree murder, when victim was a person under 18 years of age and the defendant was at least 17 years of age at the time of the commission of the offense and the offense was sexually motivated; certified as a sexually dangerous person pursuant to the Sexually Dangerous Persons Act or any substantially similar federal, sister state, or foreign country law; found to be sexually violent pursuant to the Sexually Violent Commitment Act or substantially similar federal, sister state, or foreign country law; convicted of a $2^{\text {nd }}$ or subsequent offense, after July 1, 1999 which would require registration pursuant to the sex offender registration Act; or a conviction for an offense of federal law, Uniform Code of military Justice, law of another state or foreign county that is substantially equivalent to any of these listed above" (p. 2).
} 
In the end, the cardinal difference between a sexual predator and a criminal sex offender are the longevity of registration, which sexual predators are subjected to registration for life. Also effective on July $1^{\text {st }}, 1999$, individuals who are labeled as either sexually violent or sexually dangerous are to register for natural life every 90 days. Under Illinois Sex Offender Registration Act a sexually violent person is defined as an individual

"convicted of a sexually violent offense, has been adjudicated delinquent for a sexually solvent offense, or has been found not guilty of a sexually violent offense by reason of insanity and who is dangerous because he or she suffers from a mental disorder that makes it substantially probable that the person will engage in acts of sexual violence" (725 ILCS \& 207/5(f) (LexisNexis 2013)).

A sexually violent individual resides at the Illinois Department of Health Services (IDHS) after their release from prison due to the court's belief they are likely to re-offend (Sex, 2003; Guide, 2006). The definition of a sexually dangerous individual established in July 24,1997 , are those who look as if to have suffered from a mental illness for a period of over a year. Further, they displayed propensities of sexual offenses, in particular against children. In addition, the individual has demonstrated an increased likelihood of sexual offenses (725 ILCS § 205/1-01 (LexisNexis 2013)), which will be determined by a reputable evaluator with a background in medicine, psychology, or evaluations of sex offenders who is licensed in a U.S. state (725 ILCS § 205/4.01 (LexisNexis 2013)). This label can be removed if an application is completed and the individual is no longer determined to be dangerous. They can either discharge the individual or place them on conditional release (725 ILCS § 205/10 (LexisNexis 2013)).

There are multiple responsibilities sex offenders must abide by that vary by each jurisdiction when they are in the registry, which makes it difficult to make sure all sex offenders are compliant. U.S. states vary on how they deal with noncompliance by sex offenders. Some will charge the sex offender with a misdemeanor or felony. Typically, supervised sex offenders 
have their parole or probation rescinded. Confinement for 90 days or more can be imposed; other U.S. states may range from one to five years and/or a fine up to $\$ 5,000$. Illinois along with 17 U.S. states have the potential to increase the imposed penalties on sex offenders for their failure to register (Sex offender registration, 2012). In 2010, a controversial amendment in the Illinois Sex Offender Registration Act imposed additional registration requirements, which involved any individual who has ever registered under the Act. This law mandated that any new felony offense committed by a retired registered sex offender after July 1, 2011 is now required to register for ten years, as well as, any current registered sex offender may be applicable to an additional 10 year registration period (730 ILCS § 150/3 (LexisNexis 2013)).

According to the Illinois Sex Offender Information (Frequently Asked Questions; 2014), noncompliance is deemed as a sex offender who failed to register within three days, register annually or quarterly (if applicable), provided inaccurate information during registration, or failed to notify change of address or other information. Location unknown is defined as a sex offender under the registry who is considered missing when they have vacated their reported address, which was verified by law enforcement (Frequently Asked Questions; 2014). A sex offender's failure to comply with the sex offender registration laws of the Sex Offender Registration Act of Illinois will result with a Class 3 felony and three to five years imprisonment. Further, those with ten years of registration will now be given an additional ten years from their non-compliance date. After the first violation any other violations for non-compliance will result in a Class 2 felony. Yeagle (2012) reported that the state of Illinois has an extremely high rate of compliance of $93 \%$.

The criticisms of the sex offender registries are many. Not only does registration limit housing availability for registered sex offenders (Zevitz \& Farkas, 2000b), but inaccuracies and 
incompleteness are common in sex offender registries (Levenson \& Cotter, 2005; Tewksbury, 2002; Tewksbury \& Higgins, 2005). In regards of incompleteness for photographs, Tewksbury (2002) analyzed the Kentucky Sex Offender Registry, which included 14 of 120 Kentucky counties, totaling 537 registered sex offenders. He found urban residents (63.8\%) were more likely to have a photograph on the Kentucky sex offender registry than those from rural areas (41.5\%). Another study conducted by Tewksbury and Higgins (2005) discovered Midwestern U.S. states have less information, and less likely to include a photograph (62.5\%), as well as home address (75.0\%) than other regions in the U.S. Fortunately, a majority of Midwestern U.S. states (87.5\%) and Southern U.S. states (87.5\%) have the ability to search the sex offender registry database by county, whereas Western (45.5\%) and Northeastern U.S. states (40.0\%) cannot.

Residency Restrictions

Residency restrictions and lengths for sex offenders vary state-by state (Grubesic et al., 2011; Meloy et al., 2008), as well as by community (Grubesic et al., 2011; Zandbergen \& Hart, 2009). Except Kansas, every state has some sort of sex offender residency restriction law in place, under consideration, or an ordinance. Delaware and Florida led the way with passing the first residency restriction law in 1995. Thirty U.S. states have residence restriction laws. There are five U.S. states with a 1,501 foot to 2,000 foot restriction, 14 U.S. states with 1,000 foot to 1,500 foot restriction, six U.S. states with 500 foot to 999 foot restriction zone, and five other U.S. states (Maryland, Minnesota, Oregon, South Carolina, and Wisconsin) with various residency restrictions (Meloy et al., 2008). Illinois maintains one of the shortest lengths (Grubesic et al., 2011; Hughes \& Burchfield, 2008; Meloy et al., 2008) at 500ft (720 ILCS § 5/119.3 (LexisNexis 2014)). 
Residency restrictions in the state of Illinois are only applicable to a child sex offender ${ }^{7}$ in the Illinois sex offender registry ${ }^{8}$. Child sex offenders must not be present within 500 feet of a school zone, day care centers, parks, and facilities oriented towards individuals under 18 years of age. The 500 foot restriction is measured by the closest edge of the facility oriented towards under 18 individuals to the edge of the registered child sex offender's residence. This restriction does not apply to those who bought their residence before July $7^{\text {th }}, 2000$, when residency restrictions first became effective in the state of Illinois. An Illinois registered child sex offender cannot live within 500 feet of their victim, but this does not apply to those who bought their residence prior to August $22^{\text {nd }}, 2002$. Further, registered child sex offenders cannot live and rent in a residential unit with an individual who is 18 years of age or less, which is applicable as of January $1^{\text {st }}, 2009$ (720 ILCS $\S 5 / 11-9.3$ (LexisNexis 2014)). An amendment in Illinois sex offender legislation effective August, $20^{\text {th }}, 2004$, stated a sex offender or sexual predator can only be registered in their residence jurisdiction, regardless of employment. A significant amendment on January $1^{\text {st }}, 2006$ stated a fixed residence is no longer defined as ten days or more, but five days or more (Guide, 2006). The amendment still retained that a letter will be mailed to each sex offender's address to confirm proof of residence and risk non-compliance if not mailed within five days and not the previously stated 10 days (Guide, 2006). According to the Illinois Sex Offender Registration law, a sex offender must now register within three days instead of the previous five days if they change their address (730 ILCS § 150/3 (LexisNexis 2013)) or residence

\footnotetext{
${ }^{7} \mathrm{~A}$ child registered sex offender is an individual who victimized someone less than 17 years of age (720 ILCS § 5/11-9.1(b) (LexisNexis 2014)).

${ }^{8}$ Effective in 2011, both a sexual predator and child sex offender cannot be present or loiter within 500 feet of public parks (720 ILCS § 5/11-9.4-1 (LexisNexis 2014)).
} 
in any place for three days or more (730 ILCS $\S 150 / 6$ (LexisNexis 2013)). Those without an address must report weekly (730 ILCS § 150/3 (LexisNexis 2013)).

There are a multitude of other unintended consequences of residency restrictions. Residency restrictions are declining suitable housing options for registered sex offenders (Grubesic et al., 2011), which have forced registered sex offenders into residences located in high - crime neighborhoods (Zandbergen \& Hart, 2009), homelessness (Norman-Eady, 2007; U.S. Department of Justice, 2008), and has the potential to push them into disadvantaged areas (Burchfield \& Mingus, 2008). Furthermore, these restrictions and false addresses (U.S. Department of Justice, 2008) can make it harder for law enforcement officials to locate them (Norman-Eady, 2007). School residency restrictions have created a considerable problem amongst the child sex offender population (Hughes \& Burchfield, 2008). Compounded with the fact most available housing is located in rural areas that limit their travel to necessary resources (Chajewski \& Mercado, 2009; Grubesic et al., 2011; Norman-Eady, 2007; U.S. Department of Justice, 2008; Zandbergen \& Hart, 2006).

There is agreement that the majority available housing space left for registered sex offenders is found in rural areas when residency restrictions are applied (Chajewski \& Mercado, 2009; Grubesic et al., 2011; Norman-Eady, 2007; U.S. Department of Justice, 2008; Zandbergen \& Hart, 2006), which have created various issues for registered sex offenders. Such restrictions limit their travel to what is required of them for their conviction such as mental health treatment (Chajewski \& Mercado, 2009; U.S. Department of Justice, 2008; Zandbergen \& Hart, 2006), substance abuse treatment (Chajewski \& Mercado, 2009; U.S. Department of Justice, 2008; Zandbergen \& Hart, 2006), probation and parole officers (Chajewski \& Mercado, 2009), and limits their ability for employment (Chajewski \& Mercado, 2009; U.S. Department of Justice, 
2008), and valuable support networks (Chajewski \& Mercado, 2009; Norman-Eady, 2007;

Zandbergen \& Hart, 2006).

A number of studies have researched the impact of residency restrictions have on rural, agricultural, or county locations throughout the nation where registered sex offenders generally relocate. Chajewski and Mercado (2009) found that a 1,000 foot restriction left more available space in a rural area (89.16\%) than a county area (82.42\%), and in an urban area $(51.40 \%)$. These percentages decreased significantly when the 2,500 foot restriction was applied with $54.44 \%$ available space in rural areas, $36.90 \%$ in county areas, and $7.34 \%$ in urban areas. In summation, urban areas were essentially off-limits to sex offenders, forcing them to live in rural or county areas. Zandbergen and Hart (2006) conducted their experiment of parcels in Orange County, Florida - home of Walt Disney World Resort. On average, a quarter of urban properties were restricted compared to the $7.3 \%$ in rural/agricultural and rural settlement, $10.6 \%$ of properties fell within the 1,000 foot buffer from schools. In other words, most available housing existed in low-density rural areas because a registered sex offender cannot reside in one of every four urban homes compared to the one in every ten rural homes. An investigation of where West Virginian registered sex offenders resided before their conviction if they had residence in a rural or suburban area revealed the tendency to be relocated to a rural location. Prior to their offense, sex offenders from West Virginia lived mostly in rural counties $(57.7 \%)$ than in suburban counties (42.3\%). After their release from prison these numbers become more diverse with $39.5 \%$ of sex offenders residences' in suburban counties and $60.5 \%$ in rural counties (Turley \& Hutzel, 2001). These studies confirm the movement of registered sex offenders to more rural areas. 
Community Notification

Megan Kanka was a 7-year old New Jersey resident who was sexually assaulted and murdered by a released sex offender. Her death resulted in the creation of Megan laws, which established community notification (Prentky, 1996). Not only did information on sex offender registries that was previously disclosed to local law enforcement become available to the public, but procedures on how to inform the community of the presence of a registered sex offender were also formed. This change allowed for community members the information needed to protect themselves from sexually violent offenders (Megan's Law of 1996).

The purpose of notification laws is to operate under "an informal network of neighborhood surveillance" (Zevitz, 2006, p. 195). Community notification is multi-purposed, Rudin (1996) said that the "notification laws are intended to deter recidivism, enhance police effectiveness in preventing or solving sex offenses, and promote community awareness and selfprotection" (p. 3). Prior to formal establishment of Megan's Law of 1996, Washington was the first state to enact a community notification laws for sex offenders labeled as the 1990 Community Protection Act. Megan's Law of 1996 encouraged other U.S. states to follow Washington's community notification laws of convicted offenders with sexual offenses and crimes against children (Matson \& Lieb, 1996).

U.S. states vary in how much information is disclosed about sex offenders. Where some U.S. states might release information on sex offenders considered being high-risk and others will release information about all of the sex offenders in their registry (Levenson et al., 2007). In the state of Illinois, community notification involves all sheriffs' offices and the Chicago Police Department. Although there are differences to what bodies may know about the registered sex 
offender that include their place of residence, employment, where they registered, and their institution of higher education (730 ILCS § 152/120 (LexisNexis 2013)). Zevitz (2006) mentioned how some jurisdictions in Wisconsin notified communities through extensive notification. It can be conducted through information sharing in community meetings, posting fliers or notices, news media releases, or informing via door-to-door (Fact sheet, 2008).

Illinois operates a form of community notification for registered sex offenders labeled as the Sex Offender Community Notification Law effective as of June $1^{\text {st }}, 1996$ (730 ILCS § 152/101 (LexisNexis 2013)). Originally, the name, address, and offense of the child sex offender were available to the public. The Act was modified a year later, and set to be effective July $24^{\text {th }}, 1997$. All sex offenders' information was released, which includes date of birth (Guide, 2006). The necessary bodies that are informed include institutions or non-public institutions of higher education, nonpublic and public schools, child care facilities, libraries, public libraries, public housing agencies, the Illinois Department of Children and Family Services, social service agencies, volunteer organization, and the victim. Information of a registered sex offender can be released by the sheriff of Illinois counties and Chicago Police Department, which include:

"name, address, date of birth, place of employment, school attended, e-mail addresses, instant messaging identities, chat room identities, other Internet communications identities, all Uniform Resource Locators (URLs) registered or used by the sex offender, all blogs and other Internet sites maintained by the sex offender or to which the sex offender has uploaded any content or posted any messages or information, and offense or adjudication of all sex offenders"

A request for a registered sex offender's information must be completed and available within

"72 hours or 3 business days...in person, in writing, or by telephone" (730 ILCS § 152/120

(LexisNexis 2013)). Special alerts are another form of community notification within the state of Illinois. Law enforcement agencies may release alerts around holiday seasons that involve 
children to inform parents and/or community members about the availability of the publicly accessible sex offender registry and other tools (730 ILCS § 152/122 (LexisNexis 2013)).

Unfortunately, community notification meetings create unfavorable feelings, such as fear, pessimism, outrage, and anxiety amongst the community members (Matson \& Lieb, 1996; Perkins, Florin, Rich, Wandersman, \& Chavis, 1990; Zevitz \& Farkas, 2000a). Zevitz and Farkas (2000a) discovered that $38 \%$ of their Wisconsin respondents were more concerned about a recently placed sex offender in their community following a community notification meeting. Others who attended experienced increased outrage and anxiety about a sex offender in their community, and didn't seem keen on accepting sex offenders. Community members in the state of Washington expressed similar unpleasant feelings in which they reacted negatively of sex offenders in their neighborhood when they attended community notification meetings about the return of convicted sex offenders in their neighborhood (Matson \& Lieb, 1996). In Skogan and Maxfield's (1981) examination of community members who relayed secondhand information via interpersonal communication, they discovered it magnifies the crime and can influence fear. Zevitz (2004) found "the fear brought about by sex offender placement, carried out publicly and in close proximity to homes and businesses, is viewed as more than a psychological response to the perception of vulnerability to victimization" (p. 205). In addition, Zevitz (2004) believes the placement of a sex offender in their neighborhood will deteriorate the community moral and thereby make them feel powerless to make an influence, which was indicative of the decreased attendance to their neighborhood meetings.

There are major controversies with community notification laws. Some of the controversies are that the purposes of Megan's Law of 1996 are mere assumptions (Zevitz, 2006), lack empirical data (Hughes \& Kadleck, 2008; Prentky, 1996; Rudin, 1996), offer a false 
sense of security to appease the public's outrage (Hughes \& Kadleck, 2008; Rudin, 1996; Zevitz, 2006), and create limited availability in housing for registered sex offenders (Zevitz \& Farkas, 2000b). Further, some registered sex offenders believed the amount of disclosure of their personal information is not fair, such as their address and work location (Levenson \& Cotter, 2005). Community notification laws are viewed as to have been built for failure amongst the sex offender population as a result of stress from the label (Prentky, 1996), which is viewed a permanent marker of their crime (Rudin, 1996). Such stresses are compounded if a neighborhood viewed as an unsuitable environment for success (Prentky, 1996).

The unfortunate result of such laws was placed upon neighborhoods who dealt with the brunt of these legal movements, especially those that maintain characteristics of disorder. Neighborhoods that exhibited forms of disorder gave the impression deviant behavior is accepted where registered sex offenders are commonly located (Suresh et al., 2010). There is a general consensus registered sex offenders are forced into socially disorganized neighborhoods (Suresh et al., 2010; Tewksbury \& Mustaine, 2006), that are located in rural areas to comply with residency restrictions (Chajewski \& Mercado, 2009; Grubesic et al., 2011; Norman-Eady, 2007; U.S. Department of Justice, 2008; Zandbergen \& Hart, 2006), far from much needed resources (Chajewski \& Mercado, 2009; Grubesic et al., 2011; Norman-Eady, 2007; U.S. Department of Justice, 2008; Zandbergen \& Hart, 2006). With the number of criticisms about the tools created by sex offender legislation, it seems to be of no surprise that registered sex offenders can further unsettle a neighborhood that is considered unstable. 


\section{Social Disorganization}

Due to sex offenders laws, registered sex offenders are generally found in areas demarcated with a multitude of socially disorganized variables (Burchfield \& Mingus, 2008; Mustaine \& Tewksbury, 2008; Mustaine et al., 2006a; Mustaine et al., 2006b; Socia \& Stamatel, 2012; Suresh et al., 2010; Tewksbury \& Lees, 2006). Areas registered sex offenders have placed residence typically had lower percentages of high school graduates (Mustaine \& Tewksbury, 2008; Mustaine et al., 2006a), lesser college educated people (Mustaine \& Tewksbury, 2008; Mustaine et al., 2006a; Mustaine et al., 2006b), lesser 19 and younger population (Mustaine \& Tewksbury, 2008; Mustaine et al., 2006a), lower house values (Larsen et al., 2003; Linden \& Rockoff, 2008; Mustaine \& Tewksbury, 2008; Mustaine et al., 2006a; Pope, 2008; Tewksbury \& Lees, 2006; Zevitz, 2004), lower household incomes (Mustaine \& Tewksbury, 2008; Mustaine et al., 2006a; Suresh et al., 2010), lesser home stability (Mustaine \& Tewksbury, 2008; Mustaine et al., 2006a; Mustaine et al., 2006b) and lesser home ownership (Mustaine \& Tewksbury, 2008; Mustaine et al., 2006a; Mustaine et al., 2006b; Mustaine \& Tewksbury, 2011). Further, there were higher rates of female-headed households (Mustaine \& Tewksbury, 2008; Mustaine et al., 2006a), higher rates of unemployment (Burchfield \& Mingus, 2008; Mustaine et al., 2006a; Suresh et al., 2010), and higher rates of poverty (Mustaine \& Tewksbury, 2008; Mustaine et al., 2006a; Suresh et al., 2010). The level of socially disorganized variables found in areas registered sex offenders placed residence in confirmed the impression that these "[d]isadvantaged areas tend to invite criminals and members on the fringes of society because of the atmosphere of neglect that is present in them" (Mustaine et al., 2006a, p. 340).

Within these socially disorganized communities are elements of social and physical disorder. Forms of social disorder are deemed as teenage impropriety (Perkins et al., 1992; 
Perkins \& Taylor, 1996; Sampson \& Raudenbush, 1995; Skogan \& Maxfield, 1981; Taylor, 1999a), drug use/dealing (Perkins et al., 1992; Sampson \& Raudenbush, 1995; Skogan \& Maxfield, 1981), gangs (Price-Spratlen \& Santoro, 2011; Sampson \& Raudenbush, 1995), homeless people (Perkins \& Taylor, 1996), sexual harassment (Taylor, 1999a), strangers (Sampson \& Raudenbush, 1995), threatening behavior (Perkins et al., 1992; Perkins \& Taylor, 1996; Sampson \& Raudenbush, 1995; Taylor, 1999b), public intoxication (Perkins \& Taylor, 1996; Sampson \& Raudenbush, 1995; Taylor, 1999a), and prostitution (Perkins \& Taylor, 1996; Sampson \& Raudenbush, 1995; Taylor, 1999a). Physical disorder was physical decay of scenery which includes building abandonment (Perkins et al., 1992; Perkins \& Taylor, 1996; Price-Spratlen \& Santoro, 2011; Seo \& Rabenau, 2011; Skogan \& Maxfield, 1981; Taylor, 1999a), abandoned cars (Perkins et al., 1992; Perkins \& Taylor, 1996; Sampson \& Raudenbush, 1995; Seo \& Rabenau, 2011; Taylor, 1999a); vandalism/graffiti (Perkins et al., 1990; Perkins et al., 1992; Perkins \& Taylor, 1996; Sampson \& Raudenbush, 1995; Seo \& Rabenau, 2011; Skogan \& Maxfield, 1981; Taylor, 1999a), unkempt yards (Perkins et al., 1990; Perkins et al., 1992; Perkins \& Taylor, 1996; Price-Spratlen \& Santoro, 2011; Seo \& Rabenau, 2011; Taylor, 1999a), vacant lots (Taylor, 1999a), and litter (Perkins et al., 1990; Perkins \& Taylor, 1996; Price-Spratlen \& Santoro, 2011; Sampson \& Raudenbush, 1995; Seo \& Rabenau, 2011; Taylor, 1999a).

Suresh et al. (2010) asserted that crime and criminals are invited into areas are socially disadvantaged. After a geographical and spatial examination of residences' characteristics of Chicago registered sex offenders the researchers discovered this population was forced to live in undesirable, disorganized areas. The authors believed as registered sex offenders concentrated into a socially disorganized area, residents will no longer wish to live there by choice. Consequently, the community will further deteriorate physically and socially, thereby invite and 
allow crime to occur in such areas. In summation, "social processes which have the effect of relegating registered sex offenders to disadvantaged and undesirable communities will only serve to drive those neighborhoods deeper into social problems" (p. 206). This belief that registered sex offenders do not choose where they live and are forced into communities that are financially struggling and unstable is further reinforced by the research of Mustaine et al. (2006b), and an investigation by Tewksbury and Mustaine (2006) conveyed the prevalence of disorder in neighborhoods registered sex offenders resided.

Elements of physical and social disorder are common in neighborhoods where registered sex offenders reside (Suresh et al., 2010; Tewksbury \& Mustaine, 2006). An investigation conducted by Tewksbury and Mustaine (2006) looked at the environment of registered sex offenders residential locations in Seminole County, Florida. Neighborhood conditions that were assessed included: "abandoned cars, boarded up/abandoned buildings, graffiti, litter in public, non-lawn items on the law, and vacant lots" (p. 66). They uncovered $32.3 \%$ of registered sex offenders lived in neighborhoods with vacant lots, $15.3 \%$ had abandoned/boarded up buildings, and $11.5 \%$ had abandoned cars. Other notable signs of disorder from their study included litter in public (22.9\%), and $19.8 \%$ of residences containing non-lawn items on the lawn. One form of physical disorder, vacant housing, has exhibited a positive correlation to the concentrations of registered sex offenders (Suresh et al., 2010). In summation, registered sex offenders are forced to live in socially undesirable neighborhoods, and visibly deteriorated neighborhoods.

There is a correlation between high concentrations of registered sex offenders and social disorganization (Hughes \& Burchfield, 2008; Hughes \& Kadleck, 2008; Linden \& Rockoff, 2008; Mustaine \& Tewksbury, 2008; Mustaine et al., 2006a; Mustaine et al., 2006b; Suresh et 
al., 2010; Tewksbury \& Mustaine, 2008; Tewksbury et al., 2007). In other words, communities with clusters of registered sex offenders are generally more socially disorganized than those without clusters. Burchfield and Mingus (2008) believed that high concentrations of sex offenders in a neighborhood, particularly a disadvantaged neighborhood, would add another layer of disadvantage especially one that is already vulnerable. As these clusters of registered sex offenders grow in number the likelihood "residents of more disorganized areas will be unable or unwilling to rally against these people and/or care whether another criminal moves in, thus making it an 'easier' place to set up residence" increase (Mustaine \& Tewksbury, 2008, p. 73). There is the question of whether or not the state of the neighborhood invited registered sex offenders or did the presence of registered sex offenders create elements of social disorganization and thereby produce a spiral of decline? To partially answer the question, Tewksbury and Mustaine (2006) investigation of registered sex offenders in Seminole County, Florida found they do not live in excessively disorganized neighborhoods but they do tend to cluster and live in neighborhoods that are already considered oppressed.

Housing

Housing is a major obstacle for registered sex offenders (Mustaine et al., 2006b; Turley \& Hutzel, 2001; Zandbergen \& Hart, 2006; Zevitz, 2004; Zevitz \& Farkas, 2000b). It is apparent that available housing for this particular population are frequently in areas that are socially disorganized (Burchfield \& Mingus, 2008; Mustaine \& Tewksbury, 2008; Mustaine et al., 2006a; Mustaine et al., 2006b; Socia \& Stamatel, 2012; Suresh et al., 2010; Tewksbury \& Lees, 2006) with a multitude of housing dilemmas (Bian et al., 2013; Larsen et al., 2003; Linden \& Rockoff, 2008; Mustaine \& Tewksbury, 2008; Mustaine et al., 2006a; Mustaine et al., 2006b; Pope, 2008; Suresh et al., 2010; Tewksbury \& Lees, 2006; Zevitz, 2004). Without a meaningful investment, 
such as a home, these areas grow in number of neighbors who have fewer stakes in their community, therefore make residences for registered sex offenders much more easily to live in compared to those with neighbors that have more stakes. Meaning, these areas are much more vulnerable to registered sex offenders (Tewksbury \& Lees, 2006).

The presence of a registered sex offender in a neighborhood has produced uneasy feelings amongst neighborhood residents with one outcome being, giving the impression of an open invitation to more registered sex offenders into their surroundings (Cowan et al., 2001; Davey, 2006; Parks, 2001; Zevitz, 2004). In reference to lowa's residency restrictions, an Illinois resident near the lowa border said, “[w]e don't want to be a dumping ground for their sex offenders" (Davey, 2006, pp. 9). In Parks' (2001) newspaper article, a resident voiced at a community notification meeting “[t]he other municipalities didn't want him, so he's being dumped here" (p. 3). An alderman was interviewed and expressed how he does not Racine, Wisconsin to be known as a popular spot for registered sex offenders to reside. The alderman provided another reinforcing statement and stated "we know they have to live somewhere...but why are we being dumped on?" (p. 13).

This concern by community members that their neighborhood will turn into a dumping ground is a sensible reaction. Community members and city officials have utilized sex offender legislation to their benefit through the establishment of tiny parks. Neighborhoods across the nation in major cities - Miami, Houston, Los Angeles — have built parks to force convicted sex offenders to live elsewhere instead of their own neighborhoods (Lovett, 2013). It is clear that communities are concerned that the presence of registered sex offenders has the potential to create a spiral decline in their neighborhood. Similar to the belief Burchfield and Mingus (2008) stated, perhaps neighborhood residents realize it would add another layer of disadvantage to 
their neighborhood? In Zevitz's (2003) research, the presence of one registered sex offender has the potential to disrupt the stability of a neighborhood. In the eyes of neighborhood residents, high concentrations of registered sex offenders will attract others, and soon enough their neighborhood crime rates would increase (Zevitz, 2004).

Oddly, those who have adjusted to their urban neighborhood crime accepted it as a piece of their everyday life, especially if they cannot afford to move (Skogan \& Maxfield, 1981), which this type of behavior is strikingly parallel to the presence of a registered sex offender. Residents have withdrawn from their community, but yet do not move when a registered sex offender is in their neighborhood (Suresh et al., 2010). In Zevitz's (2003, 2004) exploration of what happens when a registered sex offender moves into a neighborhood, over a fifth of the participants were apparently making plans to move out of the neighborhood within the next year due to the neighborhood's unfavorable conditions. Many of those planning on moving claimed that the residence of a registered sex offender created a reason for their moving (Zevitz, $2003,2004)$, which was exhibited in the increase in home sales of surrounding properties once a registered sex offender moved in (Linden \& Rockoff, 2008). One respondent stated, "having offenders in this neighbor-hood has changed it a lot...so we're going to move" (Zevitz, 2004, p. 217). Residents in the sample reported they felt worse about their own neighborhood once Broadway, a registered sex offender, had moved in (41\%). Unfortunately, a fully $41 \%$ indicated that moving out of the neighborhood was not a viable option (Zevitz, 2003). The mere presence of even one registered sex offender has the ability to influence the essence of a neighborhood, and even encourage neighborhood residents to move out.

Is it fair to say registered sex offenders are considered a form of social disorder if they illustrate a negative impact on property values within a neighborhood? It is known that types of 
social disorders can influence a neighbor's house value (Cook, 2008). Sampson and Raudenbush (1995) asserted that: "disorder triggers attributions and predictions in the minds of insiders and outsiders alike. It changes the calculus of prospective home buyers, real estate agents, insurance agents, and investors and shapes the perceptions of residents who might be considering moving" (p. 604). What is known is that property values may be negatively affected by the unwillingness of non-offenders to live near sex offenders (Suresh et al., 2010). One resident in Zevitz's (2004) study expressed how he was worried about the property value of his home would plummet due to the recent residence of a sex offender, which he planned to sell. An lowan resident stated"[n]obody wants to have something associated with sex offender's right beside them" (Davey, 2006, pp. 3). Such a scenario played out in Pennsylvania. Oliver Beck encountered a lawsuit against a family for their 'virtually unmarketable' house and sued to force Beck to purchase their home. Beck was charged with an indecent assault of the family's less than 18 year old daughter. After his release from prison and now a registered sex offender the family had difficulty selling their house with Becks' nearby residence (Ng, 2013). The worry about the effect of a registered sex offender and your house value should be of concern.

What is known is that registered sex offenders live in census tracts where housing values and average household income are lower. Census tracts with a heavy concentration of registered sex offenders differed in median housing values $(\$ 66,560$ vs. $\$ 86,029)$ and average household income $(\$ 27,101$ vs. $\$ 36,062)$ much more than areas with a lighter concentration of registered sex offenders (Mustaine et al., 2006a). In another similar study, registered sex offenders lived in areas where median housing values and housing median incomes were lower than the county or national averages (Mustaine \& Tewksbury, 2008). On the other hand, Linden and Rockoff (2008) discovered that after they controlled their selected variables for housing 
property characteristics, registered sex offenders do not choose to reside in significantly cheaper neighborhoods compared to other areas in the county.

Larsen et al. (2003), Linden and Rockoff (2008), and Pope (2008) investigated how the residence of a sex offender in a county within a U.S. state has affected neighboring properties with Wentland et al. (2013) and Bian et al. (2013) who had examined the city of Lynchburg and surrounding areas, which summaries of each study's data were created and displayed in Table 1, Table 2, and Table 3, respectively. Each study was conducted in a different manner, but produced the same result, that the nearby residence of a registered sex offender influenced the property value. The financial impact onto selling price was determined differently amongst the studies, Larsen et al. (2003) matched with the average selling prices of sold homes within each concentric ring, Linden and Rockoff (2008) compared the median selling price before the registered sex offender's arrival, Pope (2008), Wentland et al. (2013) and Bian et al. (2013) used the average selling prices of the homes in their sample. There are a number of take away points that were prevalent in these five studies. First, the largest financial impact occurred within 0.1 of a mile. Second, the financial impact was lessened as the distance between the home and the residence of the registered sex offender increased. Third, the more dangerous the registered sex offender, the greater the financial impact. Lastly, four or more registered sex offenders became the tipping point of a neighborhood's financial equilibrium. 
Table 1

Summary Results of Larsen et al. (2003), Linden and Rockoff (2008), and Pope (2008)

\begin{tabular}{|c|c|c|c|c|}
\hline Study & Larsen et $a$ & $(2003)$ & $\begin{array}{l}\text { Linden and } \\
\text { Rockoff (2008) }\end{array}$ & Pope (2008) \\
\hline County & $\begin{array}{l}\text { Montgome } \\
\mathrm{OH}\end{array}$ & y County, & $\begin{array}{l}\text { Mecklenburg } \\
\text { County, NC }\end{array}$ & Hillsborough County, FL \\
\hline $\begin{array}{l}\text { Type of } \\
\text { notification }\end{array}$ & $\begin{array}{l}\text { Limited } \\
\text { disclosure }\end{array}$ & $\begin{array}{l}\text { Passive } \\
\text { notification }\end{array}$ & No data & No data \\
\hline Directly adjacent & No data & No data & $11.6 \%^{+}$ & No data \\
\hline Within $1 / 10^{\text {th }}$ of & $17.4 \%$ or & $7.5 \%$ or & $4.0 \%$ or $\$ 5,500^{+}$ & $2.3 \%$ or $\$ 3,500^{+}$ \\
\hline a mile & $\$ 11,864^{*}$ & $\$ 4,208^{*}$ & & \\
\hline $1 / 10^{\text {th }}-2 / 10^{\text {th }}$ & $10.2 \%$ or & $5 \%$ or & No impact & No impact \\
\hline of a mile & $\$ 7,475^{*}$ & $\$ 4,303^{*}$ & & \\
\hline $2 / 10^{\text {th }}-3 / 10^{\text {th }}$ & $9.3 \%$ of & $3.8 \%$ or & No impact & No impact \\
\hline of a mile & $\$ 7,188^{*}$ & $\$ 3,465^{+}$ & & \\
\hline $3 / 10^{\text {th }}-4 / 10^{\text {th }}$ & $6.4 \%$ or & $3.9 \%$ or & No data & No data \\
\hline of a mile & $\$ 5,104^{+}$ & $\$ 3,843^{+}$ & & \\
\hline $4 / 10^{\text {th }}-5 / 10^{\text {th }}$ & $0.8 \%$ or & $1.8 \%$ or & No data & No data \\
\hline of a mile & $\$ 703$ & $\$ 1,932$ & & \\
\hline
\end{tabular}


Table 2

Summary Results of Wentland et al. (2013)

\begin{tabular}{|c|c|c|c|c|c|c|c|c|c|c|}
\hline Distance & Sale price & $\begin{array}{l}\text { Controllin } \\
\text { g for } \\
\text { Additional } \\
\text { R.S.O. }\end{array}$ & $\begin{array}{l}\text { Move } \\
\text { out }\end{array}$ & $\begin{array}{l}\text { Liquidity } \\
\text { and selling } \\
\text { price } \\
\text { jointed }\end{array}$ & $\begin{array}{l}\text { Liquidity - } \\
\text { Days on } \\
\text { market }\end{array}$ & $\begin{array}{l}\text { Four } \\
\text { bedrooms }\end{array}$ & $\begin{array}{l}\text { Each } \\
\text { additional } \\
\text { bedroom }\end{array}$ & $\begin{array}{l}\text { Each } \\
\text { additional } \\
\text { bedroom } \\
\text { to days on } \\
\text { market }\end{array}$ & Violent & $\begin{array}{l}\text { Violent - } \\
\text { Days on } \\
\text { market }\end{array}$ \\
\hline$\leq .10$ mile & $\begin{array}{l}9.2 \% \text { or } \\
\$ 15,533^{* *}\end{array}$ & $\begin{array}{l}7.4 \% \text { or } \\
\$ 12,273^{*}\end{array}$ & $\$ 5,281$ & $\begin{array}{l}7 \% \text { or } \\
\$ 11,712^{* *}\end{array}$ & $\begin{array}{l}80 \% \text { longer } \\
\text { or } 88^{* *}\end{array}$ & $\$ 24,954^{*}$ & $\$ 12,476^{* *}$ & $77^{* *}$ & $\$ 17,432^{*}$ & $112^{*}$ \\
\hline$\leq .25$ mile & $\$ 10,110^{* *}$ & $\$ 7,092^{*}$ & $\$ 367$ & $\$ 6,149^{* *}$ & $45^{* *}$ & $\$ 7,381$ & $\$ 354$ & 9 & $\$ 1,528$ & 7 \\
\hline$\leq .50$ mile & $\$ 5,606^{*}$ & $\$ 4,285$ & $\$ 2,694$ & $\$ 3,875^{*}$ & $34^{* *}$ & $\$ 1,366$ & $\$ 812$ & 7 & $\$ 7,822^{+}$ & $54^{+}$ \\
\hline$\leq 1$ mile & $\$ 3,796^{+}$ & $\$ 3,710^{+}$ & $\$ 353$ & $\$ 3,339^{*}$ & $24^{*}$ & $\$ 18,582^{* *}$ & $\$ 4,829^{* *}$ & $32^{* *}$ & $\$ 3,438$ & 21 \\
\hline $\begin{array}{l}\text { Additional } \\
\text { R.S.O. } \leq 1 \\
\text { mile }\end{array}$ & No data & $\begin{array}{l}0.4 \% \text { or } \\
\$ 695^{+}\end{array}$ & $+\$ 98$ & $\$ 689^{* *}$ & $4^{*}$ & $\$ 701^{* *}$ & No data & No data & No data & No data \\
\hline
\end{tabular}


Table 3

Summary Results of Bian et al. (2013) Registered Sex Offenders Within $\leq .25$

\begin{tabular}{rl|lll}
$\begin{array}{r}\text { Number of } \\
\text { registered sex } \\
\text { offenders }\end{array}$ & Sale price & Liquidity and selling price jointed & Liquidity - Days on market & Three+ bedrooms \\
\hline 1 & $5 \%$ or $\$ 8,338^{*}$ & $\$ 7,692^{*}$ & $47 \%$ or $52^{* *}$ & $\$ 8,909$ \\
2 & $\$ 6,862$ & $\$ 6,396^{+}$ & $47^{*}$ & $\$ 5,482$ \\
3 & $\$ 10,697$ & $\$ 8,182$ & 62 & $\$ 4,498$ \\
$4+$ & $16 \%$ or $\$ 25,099^{*}$ & $\$ 26,016^{* *}$ & $147 \%$ or $164^{*}$ & $26 \%$ or $\$ 43,766^{* *}$ \\
\hline
\end{tabular}

$\underset{\perp}{\text { Notes. }+p<.10, * p<.05, * * p<.01}$ 
Three of the research studies were located in an urban area that contained a major city.

Larsen et al. (2003) conducted their study sometime during the millennium year and reported Montgomery County population at 558,427. Furthermore, they had a large city within the county, Dayton, Ohio. Linden and Rockoff (2008) investigated Mecklenburg County with Charlotte, North Carolina being the largest city. At the time the information was pulled, the county had an estimated population of 769,369 on July $1^{\text {st }}, 2006$ (U.S. Census Bureau, 2007b). Pope (2008) had the largest county by population. This is mainly due to the city of Tampa, Florida, which he claimed was approximately 300,000 people according to the 2000 decennial U.S. Census Bureau. He collected his registered sex offender list from April 1997 to November 2006. On July $1^{\text {st }}, 1997$, the estimated population of Hillsborough County, Florida was 943,919 (U.S. Census Bureau, 2010), which increased to an estimated 1,772,745 for July $1^{\text {st }}, 2006$ (U.S. Census Bureau, 2007a). Interestingly, the other research study's conducted by Wentland et al. (2013) and Bian et al. (2013) was in Lynchburg, Virginia and its surrounding areas, which is an area that is considered not a U.S. county, but an independent city. These researchers stated that they examined a suburban/rural area, but were vague in whether or not the surroundings areas of Lynchburg were either suburban or rural. The 2010 decennial U.S. Census Bureau population of Lynchburg, Virginia was reported at 75,568 (U.S. Census Bureau State \& County QuickFacts, 2013d), a much lesser number than the three other research studies that investigated household reactions to registered sex offenders within U.S. counties. Be that as it may, an inspection of persons per square mile revealed that all of these research studies that performed such observations upon communities are much more alike.

All five research studies exhibited high levels of persons for square mile, in accordance to the records from the 2010 decennial U.S. Census Bureau. Of these five, three of the studies 
examined a U.S. county while the other two examined an independent city, which is a common designation in the state of Virginia, and are completely independent from counties. In the end, the financial results produced from the observation of the independent city of Lynchburg and its surrounding area should not be taken with total confidence that they are just as representative as the three previous studies that have examined household reactions to nearby registered sex offenders within a U.S. county. With that said, the persons per square mile in Larsen et al. (2003), Linden \& Rockoff (2008), Pope (2008), Bian et al. (2013), and Wentland et al. (2013) for their respective U.S. counties are Montgomery with 1,159.5 (U.S. Census Bureau State \& County QuickFacts, 2013c), Mecklenburg with 1,755.5 (U.S. Census Bureau State \& County QuickFacts, 2013b), Hillsborough with 1,204.9 (U.S. Census Bureau State \& County QuickFacts, 2013a), and the independent city of Lynchburg, Virginia with 1,538.2 (U.S. Census Bureau State \& County QuickFacts, 2013d).

They also differed in the number of registered sex offenders that resided in their counties, but were comparable in the type of housing they selected to be investigated. Larsen et al. (2003) contained 26 limited disclosure sex offenders and 223 passive notification sex offenders for a total of 249 registered sex offenders with a single-family home. They focused on single family housing transactions that occurred during 2000. Further, the number of homes that were reviewed within the limited disclosure sex offenders was 535 and 1,827 for the passive notification sex offenders. Linden and Rockoff (2008) corresponded 174 registered sex offenders living in single family homes in Mecklenburg County, North Carolina to homes sold from January 1994 to December 2004. The value of the house was adjusted for inflation and updated to December 2004. The registered sex offenders selected had at least a year of residence at their home. Pope (2008) also used single-family housing transactions from October 
1996 to April 2006 within Hillsborough County. The registered sex offenders must have lived at the residence for at least six months, which amounted to 322 total registered sex offenders utilized in his analysis, but Pope (2008) does not offer the number of sexual predators in his list of registered sex offenders. Beyond the elimination of mobile homes, the authors do not state the exact type of properties examined except that they were all residential properties.

Wentland's et al. (2013) registered sex offender list included an astounding 2,031, whereas Bian et al. (2013) maintained 812 registered sex offenders that were within or equal to a quarter mile of a home. A reason for this high number in Wentland's et al. (2013) research may be that they did not eliminate any registered sex offenders in order to retain a representative sample compared to Linden and Rockoff (2008) and Pope (2008) who had eliminated transient registered sex offenders. Wentland et al. (2013) also examined whether or not a difference in label would produce a different financial impact upon a marketed property, but they did not provide the number of violent sex offenders.

Each of the authors' findings resulted in a different financial impact on house values by the sex offender's residence within a neighborhood of the investigated county is discussed thoroughly here. Larsen et al. (2003) experienced a sizeable impact, with effects up to 0.5 of a mile away from the sex offender's residence. This may be the case due to an observation Linden and Rockoff (2008) made that Larsen et al. (2003) did not take in account that registered sex offenders typically reside in neighborhoods with socially disorganized markers. Their examination revealed a pattern that registered sex offenders financially impacted nearby homes at a greater level than those further away. The authors divided their list of registered sex offenders into their type of notification, limited disclosure and passive notification. Sex offenders who are labeled as limited disclosure are considered to be more dangerous whereas 
those with passive notification are less dangerous offenders. There is an obvious financial difference between limited disclosure and passive notification, with limited disclosure offenders producing a more drastic effect. Of those classified as limited disclosure, the authors discovered that houses that sold in 2000 within 0.1 of a mile of the nearest offender's home sold $17.4 \%$ less or $\$ 11,864$. Homes to the nearest limited disclosure registered sex offender within one-tenth to two-tenth of a mile experienced a $10.2 \%(\$ 7,475)$ reduction in selling price, a $9.3 \%(\$ 7,188)$ loss between 0.2 and 0.3 of a mile, $6.4 \%(\$ 5,104)$ loss between 0.3 and 0.4 of a mile, and $0.8 \%$ (\$703) loss between 0.4 and 0.5 of a mile. Those with a passive notification classification or less dangerous offenders produced a more lenient effect on house values. Sold homes within a 0.1 of a mile of the nearest offender's home experienced a $7.5 \%$ depreciation or $\$ 4,208$. Homes to the nearest passive notification registered sex offender within 0.1 to 0.2 of a mile sold for $5 \%$ $(\$ 4,303)$ less, 0.2 to 0.3 of a mile sold for $3.8 \%(\$ 3,465)$ less, 0.3 to 0.4 of a mile sold for $3.9 \%$ $(\$ 3,843), 0.4$ to 0.5 of a mile sold for $1.8 \%(\$ 1,932)$ when compared to homes outside of the half-mile buffer zone.

Linden and Rockoff (2008) added the value of time and obtained approximate move-in dates of registered sex offenders and observed surrounding properties that were sold between 1994 and 2004 two years before and after from their arrival into a neighborhood. They determined after the control variables (home property characteristics) were considered that before the arrival of a registered sex offender, home sale was reduced by .7\% when compared to homes within the 0.1 to 0.3 of a mile buffer zone, but post arrival of a registered sex offender produced a $3.3 \%$ reduction in price for the sum total of $4 \%$ or a $\$ 5,500$ decline in sale price. Sold homes from 0.1 to 0.3 of a mile radii experienced no there difference in selling price before and after the offender's arrival and were relatively similar in property characteristics, therefore were 
used as controls. Before their arrival to the neighborhood, the real estate market had produced an even trend, but as a result of their arrival, homes closest to the offender experienced a dip in sale price when compared to the trend, as well as an increased probability of a home sale to occur. Additionally, homes within .05 miles of the offender experienced a sale on average $\$ 125,000$, whereas prior to their arrival sold for $\$ 145,000$, and the closer the home was to the registered sex offender the lesser the value after the fluctuation of real estate market was taken in consideration. For instance, homes directly adjacent to an offender's home were estimated to experience an $11.6 \%$ depreciation. Using the median value of a home in Mecklenburg County, North Carolina, Linden and Rockoff (2008) calculated that the county can potentially experience $\$ 60$ million depreciation in property value when taken in account of the 373 registered sex offenders that placed residence in the county. According to the researchers with such a financial loss, it may indicate that neighborhoods are willing to pay for policies to not allow sex offenders in their communities because their property value loss is so high. This was evident through the practice conducted by multiple metropolitan U.S. cities who had established tiny parks to bar individuals convicted of sexual crimes from their neighborhoods (Lovett, 2013).

Pope (2008) conducted a very comprehensive investigation of the registered sex offenders in Hillsborough County, Florida, and discovered results that showed declined property values around an offender's residence that included a rebound effect once the offender left the neighborhood. He looked at single-family homes that were sold from October 1996 to April 2006, attained property characteristics/prices from the Hillsborough County Property Appraiser's Office, and a GIS parcel map from the appraiser's office. Pope (2008) had chosen a U.S. state that retained the residential histories of offenders, and was able to examine their arrival and departure dates from the neighborhood to witness if the neighborhood rebounds 
economically. His list set included only registered sex offenders who resided at the listed address for six months or longer. Like Linden and Rockoff (2008), Pope (2008) ventured to discover whether or not a non-offender's home to the nearest registered sex offender labeled as a sexual predator was more impactful upon housing prices, which resulted in an insignificant finding. What did produce an effect was homes that are within 0.1 of a mile of the nearest offender will depreciate by $2.3 \%$ or $\$ 3,500$ with no impact beyond 0.1 of a mile after controlling for home property characteristics. Once the offender departed the neighborhood the property value rebounded, indicating that the offender is contributing to the reduction in the property value therefore strengthened the causal link between registered sex offenders and their effect on the prices of residential locations.

To begin, Wentland's et al. (2013) research study differed from the previous three studies due to its examination of Lynchburg, Virginia and the surrounding areas, and not a U.S. county. The researchers described the observed area as largely suburban and rural. As a result of their investigation of an area not defined as U.S. county, their conclusions should be taken with some caution. Although this may be true, their findings from their remarkable study revealed by and large similar findings when compared to the other studies. With that in mind, their study produced the greatest financial impact upon home values. Their property dataset included 12,426 sold and 7,295 unsold properties for a total of 19,721 residential properties between July 1999 and June 2009 in central Virginia. An examination at unsold properties was to eliminate sample selection bias, which the previous three studies created as a result of only observing sold homes. They did not discuss what types of residential properties were included, but did mention that outliers and mobile homes were eliminated from the initial housing dataset. The registered sex offender dataset included 2,031 Virginian registered sex offenders, 
which the researchers were also able to obtain their move-in and move-out dates from their residences. Unlike the previous studies, Wentland et al. (2013) utilized different radii zones from a nearby registered sex offender that were comprised of less than a 0.1 of a mile, less than .25 of a mile, less than .5 of a mile, and less than a mile, but provided no reasoning for these chosen distances. Although similar to the previous studies, these researchers utilized the "crow flies" distance to measure the distance from a registered sex offender's home to a nearby marketed property. Their research produced a strong effect that sustained the financial phenomenon of the nearby residence of a registered sex offender from 0.1 of a mile up to a mile, with all of the examined variables experiencing the greatest impact within 0.1 of a mile. The summary of their findings can be viewed in Table 2.

The variables examined by Wentland et al. (2013) to observe the effect produced by the nearest residence of a registered sex offender that were similar to the ones studied by Larsen et al. (2003), Linden and Rockoff (2008), and Pope (2008) included overall sale price, move-out, and sex offender classification. The nearest registered sex offender reduced properties within 0.1 of a mile by $9.2 \%{ }^{9}$ or $\$ 15,533$ with the effects diminishing the further the marketed property is from the registered sex offender's residence. The authors reasoned for the more dramatic financial impact as a result of, 1) the area observed and, 2) the effect of transient registered sex offenders. To address the area issue, they examined a suburban and rural area. They believed that the perception of a neighbor is markedly different than one in an urban setting. This belief that a neighbor is differently defined in a suburban/rural area is also applied as to why the researchers found a financial impact beyond 0.3 miles. Additionally, the authors believed in those types of settings, residents are willing to pay more to avoid crime. In regards of transient

\footnotetext{
${ }^{9}$ Based on the average sale price of homes within the study's sample.
} 
registered sex offenders, unlike Linden and Rockoff (2008) and Pope (2008), Wentland et al. (2013) did not include a cut-off length of residence of the registered sex offender, whereas the previous researchers removed registered sex offenders that did not reside in the county for more than six months and one year. Similar to Pope (2008), these researchers examined if surrounding households would react to a registered sex offender who had moved out of their residence, and they too found that marketed property prices recovered once the registered sex offender moved out, but there was no statistical significance when compared to the control group of homes across all of the concentric zones. Like Linden and Rockoff (2008) and Pope (2008), Wentland et al. (2013) examined whether or not registered sex offenders distinguished by their level of dangerousness produced a greater impact upon household. In the state of Virginia, registered sex offenders are separated into their type of convicted crime, violent or non-violent. Homes near a violent registered sex offender experienced a greater financial impact and a lengthened period of time on the market than a non-violent registered sex offender.

Wentland's et al. (2013) research study is unique as they examined multiple variables previously unobserved by the previous studies that investigated the household reactions to the presence of registered sex offenders, which included a data set of sold and unsold homes, controlled for multiple nearby registered sex offenders, liquidity, and number of bedrooms, as well as an expanded concentric zone up to a mile, and a suburban and rural type of community setting. An examination was performed that controlled the impact of more than a single registered sex offender. They uncovered that when multiple registered sex offenders were controlled for they experienced a lesser pronounced financial impact when compared to the nearest single registered sex offender equation. The financial impact declined the further away 
the marketed property is from the residence of the registered sex offender. With each additional registered sex offender within a mile of the marketed property, an additional loss of $\$ 695$ will occur upon that home. The reasoning behind the lesser impact was that if the homeowners enforced a method of protection from one registered sex offender, it will as a result, not be further increased from the additional registered sex offenders. Another variable that was not examined by the previous studies was the liquidity of residential real estate to reduce market factors. Again, their findings revealed that homes up to a mile reduced in selling price, as well as lengthened the period of time the home was on the real estate market. The greatest impact was experienced within a 0.1 of a mile with a reduction of $7 \%$ or $\$ 11,712$, and an increase of approximately 88 days of the home being on the market —an $80 \%$ increase than average. An examination was conducted whether or not a four-bedroom home can experience a greater impact than a two-bedroom home to the nearby residence a registered sex offender. A four-bedroom home within 0.1 of a mile of a registered sex offender sold for $\$ 24,947$ less and with each additional bedroom a $\$ 12,476$ loss will be experienced. With each additional registered sex offender within a mile of a four-bedroom home, a further $\$ 701$ loss will be experienced. Furthermore, a four-bedroom home will spend 174 days longer on the real estate market compared to 20 days for a two-bedroom home. The assumption held by the authors is that a family with a greater number of children will be much influenced by the presence of a registered sex offender in their community, as a result, less likely to invest in that particular home.

An apparent extension of Wentland's et al. (2013) research, Bian et al. (2013) examined the concentration effect of registered sex offenders upon sold and unsold homes within less than or equal to a quarter mile with their results exhibited in Table 3. Bian's et al. (2013) 
maintained the same real estate data from Wentland et al. (2013), but only 812 homes were relevant to the purpose of their research study. A single registered sex offender resided nearby 584 sold homes, with 167 homes nearby two registered sex offenders, 38 sold homes were nearby three registered sex offenders, and 23 sold homes were within four or more registered sex offenders. Bian et al. (2013) examined three variables, the effect registered sex offender clustering have on sale price, family homes, and sale price jointed with liquidity and discovered that the nearby residence of four or more registered sex offenders produced the greatest impact across all three variables, thus, represented the financial tipping point of a neighborhood's ability to sell homes.

Their first variable, the effect of the number of registered sex offenders had upon sale price of sold homes within the observed distance exposed that the greatest effect onto sale price was four or more registered sex offenders, which produced a financial loss of $16 \%$ or $\$ 25,099$ in selling price. Although the nearby residence of a single registered sex offender did not produce a similar financial impact as four or more registered sex offender, it was still significant at an $\$ 8,338$ financial loss or five percent on average. Based on their results, the authors suggested that the nearby residence of four or more registered sex offenders represented the tipping point of a neighborhood's ability to proficiently sell homes, whereas, a neighborhood with three or less registered sex offenders within or equal to the distance of a quarter mile of a home retained its neighborhood equilibrium. As the number of registered sex offender's increase, the assumption held by Bian et al. (2013) is that this financial phenomenon would continue, especially taken in consideration, that an additional registered sex offender within the observed distance produced $\$ 5,454$ monetary loss upon the sold homes. 
Bian et al. (2013) examined their second variable of family homes, which they defined as homes with three or more bedrooms, and discovered a similar reaction upon sold homes by the nearby residences of four or more registered sex offenders. These family homes nearby four or more registered sex offenders experienced a $26 \%$ or $\$ 43,766$ financial loss, on average.

Although homes nearby three or less registered sex offenders were financially impacted, they did not produce a significant effect as homes nearby four or more registered sex offenders.

Lastly, Bian et al. (2013) examined their third variable, sale price jointed with liquidity. With this variable taken in consideration, they produced similar results across the number of registered sex offenders and their impact onto sale price of their sample of homes. Again, the greatest financial impact was produced by the nearby residence of four or more registered sex offenders at a $\$ 26,017$ financial loss, and extended the home's time on the market by $147 \%$ longer or 164 days. There was also a statistical significance effect found in sold homes with a single registered sex offender nearby, which produced a financial loss of $\$ 7,693$ and lengthened the time on the market by 52 days or $47 \%$, on average. Furthermore, a statistical significance was produced amongst homes within the residence of two sex offenders at a $\$ 6,396$ loss.

In conclusion, the residences of registered sex offenders in communities have caused major social and financial effects. Individuals who have been convicted of sexual crimes return to civilian life into indecent neighborhoods (Suresh et al., 2010), which are riddled in disorder (Tewksbury \& Mustaine, 2006). These conditions have shown to worsen as the number of registered sex offenders becomes concentrated in a particular area (Burchfield \& Mingus, 2008). The company of a registered sex offender in a neighborhood have created tense feelings that have motivated some to move out (Zevitz, 2003, 2004) with some residents concerned about their house price being affected (Zevitz, 2004), which has been shown to occur in three counties 
across the nation (Larsen et al., 2003; Linden \& Rockoff, 2008; Pope, 2008), and in an independent city (Bian et al., 2013; Wentland et al., 2013). According to the sex offender legislation, the presence of registered sex offenders produced disastrous repercussions upon neighborhoods, in order to be in compliance with sex offender legislation. Similarly, the framework of the broken windows theory suggested that disorder has a devastating impact on neighborhoods labeled as the spiral of decline, a reaction comparable to the presence of registered sex offenders created.

\section{Theoretical Framework}

Broken windows theory was written in The Atlantic Monthly Review and established by Kelling and Wilson (1982) to explain the relationship between disorder and crime within urban communities. If disorder is present within a neighborhood, it will invite more disorder, and therefore lead to crime. Residents will move out because they feel as if their safety is compromised, and inadvertently cause the community to decline into chaos. The useful analogy they utilized was an unrepaired broken window, which stated "if a window in a building is broken and is left unrepaired, all the rest of the windows will soon be broken" (p. 31). There were several studies that inspired these authors to lay the foundation for the broken windows theory: Newark foot patrol experiment and the Zimbardo's car experiment in 1969.

There are two main elements Kelling and Wilson (1982) discuss: the fear of crime and disorder. Both of these elements came about from the findings of the Newark foot patrol experiment. This involved an evaluation conducted five years after the implementation of the Safe and Clean Neighborhoods Act in New Jersey that intended to reduce crime and improve the community life. At the end of the evaluation there were no significant effects on crime rates, nevertheless, there were increases in citizen perception of safety, neighborhood quality, and 
satisfaction with police services (The Newark foot patrol experiment, 2013). The authors were puzzled as to how perception of safety increased within the Newark citizens regardless of the unchanged levels of crime. The results suggested that crime was not solely responsible for the effect upon the perception of safety of citizens; disorder was seen as another element that can have an influence. They came to an unlikely conclusion that has been neglected, which includes the factor of undesirable people. "[T] he fear of being bothered by disorderly people. Not violent people, nor necessarily, criminals, but disreputable or obstreperous or unpredictable people: panhandlers, drunks, addicts, rowdy teenagers, prostitutes, loiterers, the mentally disturbed" ( $p$. 30). Moreover, "...serious street crime flourishes in areas in which disorderly behavior goes unchecked. The unchecked panhandler is, in effect, the first broken window" (p. 34). This panhandler conveys the message that disorder is tolerated in the surrounding area and the community lacks control. On the other hand, if there is no panhandler present, it conveys the message that the neighborhood is well-tended. In other words, the condition and appearance of the community will signify to others the level of care for the surroundings.

The following factors contribute to a weak community sense: untended property, rambunctious children, and strangers. Untended property has the ability to weaken a community. Not only does disorder include social aspects, but also physical aspects. This type of environment invites criminal-like behavior and mistrustful characters within a community. It portrays the message to others that such deviant behavior is tolerated. There is a sense of lawlessness. It gives confidence to undesirable people to engage in criminal-like behavior. They can be more successful in these environments. The area has cultivated such disorder. As these factors increase in number, so too will the citizens who leave the community, thereby weaken community social ties. Vulnerable citizens will choose to withdraw themselves from the 
community both psychically and socially. This reaction from community members has to potential to cause a downward spiral for the community into crime and violence. If a broken window is apparent it must be repaired before the surrounding area is irreparable. A welltended area will decrease the chance of criminal-like behavior to occur. Furthermore, this also prevents community members leaving their own community and creating a downward spiral into chaos. The appearance of a safe neighborhood can also attract more citizens (Kelling \& Wilson, 1982).

Kelling and Wilson's (1982) work was also inspired by the field experiment embarked on in 1969 by Philip Zimbardo of what would occur to an abandoned vehicle — 1959 green Oldsmobile — in two middle-class environments (Diary of a vandalized car, 1969). These vehicles appeared abandoned due to the lack of license plates and opened hoods (Diary of a vandalized car, 1969; Zimbardo, 2007). Palo Alto — home of Stanford University-was chosen as one location. His second location was one of the five boroughs of New York City, Bronx — home of New York University. Palo Alto was a suburban area, in contrast to the Bronx, which was more urban. According to Kelling and Wilson (1982), the sense of community differed, which might explain the different reactions to an abandoned vehicle. Over the course of Zimbardo's (2007) experiment, the vehicles abandoned would be recorded by cameras, photographs, and field observers for any potential criminal behavior conducted upon the vehicle.

Immediately, the vehicle abandoned in the Bronx was being vandalized, whereas the vehicle in Palo Alto was not vandalized. In total, the Bronx vehicle experienced 23 counts of vandalism. Different from the Palo Alto vehicle, which had no counts of vandalism, and when the vehicle was removed from the Stanford campus three concerned citizens called a possible motor vehicle theft. Surprisingly, all of the acts of vandalism conducted onto the Bronx vehicle 
occurred in the daytime. Additionally, the offenders varied far from a stereotypical criminal (Zimbardo, 2007).

Zimbardo's explanation was described in the Times magazine article Diary of a Vandalized Car published in 1969. He concluded, big-cities offered a lack of personal identity. Although, it seemed at the time he did not offer a reason for the lack of vandalism in Palo Alto. Zimbardo elaborated the car experiment in his 2007 novel The Lucifer Effect. His definition of community involved "people caring enough to take action in the face of an unusual or possibly illegal event on their turf" (p. 25). In other words, the lack of community promotes anonymity, thereby antisocial behavior. Furthermore, Zimbardo (2007) related the similarities of his car experiment to the broken windows theory. By using the concept of anonymity, he claimed that no one individual has a "sense of personal accountability and civil responsibility for their actions" (p. 25). Sense of a community is compromised as a result of increased physical disorder, which would prevail if not taken care of properly.

The sequence described by the broken windows theory (Kelling \& Wilson, 1982) parallel with how neighborhoods have reacted to the residence of a registered sex offender. What we know about the theoretical framework is that disorder will invite more disorder (Kelling \& Wilson, 1982). The sex offender literature has shown that the residence of one registered sex offender has the potential to destabilize a neighborhood (Zevitz, 2003). Neighborhood residents fear that the residence of this one registered sex offender will attract others, and be labeled as a community that is a harbor for registered sex offenders (Cowan et al., 2001; Davey, 2006; Parks, 2001; Zevitz, 2004). Furthermore, high concentrations of registered sex offenders correlate with high levels of social disorganization (Hughes \& Burchfield, 2008; Hughes \& Kadleck, 2008; Linden \& Rockoff, 2008; Mustaine \& Tewksbury, 2008; Mustaine et al., 2006a; Mustaine et al., 2006b; 
Suresh et al., 2010; ; Tewksbury \& Mustaine, 2008; Tewksbury et al., 2007). Stated in the broken windows theory is that the neighborhood is well-kept if there are no panhandlers present (Kelling \& Wilson, 1982). Not a panhandler, a registered sex offender is regarded as a disgraced person in society (Mustaine \& Tewksbury, 2008; Mustaine et al., 2006a; Tewksbury, 2005). Additionally, Zimbardo's car experiment which inspired Kelling and Wilson's (1982) work, discovered incivilities can influence an observer's perception that no one cares for the area, which supported the sex offender literature since registered sex offenders generally live in neighborhoods littered with crime and disorder (Suresh et al., 2010; Tewksbury \& Mustaine, 2006). In due time, the community that is in disarray will promote citizens to leave and/or withdraw from the community (Kelling \& Wilson, 1982). Similarly, once news of a registered sex offender has been placed into a community residents planned on moving, with some expressed concern of the influence the registered sex offender may have on their property value (Zevitz, 2004). This financial phenomenon on home property values has been demonstrated in three heavily populated U.S. counties (Larsen et al., 2003; Linden \& Rockoff, 2008; Pope, 2008) and in central Virginia (Bian et al., 2013; Wentland et al., 2013) inhabited by registered sex offenders. Such a reaction to registered sex offenders is similar to the reaction described in broken windows theory in the fear of crime and disorder in a community, which has the potential to cause a downward spiral for the area (Kelling \& Wilson, 1982).

\section{Skogan's Scholarly Work}

Research has confirmed that registered sex offenders live in socially disorganized neighborhoods (Burchfield \& Mingus, 2008; Mustaine \& Tewksbury, 2008; Mustaine et al., 2006a; Mustaine et al., 2006b; Socia \& Stamatel, 2012; Suresh et al., 2010; Tewksbury \& Lees, 2006), that include various forms of social disorder such as litter and unkempt lawns (Tewksbury 
\& Mustaine, 2006). The presence of such disorder in neighborhoods that registered sex offenders reside in relate to Skogan's (1990) in-depth examination of what he labeled the 'spiral of decay in American neighborhoods'. For his paramount study on the relationship between crime and disorder he gathered data from 40 residential neighborhoods in six American cities - Atlanta, Chicago, Houston, Newark, Philadelphia, and San Francisco - through the use of surveys and interviews, and observed the role disorder had upon a neighborhood. These measurements were conducted from 1977 to 1983 . He differentiated physical and social disorders and discovered that within a neighborhood context these two elements are correlated. Consequently, Skogan's (1990) findings indicated that disorder should be considered as a serious element of neighborhood decline. Perkins and Taylor (1996) summed up Skogan's (1990) spiral of decline best, a "resident fears and avoidance behaviors increase, informal social controls weaken, incivilities proliferate, potential offenders are emboldened, criminals from adjoining areas are attracted to the locale, and the downward spiral becomes self-reinforcing" (p. 67). All things considered, the findings from Skogan's (1990) research supported the broken windows theory.

Skogan had many other related works with disorder as his topic at hand. In his academic work, Skogan (1999) has identified

"a variety of disorder problems: loitering; vandalism; street harassment; fly dumping; massage parlors; abandoned buildings; noise; abandoned cars; junk-filled vacant lots; truancy; panhandling; litter and trash; graffiti; public drinking; broken windows; public gambling; loud parties; school disruption; public insults; spray painting; dilapidated buildings; taverns; topless bars; dirty streets and sidewalks; pornographic theaters" ( $p$. 44).

Important to realize, Skogan (1990) labeled social and physical disorder as two different types of disorder. Social disorder is related to human behavior, whereas, physical disorder are visual 
signs of decay. Communities that displayed such physical and social disorder make them unsuitable, uninviting places to live in. Kelling and Wilson (1982) mentioned both types of disorders, but did not distinguish the differences as Skogan (1990) had done in his research. Not an exhaustive list, types of social disorder include public drinking and loitering youths. On the other hand, physical disorder consists of abandoned, neglected buildings, and vacant lots. The general rule is that social disorders occur here and there while physical disorders are continuing. In the final analysis, Skogan (1990) found a significant correlation between level of disorder and the stability of neighborhoods across America and established the connection between fear of crime and crimes rates with physical and social disorder. Although his findings strengthened the crime-disorder connection he warned that this disorder-fear of crime relationship is a wary conclusion.

Comparatively to Kelling and Wilson's (1982) broken windows theory, the neighbors in Skogan's (1990) research were less likely to be involved in the community if disorder-social and physical—continues to persist, which will further increase the presence of disorder. Skogan (1990) mentioned that a high level of disorder causes neighbors to move out. An area with disorder has less appeal for investment, creating a decline. Businesses tend not to invest in these areas, thereby not attracting any individuals and affecting the real estate value downward. A neighborhood with disorder can have a negative impact for the pursuit of homes and their prices. As disorder increases, neighbor satisfaction of their neighborhood decreases. This sequence further decays the neighborhood.

Skogan (1990) tagged the 'spiral of decay' as a neighborhood that has become an uninviting location through identifiable physical and social factors that convey the scenery and culture that is unappealing to potential neighbors. Elements of disorder have the potential to 
destroy the essence of a neighborhood and motivate decline. Sex offender literature has exhibited that registered sex offenders have the same effect as Skogan's (1990) description of disorder. It is stated that social disorder is related to human behavior, and one result of this disorder is neighborhood residents leaving their residence (Skogan, 1990), which some have expressed when a registered sex offender moved in (Zevitz, 2004). Consequently, a spiral of decay will form. Investments are not likely to occur and affect real estate value downward (Skogan, 1990). U.S. counties have experienced a negative reaction on property values due to the nearby residence of a registered sex offender (Larsen et al., 2003; Linden \& Rockoff, 2008; Pope, 2008), which was also evident in central Virginia (Bian et al., 2013; Wentland et al., 2013). Disorder also has the ability to influence neighborhood satisfaction (Skogan, 1990). Similarly, neighborhood residents have reported feelings of anxiety that their neighborhood will become a relocated setting for registered sex offenders (Cowan et al., 2001; Davey, 2006; Parks, 2001; Zevitz, 2004). An interesting finding from Skogan and Hartnett's (1997) research is that disorder is perceived differently from each neighborhood. So would the financial reaction in U.S. counties as a result of nearby residents of registered sex offenders apply to another U.S. county, specifically, one that is much smaller in population and less urban? 
CHAPTER III

METHODS

Introduction

Sex offender legislation has created drastic repercussions for persons convicted of a crime that has labeled them a registered sex offender and inadvertently affected communities socially and financially. Such legislation have forced registered sex offenders to place their residence in socially disorganized neighborhoods (Suresh et al., 2010) to abide by their legal requirements. Urban areas are generally off limits for registered sex offenders, and as a result, they have relocated into generally rural, agricultural, or county areas (Chajewski \& Mercado, 2009; Turley \& Hutzel, 2001; Zandbergen \& Hart, 2006). Five studies have observed that registered sex offenders can influence surrounding property values, but these studies were conducted in major metropolitan areas (Bian et al., 2013; Larsen et al., 2003; Linden \& Rockoff, 2008; Pope, 2008; Wentland et al., 2013). Have registered sex offenders who are in compliance of sex offender legislation created similar financial and social consequences onto other areas, such as McLean County, Illinois? The present study will confirm and extend upon the literature on the financial effect on a sold house by the nearby residence of a registered sex offender within a U.S. county (Larsen et al., 2003; Linden \& Rockoff, 2008; Pope, 2008) and an independent city (Bian et al., 2013; Wentland et al., 2013) through an examination of 
registered sex offenders and sexual predators ${ }^{10}$ and their effect upon home sales in McLean County, Illinois, with variables that were collected from tax assessor's offices' in McLean County, Illinois of home property characteristics to control for selling price and variables from the 2010 decennial U.S. Census Bureau for each of the county's census blocks to be used to control for outside influences onto the neighborhood.

The following research questions were addressed in this study:

1. Does the concentration of registered sex offenders within 0.2 of a mile affect home sale value after controlling for disorder and property characteristics?

a. Does the concentration of sexual predators within 0.2 of a mile affect home sale value after controlling for disorder and property characteristics?

2. Does the distance of the nearest registered sex offender within 0.2 of a mile affect home sale value after controlling for disorder and property characteristics?

a. Does the distance of the nearest sexual predator within 0.2 of a mile affect home sale value after controlling for disorder and property characteristics?

This quantitative case study explored whether or not the residences of individuals convicted of sexual crimes and designated as a registered sex offender and/or sexual predator in McLean County, Illinois can influence nearby home sale prices. These were observed through the utilization of ArcGIS, a mapping software program, which,

\footnotetext{
${ }^{10}$ As a reminder, sexually violent persons were combined with sexual predators as there were too few of sexually violent persons to produce a significant effect, and has been referred to as sexual predators since its first mention on page eight. The cardinal distinction between a sexual predator and sexually violent person within Illinois sex offender legislation is that those with a sexually violent person label suffer from a mental disorder.
} 
1) mapped, measured, and calculated the concentrations and distances of the residences of registered sex offenders and sexual predators that were collected from the Illinois sex offender registry website,

2) geocoded sold homes from December 2012 - December 2013 that were obtained from multiple assessor's offices with their property characteristics, and

3) mapped the selected 2010 decennial U.S. Census Bureau variables that were gathered from their respective website, American FactFinder, along with a self-created indicator of census block disorder for each appropriate census block in McLean County, Illinois.

Once the appropriate information was joined via the spatial join function in ArcGIS it was transferred to Excel then to SPSS for analysis. Correlation and regression analyses were then conducted.

\section{Setting}

The county under observation is home to an estimated 2012 population of 172,281 residents across $1,183.38$ square miles ${ }^{11}$, making it the largest county by size in the state of Illinois, with an approximate 143.3 persons per square mile (U.S. Census Bureau State \& County QuickFacts, 2012). McLean County is home to a mid-sized city and/or twin municipality, Bloomington-Normal, which is surrounded by rural and agricultural areas. McLean County's population and population density pales in comparison to the three studies that examined housing transactions by U.S. counties (Larsen et al., 2003; Linden \& Rockoff, 2008; Pope, 2008)

\footnotetext{
${ }^{11}$ Again, a reminder, to depict the enormous size of McLean County, Illinois, the 2010 U.S. Census reported the land area of Rhode Island, a U.S. state, to be 1,033.81 square miles (U.S. Census Bureau State \& County QuickFacts, 2014).
} 
and the two studies that examined central Virginia (Bian et al., 2013; Wentland et al., 2013). The current study swayed from those five studies and examined outside of an urban, dense environment.

The 2010 decennial U.S. Census Bureau recognized urbanized areas as a population over 50,000 , urban clusters are defined as a population from 2,500 to 50,000 , and those not labeled as either are considered rural areas. The twin municipality located in McLean County, Bloomington-Normal, is the only area in the county identified as an urbanized area and the town of Heyworth is the only area in the county identified as an urban cluster (Qualifying Urban Areas for the 2010 Census, 2012). The subsequent areas are designated as rural areas: Anchor, Arrowsmith, Bellflower, Bloomington, Carlock, Chenoa, Colfax, Cooksville, Danvers, Downs, Ellsworth, Gridley, Hudson, Le Roy, Lexington, Merna, McLean, Saybrook, Shirley, Stanford, and Towanda.

Some relevant information reported by the data of the 2010 decennial U.S. Census Bureau for McLean County include, race, household, and poverty. McLean County is predominately White (85.2\%) with a minimal population of Blacks or African American (7.6\%), Asians (4.8), Hispanics or Latinos (4.6\%), and American Indian and Alaska Native (0.3\%). As of 2011, in regards of housing, there were 70,183 housing units and 63,431 households. From 2007-2011, the median household income amounted to $\$ 59,410$ and the median owner occupied household value at $\$ 154,600$ with $79.4 \%$ of the population who had resided in the same home for over one year. Also, the county's poverty level between those years was $13.4 \%$ (U.S. Census Bureau State \& County QuickFacts, 2012). 


\section{Data Collection}

The data involved information collected from the Illinois sex offender registry, characteristics of home properties in McLean County, a property sales report from December 2012 to December 2013, and the 2010 decennial U.S. Census Bureau information of McLean County. These were then imported into ArcGIS in order to obtain the concentrations of registered sex offenders and sexual predators around home sale transactions, and the distances from the nearest registered sex offender and nearest sexual predator within 0.2 of a mile of a home sale transaction. After utilizing the spatial join function within ArcGIS to combine the above datasets, these were then exported as Excel Spreadsheets and imported into SPSS for analysis.

\section{Registered Sex Offender List}

Because of the sex offender laws, it makes the registry an appropriate way to research this study for registered sex offenders, as well as the ability to search for registered sex offenders by county for Midwestern U.S. states (Tewksbury \& Higgins, 2005) and the high compliance rate for Illinois (Yeagle, 2012). Information of individuals convicted of registerable sexual offenses in Illinois were obtained on December $12,2012^{12}$ and provided by a publicly accessible website $^{13}$, the Illinois Sex Offender Registry, which is maintained by law by the Illinois State Police (ISP), and was then compiled into an Excel spreadsheet. At the time, the list consisted of 26,109 registered sex offenders who are currently in Illinois with 302 who have reported their address in McLean County, and after the elimination process 146 registered sex

\footnotetext{
${ }^{12}$ This list reflects only a snapshot of registered sex offender's residences' in McLean County.

${ }^{13}$ Available at http://www.isp.state.il.us/sor/sor.cfm
} 
offenders remained. The process went as so. All registered sex offenders in McLean County, Illinois that maintained a valid address at the time of data collection, as well as continued to be compliant with Illinois sex offender registration laws were selected for the present study. Those eliminated from the McLean County sex offender group included those incarcerated in the Illinois Department of Corrections (IDOC) $(n=119)$ and the IDHS $(n=11)$. A total of seven McLean County registered sex offenders were incarcerated in other U.S. states or counties: Kansas, Kentucky, Mexico, Minnesota, Missouri, New Hampshire, and Oregon with five registered sex offenders being eliminated from the city of Bloomington, as a result of two of them with a listed residence coincidentally from Bloomington, Indiana and three from Bloomington, Minnesota. As a whole, registered sex offenders excluded from the list included those without known addresses/unknown location, homeless or in jail ${ }^{14}$, and non-compliant registered sex offenders. The Illinois state sex offender registry provided the following information on a person convicted of a sexual crime: Last name, first name, street address, city, state, zip code, residence county, $X$ and $Y$ coordinates, height, weight, race, gender, date of birth, victim under/over the age of 18 , compliance status, classification (sex offender, sexual predator, sexually violent, or sexually dangerous), conviction county, conviction status, age of victim, age of offender at the time of offense, and sexual convicted crimes.

The following is a description of the elimination process after the 302 registered sex offenders who identified McLean County, Illinois as their U.S. county of residence, which became 172 once those who were in the IDOC $(n=119)$ or IDHS $(n=11)$ :

\footnotetext{
${ }^{14}$ At times, the McLean County Jail may be entered as the street address instead of indicating strictly jail.
} 
A total of 117 registered sex offenders identified Bloomington, Illinois as their residence in McLean County. Those eliminated from the data set included four unknown addresses, one of which could not be matched with a parcel in the assessment data. There were four noncompliant sex offenders: two with an address and the other two addressed at McLean County Jail. Two compliant sex offenders were located at McLean County Jail. Seven sex offenders were listed as homeless. After the elimination process, a total of 99 sex offenders in Bloomington, Illinois remained ${ }^{15}, 41$ of which are sexual predators and five that are labeled as sexually violent.

A total of 30 registered sex offenders identified Normal, Illinois as their residence in McLean County. Two were eliminated for unknown addresses of which one could not be matched with a parcel, one was eliminated for a non-compliant status with a listed address, and another was listed as homeless. A total of 26 sex offenders remained with the residence of Normal, Illinois with 14 of those registered sex offenders that attained the label of sexual predator.

The twin municipality, Bloomington-Normal accounted for the majority of the registered sex offenders located in McLean County, but there are other smaller towns and cities with sparse populations neighboring within the county. There are a total of 25 registered sex offenders found in the following rural (besides Heyworth) Illinois communities: Bellflower, Carlock, Chenoa, Colfax, Downs, Ellsworth, Heyworth, Lexington, McLean, Saybrook, and Shirley. Of those 25 sex offenders, one sex offender was removed after the elimination process for a non-compliant status and a listed residence of jail, and three offenders who could not be

\footnotetext{
${ }^{15}$ Two registered sex offenders resided in an unincorporated area of Bloomington known as Twin Grove.
} 
accurately matched to a parcel for a total of 21 registered sex offenders ${ }^{16}$, of which eight are classified as sexual predators.

Of the total registered sex offender list, $78.1 \%(n=114)$ were classified as White, $18.5 \%$ $(n=27)$ were Black, $0.007 \%(n=1)$ were Asian, $0.02 \%(n=3)$ were Unknown ${ }^{17}$, and $0.007 \%(n=$ 1) was labeled as " ${ }^{\prime 18}$. In regards to gender, $96.6 \%(n=141)$ were males with $0.34 \%(n=5)$ as female offenders. The age range of the offender was 15 to 78 with the average at 32.7 years. The age range of the victim was 4 to 78 with the average at 15.8 years. Additionally, $16.3 \%(n=$ 24) were over the age of 18 compared to the $84.0 \%(n=122)$ that were under the age of 18.

The state of Illinois has classified four categories of sex offenders, registered sex offender, registered sexual predator, registered sexually violent person, and registered sexually dangerous person. In order to be classified as a sexual predator the individual must be convicted for a second or subsequent offense (Guide, 2006), conviction or attempted conviction of certain sexual offenses (Frequently Asked Questions; 2014), and as a result be subjected to lifetime registration (730 ILCS § 150/7 (LexisNexis 2013)). A sexually violent sex offender is an individual who is, simply put, suffers from a mental disorder (725 ILCS § 205/1-01 (LexisNexis 2013)). In the present study's list of registered sex offenders, there are 64 (43.8\%) sexual predators and five (0.034\%) labeled as sexually violent while the remaining 77 (52.7\%) are registered sex offenders.

\footnotetext{
${ }^{16}$ There are five registered sex offenders who have placed residence in Colfax, Illinois. Four registered sex offenders have a residence in McLean, Illinois. There are two registered sex offenders located in the following Illinois communities within McLean County: Bellflower, Chenoa, Lexington, and Saybrook. Lastly, there is a single registered sex offender in Carlock, Ellsworth, Heyworth, and Shirley.

${ }^{17}$ The author noticed those labeled as unknown for their race are most likely of Hispanic/Latino descent.

${ }^{18}$ The author reasoned that this is likely to be a typo.
} 
Sample/Home Sale Transaction and Property Characteristics

Transactions data and property characteristics of sold homes in McLean County, Illinois were obtained from the McLean County Tax Assessor's Office, City of Bloomington Township Assessor's Office, Normal Township Assessor's Office, and an online website ${ }^{19}$ managed by the Assessor's Office in the City of Bloomington. The McLean County Tax Assessor's Office was utilized for their publicly accessible computers that maintained two programs, DEVNET and Property Assessment Management System (PAMSPro) ${ }^{20}$, which involved a search by the home's parcel number to obtain the characteristics of the parcel. Those two programs were required primarily for parcels outside of the City of Bloomington and the town of Normal while properties within those two jurisdictions required a search through the online database. Additionally, the McLean County Tax Assessor's Office maintained hard copies of parcel information when the information sought for was not included in the two public computers. Similarly, the City of Bloomington retained hard copies of parcel information when not included in the online property database.

Residential home sale transaction data from December 2012 - December $2013^{21}$ was requested from the McLean County Tax Assessor's Office and required a Freedom of

\footnotetext{
${ }^{19}$ Accessible at: http://www.wevaluebloomington.org/propertydatabase.htm

${ }^{20}$ At the time of the study, the McLean County Assessor's Office is making a transition into DEVNET and away from PAMSPRO, which was discontinued for reporting use in 2004. Currently, PAMSPro is used to check the archived data of a parcel. DEVNET was the program predominantly utilized by the McLean County Assessor's Office.

${ }^{21}$ There are delayed recording procedures and human error for the home sale transactions in McLean County, Illinois. A home sale transaction might not be reported until months later or was not reported. As a result, the present study's home sale transaction dataset might not be the complete set of such transactions from December 2012 - December 2013. For instance, home sale transactions that took place
} 
Information Act (FOIA). The property type examined was residential with dwelling (R-0040).

Residential with dwellings can include a duplex, rooming house ${ }^{22}$, a single-family residence, and a townhouse. In the form of a pdf file, the sales report was converted, compiled, and organized into an Excel spreadsheet, and totaled 3,053 sold residential parcels, which was subsequently screened to drop certain sales ${ }^{23}$, and ultimately resulted in 2,547 home sale transactions. The home sales spreadsheet was then geocoded into ArcGIS, which indicated in a $100 \%$ match. A majority of the home sale transactions occurred in the City of Bloomington $(n=1,299)$ and the town of Normal $(n=691)$ with the remaining 557 transactions in the other townships ${ }^{24}$. The original sales listing report included the following information of each sale: the township of sale, 10-digit document number, parcel number ${ }^{25}$, property class, acreage, selling price, sale date ${ }^{26}$,

in the later months of the year 2013 might not be included in the present study's dataset due to delayed recording.

${ }^{22}$ Home for special needs individuals.

${ }^{23}$ The following are the reason for their exclusion from the present study: 236 parcels were eliminated as they were not single family residences; 121 parcels were eliminated as they had identical document numbers, therefore were repeats; 50 parcels were sold along with another parcel or parcels; 45 parcels information could not be found, which are unique to each sale transaction; 36 parcels were farmland; seven parcels were removed as they were repeats, as a result of switched deeds; five parcels were removed for an unknown/missing built year; three parcels were removed as they were outliers above $\$ 800,000$; two parcels once mapped in ArcGIS were located outside of McLean County, thus removed; one parcel was vacant land; and one parcel was sold outside the examined date frame.

${ }^{24}$ The following are the number of home sale transactions that occurred in their townships: Allin $(n=13)$; Arrowsmith $(n=7)$; Bellflower $(n=9)$; Bloomington $(n=34)$; Blue Mound $(n=3)$; Cheney's Grove $(n=14)$; Chenoa $(n=32)$; Cropsey $(n=1)$; Dale $(n=8)$; Danvers $(n=26)$; Dawson $(n=4)$; Downs $(n=17)$; Dry Grove $(n=24)$; Empire $(n=63)$; Funks Grove $(n=1)$; Gridley $(n=20)$; Hudson $(n=51)$; Lawndale $(n=1)$; Lexington ( $n=37)$; Martin ( $n=14)$; Money Creek $(n=13)$; Mount Hope $(n=15)$; Old Town $(n=60)$; Randolph $(n=68)$; Towanda $(n=11)$; West $(n=1)$; White Oak $(n=8)$; Yates $(n=2)$.

${ }^{25}$ To be clear, a parcel number is a 10 digit code that is an identifier for property. The first two digits typically represents the township within McLean County. These 30 townships include, Allin, Anchor, Arrowsmith, Bellflower, Bloomington, Blue Mound, Cheney's Grove, Chenoa, Cropsey, Dale, Danvers, Dawson, Downs, Dry Grove, Empire, Funk's Grove, Gridley, Hudson, Lawndale, Lexington, Martin, Money Creek, Mount Hope, Normal, Old Town, Randolph, Towanda, West, White Oak, and Yates. The next two 
and site address (street, city, state, ZIP), and after data collection was completed, expanded to include type of use, classification, story description, year built, ground square feet, building square feet, and acres.

\section{Decennial U.S. Census Bureau Variables}

The 2010 decennial U.S. Census Bureau data provided information collected about McLean County, Illinois, which is divided into 40 census tracts, 108 census block groups, and then 6,781 census blocks, the smallest representation of a neighborhood. To demonstrate designated census areas in McLean County, one census tract contained one census block group up to six census block groups. As of December 12, 2012, registered sex offenders from McLean County resided in 35 of the 40 census tracts and 65 of the 108 census block groups and 125 of the 6,781 census blocks. Important to realize, each census label differed in the amount of information offered. For instance, census tracts offered much more quantity in information, whereas census blocks presented limited amount of data due to the closer examination of a smaller area.

The unit of analysis for the present study is census blocks. Initially, census block groups were considered to be the unit of analysis for the present study due to the grander information offered that included median home value and median household income, which is information lost at the census block level. Fortunately, at that designated level, other variables were

\footnotetext{
digits indicate the section within McLean County (there are approximately 1,190 sections in McLean County), the subsequent three digits represent the block within McLean County, which is dissimilar from a census block and finally the last three numbers indicate the parcel.

${ }^{26}$ When the regression model was performed with sale date as a variable, it explained less than one percent of the total variance. Therefore, sale date was determined not to be a decent predictor and hence removed as one of the property characteristics that controlled for home selling price.
} 
retained, which all were included in the present study. Another examination was conducted in order to determine whether or not census block groups would be a proper unit of analysis. When the rate of registered sex offenders were standardized per 1,000 by population of each of the county's census block group, it was apparent, due to abundance of census block groups that maintained enormous land area, that the likelihood of yielding meaningful results is statistically low. As a result, census blocks was selected as the unit of analysis. Granted, variables such as, household information are lost; elements of disorder are still reported, better yet, to a smaller degree. To put it differently, because census blocks are the smallest level of a neighborhood, they are the most representative of a neighborhood compared to census block groups and census tracts.

Information of the 6,781 census blocks within McLean County, Illinois was downloaded from American FactFinder, a website that was created by the U.S. Census Bureau to distribute census information since 1990, as well as a shapefile downloaded from Topologically Integrated Geographic Encoding and Referencing System (TIGER) files used from the U.S. Census Bureau to display McLean County's census blocks. The 2010 census block data was collected, inserted into Excel spreadsheets, and manipulated for the current study that included: vacancy, renter occupied housing units, female-headed households, and 19 years of age and younger population. These four forms of disorder are control variables within the present study that controlled for the neighborhood status. Other variables that were collected included population and number of households per census block.

Female-headed households were exhibited by household type. The 2010 Census spreadsheet delineated between type of household, family or nonfamily. Within the family household there are two categories: husband-wife family and other family, which included the 
number of female-headed households under the 2010 decennial U.S. Census Bureau classification of female householder, no husband present. The category of female householder, no husband present, was utilized to exhibit the number of female-headed households.

Literature has exposed that registered sex offenders reside in areas with high levels of femaleheaded households (Mustaine \& Tewksbury, 2008; Mustaine et al., 2006a).

The social disorganization variable 19 years and younger population were exhibited by sex by age. The 2010 decennial U.S. Census Bureau data separated females and males into age groups (under 5,5 to 9,10 to 14,15 to 17,18 to $19,20,21,22$ to 24,25 to 29,30 to 34,35 to 39 , 40 to 44,45 to 49,50 to 54,55 to 59,60 to 61,62 to 64,65 to 66,67 to 69,70 to 74,75 to 79,80 to 84 , and 85 and over) that ranged from 0 to 85 years and over, but only the population under the age of 19 was taken in consideration for the present study. The literature has shown that registered sex offenders commonly reside in areas where there are a lesser population of 19 years and younger residents (Mustaine \& Tewksbury, 2008; Mustaine et al., 2006a). If this is the scenario in McLean County, it will indicate that the examined county's registered sex offender reside in a socially disorganized area.

To define vacancy, the occupancy status is whether or not the housing unit in the census block is occupied or vacant. This determined whether or not the housing units that surrounded registered sex offenders' residences in McLean County were vacant or occupied. An examination of vacant home units is evident of social disorganization through the literature, which has demonstrated that registered sex offenders reside in neighborhoods with high levels of vacant homes (Suresh et al., 2010).

The home ownership rate is defined by tenure in renter occupied housing units. There are three types of tenure identified in the 2010 decennial U.S. Census Bureau: owned with a 
mortgage or a loan, owned free and clear, and renter occupied. Skogan (1990) mentioned that are stable are those that consisted of owner-occupied homes, in other words neighborhoods are less stable if there were high levels of renter-occupied housing units. Registered sex offenders residences are located in areas with high renter occupied housing units (Mustaine \& Tewksbury, 2011) and low housing ownership (Mustaine \& Tewksbury, 2008; Mustaine et al., 2006a; Mustaine et al., 2006b; Mustaine \& Tewksbury, 2011), and if housing ownership is low, registered sex offenders in McLean County reside in neighborhoods with some level of social disorganization and will confirm the results from previous literature.

All four 2010 decennial U.S. Census Bureau variables within the present study were analyzed via factor analysis, in order to determine which variables highly correlated with one another after each variable was standardized to either the total number of households and total population to their respective census block. The factor analysis simplified the interpretation of the four 2010 decennial U.S. Census Bureau variables. A varimax with Kaiser method of factor rotation was selected. Factor scores were produced via regression method. Once conducted, two components were identified, thus, two indicators of disorder, which were subsequently labeled as social disorganization (female-headed households and children under the age of 19) and residential instability (renter occupied housing units and vacant homes). Of 6,781 census blocks in McLean County, Illinois, 4,254 included an indicator of census block disorder ${ }^{27}$. Important to realize, a negative factor score indicates a lesser amount of disorder, whereas, a positive factor score indicates a greater amount of disorder. The ranges when all of McLean County's census blocks when taken in consideration was -2.12 to 8.16 for social disorganization

\footnotetext{
${ }^{27}$ Missing indicators of census block disorder was largely attributed to the census block being farmland property.
} 
and -1.65 to 7.50 for residential instability. Each home sale corresponded to their respective census block once inserted into ArcGIS, and then they were joined via ArcGIS with their indicators of census block disorder.

ArcGIS

ArcGIS was utilized for the mapping and joining of the data gathered for the current study. Excel spreadsheets produced from the registered sex offender list, housing transactions in McLean County along with their property characteristics, and the 2010 decennial U.S. Census Bureau information that included an indicators of census block disorder for each census block in the county, was imported into ArcGIS. In order to determine which home sale transactions were nearby registered sex offenders and sexual predators, a buffer zone of 0.2 of a mile was created around each sold home via the buffer analysis tool supplied by ArcGIS. An example of the appearance of these buffer zones that were created around sold homes that were nearby registered sex offenders and sexual predators is displayed in Figure 1. This particular distance of a buffer zone was selected because of the previous studies that have also research for household reactions to registered sex offenders at this distance (Larsen et al., 2003; Linden \& Rockoff, 2008; Pope, 2008). To be clear, when the buffer zones of 0.2 of a mile were created through ArcGIS, all registered sex offenders within 0.2 of a mile of a home sale transaction were identified and matched to the home sales they are near to. 
Figure 1. Registered Sex Offenders and Sexual Predators Within 0.2 of a Mile From Home Sales in McLean County, Illinois

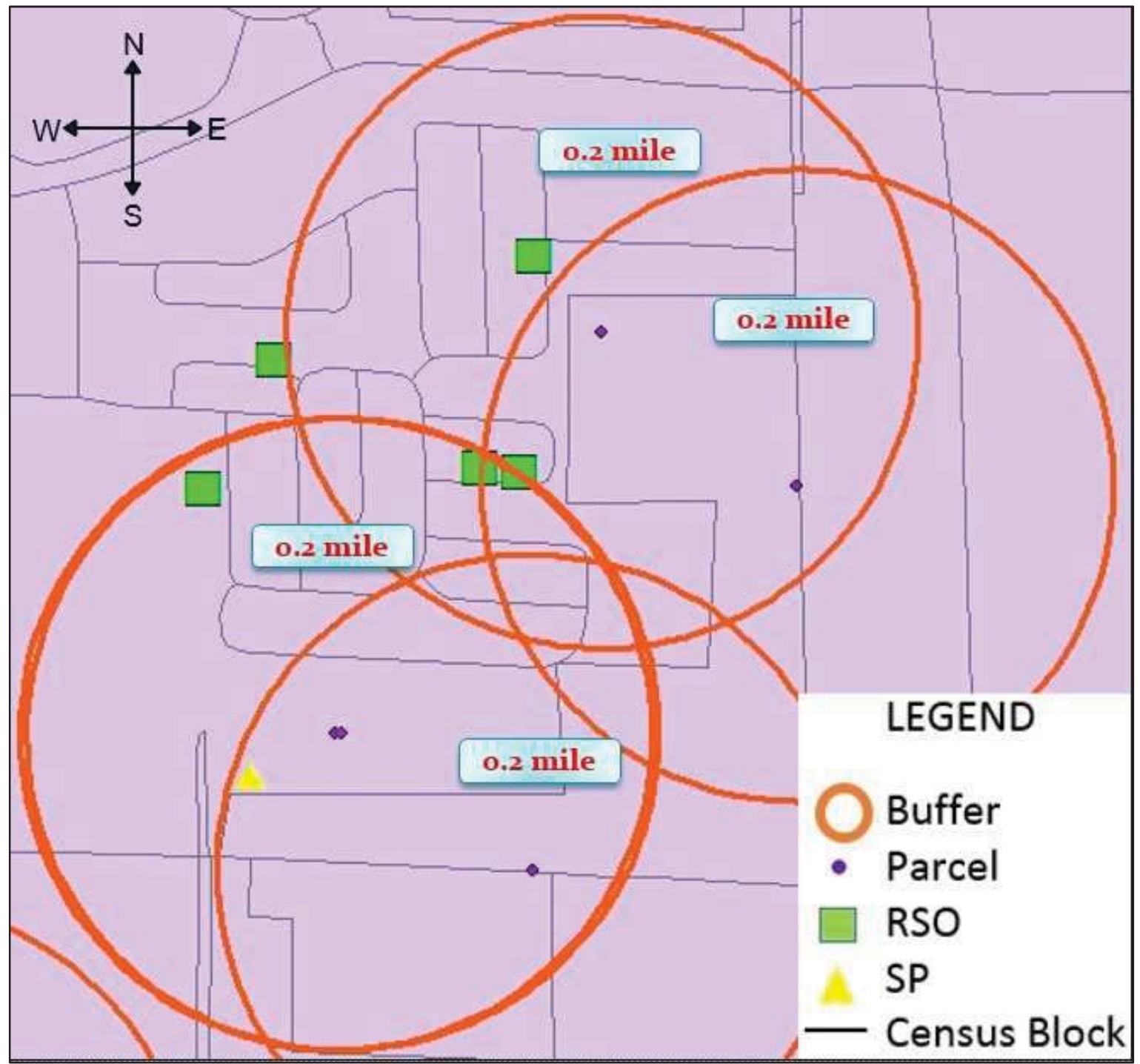

Thus, this procured the number of registered sex offenders and sexual predators within 0.2 of a mile of a sold home in order to answer the present study's concentration research question. $\operatorname{ArcGIS}^{28}$ was then utilized to calculate the distance via point distance analysis from each registered sex offender and sexual predator found within 0.2 of a mile buffer, which was then

\footnotetext{
${ }^{28}$ The data downloaded from the ISP sex offender registry $X$ and $Y$ coordinates did not match with their exact locations when placed into ArcGIS. The editor in ArcGIS was utilized to correct their locations and re-calculated geographically.
} 
converted into feet via field calculator for better understanding of the results when analyzed in SPSS. To fulfill the distance research question in the present study, only the nearest registered sex offender and nearest sexual predator were taken in consideration. The spatial join function was utilized to join the datasets of home sale transaction with property characteristics and the indicators of census block disorder to the concentrations of registered sex offenders and sexual predators, and to the distance to the nearest registered sex offender and nearest sexual predator for analysis.

\section{Measurement Instruments/Variables}

These variables are presented by the registered sex offender list, home sale price information, ArcGIS concentration and distance observations, sold homes' property characteristics, and the 2010 decennial U.S. Census Bureau variables.

\section{Sexual Predators}

Sexually violent registered sex offenders were combined with sexual predators as there were five sexually violent persons in the present study's list of registered sex offenders. Hereafter, sexually violent persons are known in the present study as sexual predators. Additionally, the present study's list of registered sex offenders was coded. Sexual predators were coded as 1 , whereas, registered sex offenders were coded as 0 , in order to distinguish them in ArcGIS. Under the present study's definition of sexual predators, within the registered sex offender list, there are 77 registered sex offenders and 69 sexual predators. 


\section{Dependent Variable}

The home's selling price is the dependent variable of the present study. Table 4exhibited that the average selling price of a sold home $(n=2,547)$ was $\$ 166,323 \cdot 21$. Sold homes from December 2012 - December 2013 ranged from $\$ 10$ to $\$ 595,000^{29}$ with a median price ${ }^{30}$ of $\$ 150,000$ with a median age of 31 years old.

Independent Variables

The independent variables were measured by concentrations of registered sex offenders and sexual predators within 0.2 of a mile to a sold home and the distance to the nearest registered sex offender and nearest sexual predator within 0.2 of a mile. Information for these variables was collected through tools offered in ArcGIS. For the independent variable of concentration, a buffer analysis was conducted then a spatial join to obtain the total number of registered sex offenders and sexual predators within the 0.2 of mile buffer. For the distance independent variable a point distance analysis was performed in order to determine the distance between the nearest registered sex offender and sexual predator to a sold home within the 0.2 of a mile buffer.

Buffer zones of 0.2 of a mile were created with the sold homes' as the epicenter in ArcGIS in order to determine the total number of registered sex offenders that are within this radius, which was subsequently separated into the total number of registered sex offenders and sexual predators. A spatial join was conducted in order to obtain the total count of registered

\footnotetext{
${ }^{29}$ Three homes were removed from the home sale dataset as they were labeled outliers and skewed the data heavily. These three homes sold for $\$ 886,000, \$ 875,000,845,000$.

${ }^{30}$ A frequency analysis was conducted in order to obtain the medians for the variables in the present study and inserted into the descriptive statistics table.
} 
sex offenders and sexual predators within each buffer between the registered sex offender list and home sale dataset. Of the 2,547 home sale transactions, a total of $553(21.7 \%)$ home sale transactions were affected by the presence of at least one registered sex offender. Within the buffer zone of 0.2 of a mile, the number of registered sex offenders nearby a home sale transaction ranged from one to seven. Of these 553 home sale transactions, 350 had at least one registered sex offender, 120 had two registered sex offenders, 50 had three registered sex offenders, 18 had four registered sex offenders, seven had five registered sex offenders, seven had six registered sex offenders, and one home sale transaction maintained seven registered sex offenders. Out of 2,547 home sale transactions, an aggregate of $376(14.8 \%)$ home sale transactions were afflicted by the nearby residence of at least one sexual predator. There were 296, 69 and 11 home sale transactions that were within one, two, and three sexual predators, respectively.

\section{Distance}

A point distance analysis was performed through ArcGIS to determine the distance of between the nearest registered sex offender and the nearest sexual predator from each home sale transaction within 0.2 of a mile. Home sale transactions that did not follow the nearest registered sex offender and nearest sexual predator rule were properly edited to the appropriate nearest registered sex offenders. The distance of miles was then converted to feet through ArcGIS's field calculator for a better interpretation once inserted into SPSS for analysis, which the results can be viewed in Table 4. The mean distance of the nearest registered sex offender within 0.2 of a mile was 617 feet (.117 of a mile), which ranged from 28 feet (or .005 of a mile) to 1,054 feet (or 0.2 of a mile). The mean distance of the nearest sexual predator within 
0.2 of a mile was 649 feet (or .123 of a mile) that ranged from 43 feet (or .008 of a mile) to 1,056 feet (or 0.2 of a mile).

\section{Control Variables}

The age of the home was determined by the subtraction of the calendar year 2013 (when the home sale transaction data was collected) to the built year. As displayed in Table 4, the age range for a sold home $(n=2,547)$ was from 0 years to 214 years. The average age of a home sold in McLean County was 41 years old.

The rate of female-headed households, the rate of vacancy, and the rate of homeownership via renter occupied housing units were standardized by the number of households in McLean County, whereas the rate of children under the age of 19 was standardized by the total population of McLean County. Social disorganization is a factor score of two variables: the percentage of children under the age of 19 and percentage of femaleheaded households (eigenvalue $=1.28$, factor loadings $>.78$ ). Residential instability represented a factor score of two variables: the percentage of renter occupied housing units and the percentage of vacant homes (eigenvalue $=1.15$, factor loadings $>.69$ ).

Of the 6,781 census blocks in McLean County, Illinois, 4,254 census blocks received indicators of census block disorder, of which $2,516^{31}$ home sale transactions received an indicator of their census' block disorder. The range for social disorganization was -1.66 to 3.60 with the mean at .16 , and for residential instability the range was -1.40 and 3.50 with the mean at -.26 . These results are exhibited in Table 4.

\footnotetext{
${ }^{31}$ There were 31 home sale transactions that did not include census block data, mostly due to the home not being in existence at the time the 2010 decennial U.S. Census Bureau was conducted. Within the 0.2 of a mile buffer, two of these 31 home sale transactions that lacked indicators of census block disorder included one registered sex offender each.
} 


\section{Descriptives}

A descriptive and frequency analysis was computed in SPSS on all variables. This included the collection of the registered sex offender list in McLean County, Illinois, home sale transaction data with property characteristics, the 2010 decennial U.S. Census Bureau variables that produced two indicators of disorder per census block via factor analysis, and the concentrations of registered sex offenders and sexual predators, and the distance of the nearest registered sex offender and the nearest sexual predator within 0.2 of a mile of a home sale. The results of the descriptive analysis can be viewed in Table 4. 
Table 4

Descriptive Statistics

\begin{tabular}{|c|c|c|c|c|c|c|}
\hline Variables & $\mathrm{N}$ & Mean & Median & $\begin{array}{c}\text { Std. } \\
\text { Deviation }\end{array}$ & Minimum & Maximum \\
\hline Selling price & 2547 & 166323.21 & 150000.00 & 96457.374 & 10 & 595000 \\
\hline \multicolumn{7}{|l|}{ Concentrations of RSO } \\
\hline within 0.2 of a mile & 2547 & .35 & .00 & .824 & 0 & 7 \\
\hline Concentrations of SP wit & & & & & & \\
\hline 0.2 of a mile & 2547 & .18 & .00 & .479 & 0 & 3 \\
\hline Distance of nearest RSO & & & & & & \\
\hline within 0.2 of a mile (mi) & 553 & .11688 & .11966 & .050306 & .005 & .200 \\
\hline Distance of nearest RSO & & & & & & \\
\hline within 0.2 of a mile $(\mathrm{ft})$ & 553 & 617.105 & 631.784 & 265.6156 & 27.9 & 1054.0 \\
\hline Distance of nearest SP & & & & & & \\
\hline within 0.2 of a mile (mi) & 376 & .12295 & .13246 & .049510 & .008 & .200 \\
\hline Distance of nearest SP & & & & & & \\
\hline within 0.2 of a mile (ft) & 376 & 649.167 & 699.365 & 261.4126 & 43.1 & 1055.5 \\
\hline Age (yrs) & 2547 & 41.03 & 31.00 & 35.445 & 0 & 214 \\
\hline Building square feet & 2547 & 1694.64 & 1575.00 & 769.917 & 0 & 22529 \\
\hline Social disorganization & 2516 & .15809 & 19893 & .575350 & -1.662 & 3.599 \\
\hline Residential instability & 2516 & -.25968 & -.48879 & .707310 & -1.400 & 3.495 \\
\hline
\end{tabular}

In order to answer the present study's research questions, multiple data sets had to be collected about McLean County, Illinois. These data sets included the following: a sex offender list; home sale transactions between December 2012 to December 2013 and property 
characteristics; and the 2010 decennial U.S. Census Bureau variables for each of the U.S.

county's census blocks, which the selected variables were separated into two groups via a factor analysis, social disorganization and residential instability. This information was inserted into a mapping software program, ArcGIS, in order to obtain the concentrations of registered sex offenders and sexual predators within 0.2 of a mile and the distances of the nearest registered sex offender and nearest sexual predator within 0.2 of a mile. Measurement variables in the present study were then appropriately described. Once all the datasets were joined through ArcGIS, they were then analyzed in SPSS, first with a descriptive analysis, and then to their respective research questions by bivariate correlations and multiple regression analyses and the outcomes were reported. 


\section{CHAPTER IV}

\section{RESULTS}

\section{Introduction}

Bivariate correlations and multiple regression analyses were conducted separately to report the outcome of the concentration and distance research questions in the current study, as well as the control variables. First, all of the variables within the concentration research question were analyzed with a bivariate correlation to determine whether or not the variables were significantly correlated. This was followed by a multiple regression analysis that was separated into models to their respective classification, registered sex offender and sexual predator. The multiple regression analysis determined which of the relationships were meaningful and produced the greatest predictor upon home selling price. Second, the same procedures were performed to answer the second research question in the present study. The SPSS outcomes for each of the research questions were constructed into correlation tables and multiple regression tables. A number of significant relationships were reported, followed by a brief interpretation of the results.

\section{Concentration}

This question was directed to the examination of whether or not the concentrations of registered sex offenders and sexual predators influenced home sale value within 0.2 of a mile after controlling for home sale property characteristics and neighborhood conditions. 
Correlation and regression analyses were conducted between the dependent variable, selling price, independent variables, concentrations of registered sex offenders and sexual predators within 0.2 of a mile, and the remaining independent variables, age and building square feet for property characteristics, and social disorganization and residential instability for neighborhood conditions, which were created from a factor analysis.

First, bivariate correlations were conducted to identify the relationships between the selling price and the concentrations of registered sex offenders and sexual predators within 0.2 of a mile, age of house, building square feet, social disorganization and residential instability. The concentrations of registered sex offenders and sexual predators consisted of a single number that ranged from 0 to 7 . Social disorganization and residential instability were produced from a factor analysis of the 2010 decennial U.S. Census Bureau variables, which included female-headed households, children under the age of 19 , renter occupied housing units, and vacant homes. The factor analysis identified two components after a varimax with Kaiser method of factor rotation and regression method was conducted that created factor scores. Female-headed households and children under the age of 19 were labeled as social disorganization and renter occupied housing units and vacant homes became the residential instability variable. The scores produced by the factor analysis for the social disorganization variable ranged from -1.7 to 3.6 where for residential instability it ranged from -1.4 to 3.5 , of which these numbers are displayed from a descriptive analysis at Table 4. A negative number represents a low level of disorder, whereas, a positive number represents a high level of disorder within that census block. Second, an ordinary least squares (OLS) regression was performed between the selling price of the sold home as the dependent variable and the independent variables, concentrations of registered sex offenders and sexual predators within 
0.2 of a mile, and the control variables, age, building square feet, social disorganization, and residential instability. Analysis was performed using SPSS REGRESSION and SPSS FREQUENCIES for evaluation of assumptions. Results of evaluation of assumptions led to transformation of the variables to reduce the number of outliers. These outliers were three home sales that sold at $\$ 800,000$ or more. Missing data included 31 home sales that did not include social disorganization and residential instability values as they were either newly built homes prior to the 2010 decennial U.S. Census Bureau collection time period or for another unknown reason, and three homes did not include building square footage information.

\section{Correlation between Dependent and Independent Variables}

Table 5 illustrates a correlation matrix and the results between the selling price of a sold home, the independent variables, concentrations of registered sex offenders and sexual predators within 0.2 of a mile, and the control variables. There was a significant negative correlation between the concentrations of registered sex offenders and a sold home's selling price, $r(2547),=-.308, p<.001$. This correlation indicated that as the concentrations of registered sex offender's increased the selling price of a sold home decreased. The concentrations of sexual predators and a sold home's selling price also exposed a significant negative correlation, $r(2547),=-.266, \mathrm{p}<.001$. This correlation indicated that as the concentration of sexual predators increased the selling price of the sold home decreased, although not as powerfully as the clusters of registered sex offenders. 
Table 5

Correlations Among Concentrations of Registered Sex Offenders (RSOs) and Sexual Predators (SPs) and Variables

\begin{tabular}{|c|c|c|c|c|c|c|c|}
\hline Variables & 1 & 2 & 3 & 4 & 5 & 6 & 7 \\
\hline 1. Selling price & & & & & & & \\
\hline $\begin{array}{l}\text { 2. Concentrations of RSO } \\
\text { within } 0.2 \text { of a mile }\end{array}$ & $-.308^{* * *}$ & & & & & & \\
\hline $\begin{array}{l}\text { 3. Concentrations of SP } \\
\text { within } 0.2 \text { of a mile }\end{array}$ & $-.266^{* * *}$ & $.792^{* * *}$ & & & & & \\
\hline 4. Age (yrs) & $-.557^{* * *}$ & $.338^{* * *}$ & $.300^{* * *}$ & - & & & \\
\hline 5. Building square feet & $.611^{* * *}$ & $-.205^{* * *}$ & $-.178^{* * *}$ & $-.318^{* * *}$ & & & \\
\hline 6. Social disorganization & $-.064^{* * *}$ & $.133^{* * *}$ & $.086^{* * *}$ & $-.038^{+}$ & -.012 & & \\
\hline 7. Residential instability & $-.346^{* * *}$ & $.330^{* * *}$ & $.280^{* * *}$ & $.402^{* * *}$ & $-.248^{* * *}$ & $-.123^{* * *}$ & \\
\hline
\end{tabular}

Notes. $+p<.10, * * * p<.001$

Correlation of the Dependent Variable and Independent Variables between the Control Variables

An examination of the correlation between a sold home's selling price and property characteristics conveyed strong negative relationships. There was a significant negative correlation between the age of house and home sale price, $r(2547)=-.557, p<.001$. Meaning, the older a sold home the lower the selling price. Additionally, there was a significant positive correlation between the building square feet and selling price, $r(2547)=.611, p<.001$. Building square feet of a sold home produced the strongest correlation out of the other variables within this correlation matrix, which is an indication that the variable building square feet may have had a strong influence on a sold home's selling price compared to the other variables in the present study.

The indicators of census block disorder exposed a negative relationship upon a sold home's selling price. There was a significant negative correlation between social disorganization 
and selling price, $r(2516)=-.064, p<.001$. This correlation indicated that a sold home's selling price may be influenced by the variables of social disorganization, female-headed households and children under the age of 19. A significant negative correlation was also produced between residential instability and a sold home's selling price, $r(2516)=-.346, p<.001$. In other words, variables within residential instability may have influenced a sold home's selling price. As a whole, indicators of census block disorder produced the strongest relationships to selling price.

In regards to the correlation results between the concentrations of registered sex offenders and sexual predators within 0.2 of a mile and census block disorder - social disorganization and residential instability - both exhibited a positive relationship. There was a significant positive correlation between the concentrations of registered sex offenders within 0.2 of a mile and social disorganization, $r(2516)=.133, p<.001$. Furthermore, there was a significant positive correlation between the concentrations sexual predators within 0.2 of a mile and social disorganization, $\mathrm{r}(2516)=.086, \mathrm{p}<.001$. These correlations indicated that areas with high percentages of children below the age of 19 and female-headed households are likely to have contained higher concentrations of registered sex offenders and sexual predators. There was a significant positive correlation between the concentrations of registered sex offenders within 0.2 of a mile and residential instability, $r(2516)=.330, p<.001$. Additionally, there was a significant positive correlation between the concentrations of sexual predators within 0.2 of a mile and residential instability, $r(2516)=.280, p<.001$. These correlations indicate that areas with renter occupied housing units and vacant homes are also likely to contain higher concentrations of registered sex offenders and sexual predators. 


\section{Regression between Dependent and Independent Variables}

Granted the bivariate correlation produced a multitude of significant correlations between the variables within the correlation question, the present study further investigated these correlations with an OLS regression analysis. Additionally, a multiple regression is an appropriate analysis to predict whether or not the model is meaningful and which variables are most meaningful to the model. A multiple regression analysis was conducted to test if the concentrations of registered sex offenders within 0.2 of a mile (Model 1 ) and the concentrations of sexual predators within 0.2 of a mile (Model 2) predicted home sale prices, after controlling for home and community characteristics.

As shown in Table 6, the concentrations of registered sex offenders within 0.2 of a mile (Model 1) significantly predicted home selling price $(b=-.057, \mathrm{p}<.001)$. Several of the control variables also predicted home selling price, including: home sale age $(b=-.368, \mathrm{p}<.001)$, building square feet $(b=.463, \mathrm{p}<.001)$, social disorganization $(b=-.074, \mathrm{p}<.001)$, and residential instability $(b=-.074, \mathrm{p}<.001)$. The overall model fit was $\mathrm{R}^{2}=.54, \mathrm{~F}(5,2510)=581.17$, $p<.001$, hence, Model 1 explained 54\% of a sold home's selling price if the home's property characteristics and the neighborhood conditions are known. The predictive regression equation developed by the unstandardized coefficients is $Y=111,219+(-6585.92)$ (Conc. RSO $)+(-$ 998.52)(Age) + (57.83)(Building Sq. Ft.) + (-12370.62)(Soc. Disorg.) + (-10035.98)(Res. Instab.). With the use of the unstandardized coefficients, for each unit of a registered sex offender within 0.2 of a mile, there is a predicted loss of $\$ 6,586$ upon the home selling price. The concentrations of registered sex offenders within 0.2 of a mile produced the lowest beta in Model 1 , thus, this variable may not be as influential upon selling price compared to the control variables in the model. 
In regards to Model 2, the concentrations of sexual predators within 0.2 of a mile significantly predicted home selling price $(b=-.046, p<.01)$. A number of the control variables also predicted home selling price, including: home sale age $(b=-.372, \mathrm{p}<.001)$, building square feet $(b=.464, \mathrm{p}<.001)$, social disorganization $(b=-.078, \mathrm{p}<.001)$, and residential instability $(b=$ $-.079, \mathrm{p}<.001)$. All the variables within Model 2 were significant predicators. The overall model fit was $R^{2}=.54, F(5,2510)=579.29, p<.001$, thus, Model 2 explained $54 \%$ of a sold home's selling price if the home's age and building square feet and the neighborhoods conditions are known. The predictive regression equation developed by the unstandardized coefficients is $Y=$ 110,644 + (-9098.09)(Conc. SP) + (-1007.60)(Age) + (57.97)(Building Sq. Ft.) + (-13095.98)(Soc. Disorg. $)+(-10695.22)($ Res. Instab). The concentration effect produced by the presence of a sexual predator can be interpreted as each sold home experienced a $\$ 9,098$ loss in property value, and each additional sexual predator within 0.2 of a mile another $\$ 9,098$ will be deducted from the sold home's selling price. To point out, this is a much higher financial loss compared to the monetary effect upon a home sale produced by the concentrations of registered sex offenders. Again, like the concentrations of registered sex offenders, the concentrations of sexual predators within 0.2 of a mile produced the weakest beta. In other words, it may not be as influential as the control variables upon home selling price.

A further investigation was conducted in order to isolate the predicted financial influence concentrations of registered sex offenders and sexual predators produced onto a sold home's selling price. The averages of the present study's variables, home sale age, building square feet, social disorganization, and residential instability were inserted into the regression equation. These means are displayed in Table 4. The following equation determined the predicted average of a sold home's selling price in McLean County, Illinois is impacted by the concentrations of registered sex offenders within 0.2 of a mile: $Y=111,219+(-6585.92)$ (Conc. 
RSO $)+(-40939.32$ [Age] $)+(98001.03$ [Building Sq. Ft.]) + (-1955.67 [Soc. Disorg.] $)+(2606.14$

[Res. Instab.]). As for the regression equation created to determine the predicted home selling price nearby concentrations of sexual predators within 0.2 of a mile, $Y=110,644+(-$

9098.09)(Conc. SP) + (-41341.83 [Age]) + (98238.28 [Building Sq. Ft.]) + (-2070.34 [Soc. Disorg.])

$+(2777.33$ [Res. Instab.]). The outcome of the equation and the average selling price of the

sample of sold homes narrowed down the predicted financial influence by the concentrations of registered sex offenders and sexual predators. The predicted financial outcomes are given for the range of registered sex offenders and sexual predators found within 0.2 of a mile, which ranged from zero to seven for registered sex offenders and zero to three for sexual predators. These predicted financial outcomes are displayed in Table 7. To illustrate Table 7, if there are no registered sex offenders or sexual predators present within 0.2 of a mile the selling price of a sold home is $\$ 166,323.21$, on average. If there is one registered sex offender present, a sold home on average sold for $\$ 162,345$ and the presence of the registered sex offender produced a $\$ 3,978$ financial loss. On the other hand, the presence of one sexual predator produced a greater financial loss where the sold home's selling price was $\$ 159,149$ and their residence created a $\$ 7,174$ reduction in selling price. 
Table 6

Concentrations of Registered Sex Offenders (RSOs) and Sexual Predators (SPs) Within 0.2 of a Mile Predicting Sold Homes' Selling Prices

\begin{tabular}{|c|c|c|c|c|c|c|}
\hline \multicolumn{7}{|c|}{$\mathrm{N}=2,515$} \\
\hline \multirow[b]{2}{*}{ Variable } & \multicolumn{3}{|c|}{ Model 1} & \multicolumn{3}{|c|}{ Model 2} \\
\hline & $\mathrm{b}$ & S.E. & $\beta$ & $\mathrm{b}$ & S.E. & $\beta$ \\
\hline Conc. RSO & $-6585.92^{* * *}$ & 1754.35 & -.057 & ------------ & ------------ & ------ \\
\hline Conc. SP & ---------------. & ---------- & ------ & $-9098.09^{* *}$ & 2917.51 & -.046 \\
\hline Age & $-998.52^{* * *}$ & 42.47 & -.368 & $-1007.60^{* * *}$ & 42.29 & -.372 \\
\hline Building Sq. Ft. & $57.83^{* * *}$ & 1.81 & .463 & $57.97^{* * *}$ & 1.81 & .464 \\
\hline Soc. Disorg. & $-12370.62^{* * *}$ & 2328.75 & -.074 & $-13095.98^{* * *}$ & 2308.29 & -.078 \\
\hline Res. Instab. & $-10035.98^{* * *}$ & 2111.31 & -.074 & $-10695.22^{* * *}$ & 2089.80 & -.079 \\
\hline Constant & $111219.06^{* * *}$ & 4177.99 & & $110643.80^{* * *}$ & 4172.57 & \\
\hline & & & $.54^{* * *}$ & & & $.54^{* * *}$ \\
\hline Adjusted $\mathrm{R}^{2}$ & & & $.54^{* * *}$ & & & $.54^{* * *}$ \\
\hline$F$ & & & $581.17^{* * *}$ & & & ${ }_{* * *}^{579.29}$ \\
\hline df & & & 5 & & & 5 \\
\hline
\end{tabular}


Table 7

Calculated Isolated Financial Effect Onto Selling Price Produced by the Concentrations of Registered Sex Offenders (RSOs) and Sexual Predators (SPS) Within 0.2 of a Mile

\begin{tabular}{|lllll|}
\hline $\begin{array}{l}\text { \# of } \\
\text { RSOs }\end{array}$ & $\begin{array}{l}\text { Conc. of RSOs } \\
\text { Predicted Financial } \\
\text { Outcome }\end{array}$ & $\begin{array}{l}\text { Isolated Financial } \\
\text { Impact of } \\
\text { Concentrations of } \\
\text { RSO }\end{array}$ & $\begin{array}{l}\text { Conc. of SPs } \\
\text { Predicted } \\
\text { Financial } \\
\text { Outcome }\end{array}$ & $\begin{array}{l}\text { Isolated Financial } \\
\text { Impact of } \\
\text { Concentrations of } \\
\text { SP }\end{array}$ \\
\hline 0 & $\$ 166,323.21$ & $\$ 0$ & $\$ 166,323.21$ & $\$ 0$ \\
1 & $\$ 162,345.26$ & $-\$ 3,977.95$ & $\$ 159,149.35$ & $-\$ 7,173.86$ \\
2 & $\$ 149,173.42$ & $-\$ 10,563.87$ & $\$ 150,051.26$ & $-\$ 16,271.95$ \\
3 & $\$ 142,587.50$ & $-\$ 17,149.79$ & $\$ 140,953.17$ & $-\$ 25,370.04$ \\
4 & $\$ 142,587.50$ & $-\$ 23,735.71$ & $\$ 131,855.08$ & $-\$ 34,468.13$ \\
5 & $\$ 136,001.58$ & $-\$ 30,321.63$ & $\$ 122,756.99$ & $-\$ 43,566.22$ \\
6 & $\$ 129,415.66$ & $-\$ 36,907.55$ & $\$ 113,658.90$ & $-\$ 52,664.31$ \\
7 & $\$ 122,829.74$ & $-\$ 43,493.47$ & $\$ 104,560.81$ & $-\$ 61,762.40$ \\
\hline
\end{tabular}

Distance

This question was directed to the examination of whether or not the distance of the nearest registered sex offender and the nearest sexual predator influenced home sale value within 0.2 of a mile after controlling for home sale property characteristics and neighborhood conditions. A correlation and regression analyses were conducted between the dependent variable, selling price, independent variables, distance of the nearest registered sex offender and sexual predator within 0.2 of a mile, and the remaining independent variables, age and building square feet for property characteristics, and social disorganization and residential instability for neighborhood conditions, which were created from a factor analysis. 
First, bivariate correlations were conducted to identify the relationships between the selling price and the distance of the nearest registered sex offender and nearest sexual predator within 0.2 of a mile, age of house, building square feet, social disorganization and residential instability. Table 4 exhibits the range from the nearest registered sex offender within 0.2 of a mile, .005 of a mile (or 28 feet) to 0.2 of a mile (or 1,054 feet) and the nearest sexual predator within 0.2 of a mile, .008 of a mile (or 43 feet) to 0.2 of a mile (or .008 of a mile). Second, an OLS regression was performed between the home sale price as the dependent variable and the independent variables, distance of the nearest registered sex offender and nearest sexual predator within 0.2 of a mile, and the control variables, age, building square feet, social disorganization, and residential instability for home sale property characteristics and neighborhood conditions. Analysis was performed using SPSS REGRESSION and SPSS FREQUENCIES for evaluation of assumptions. Results of evaluation of assumptions led to transformation of the variables to reduce the number of outliers. These outliers were three home sales that sold at $\$ 800,000$ or more. Missing data included 31 home sales that did not include social disorganization and residential instability values as they were either newly built homes prior to the 2010 decennial U.S. Census Bureau collection time period or for another unknown reason, and three homes did not include building square footage information, $\mathrm{N}=$ 2,515. Additionally, the distances supplied by ArcGIS were converted to feet via a field calculator supplied within the mapping software program from miles to better comprehend the OLS regression results.

Correlation between Dependent and Independent Variables

Table 8 illustrates a correlation matrix and the results between the selling price of the sold homes, the independent variables, distance of the nearest registered sex offender and 
nearest sexual predator within 0.2 of a mile (or 1,056 feet), and the control variables. There was a significant positive correlation between the distance of the nearest registered sex offender within 0.2 of a mile and a sold home's selling price, $r(553),=.150, p<.001$. This correlation indicated that as the distance between the nearest registered sex offender within 0.2 of a mile increased the selling price of a sold home increased as well. Notably, there was a near significant positive correlation between the distance of the nearest sexual predator and a sold home's selling price, $r(376),=.090, p<.10$. To relate to the concentrations of registered sex offenders and sexual predators within 0.2 of a mile, the correlations for the distance research question produced weaker correlations.

Table 8

Correlations Among Distance of the Nearest Registered Sex Offender (RSO) and Nearest Sexual Predator (SP) and Variables

\begin{tabular}{llllllll}
\hline Variables & 1 & 2 & 3 & 4 & 5 & 6 & 7 \\
\hline 1. Selling price & - & & & & & \\
2. Distance of the nearest RSO & $.150^{* * *}$ & - & & & & \\
$\quad \begin{array}{l}\text { within 0.2 of a mile } \\
\text { 3istance of the nearest SP }\end{array}$ & $.090^{+}$ & $.842^{* * *}$ & - & & & \\
$\quad$ within 0.2 of a mile & $-.557^{* * *}$ & $-.112^{*}$ & -.032 & - & & \\
4. Age (yrs) & $.611^{* * *}$ & .015 & -.021 & $-.318^{* * *}$ & - & \\
5. Building square feet & $-.064^{* * *}$ & $-.090^{*}$ & .026 & $-.038^{+}$ & -.012 & - \\
6. Social disorganization & $-.346^{* * *}$ & $-.148^{* * *}$ & -.080 & $.402^{* * *}$ & $-.248^{* * *}$ & $-.123^{* * *}$ \\
7. Residential instability & & & & &
\end{tabular}
Notes. $+p<.10,{ }^{*} p<.05, * * * p<.001$ 
Correlation of the Dependent Variable and Independent Variables between the Control Variables

The correlation analysis of distance of the nearest registered sex offender and sexual predator within 0.2 of a mile produced strong relationships between selling price and property characteristics. There was a significant negative correlation between age of house and selling price, $r(2547)=.-557, p<.001$ and a significant positive correlation between the building square feet and selling price, $r(2547)=.611, p<.001$. The interpretation of these findings indicated that as the age of a sold home increased the selling price decreased, whereas, as the building square feet increased so does the selling price of a sold home.

Indicators of census block disorder produced negative relationships upon sold homes' selling price. A significant negative correlation existed between social disorganization and selling price, $r(2516)=-.064, p<.001$. This finding indicated that a sold home's selling price may be influenced in a decrease in sale price by the variables of social disorganization, female-headed households and children under the age of 19. Similarly, a significant negative correlation occurred between residential instability and a sold home's selling price, $r(2516)=-.346, p<.001$. That is to say, a sold home's selling price may be influenced in a reduction in sale price by variables within residential instability, which included renter occupied housing units and vacant homes.

An examination of the correlation results between the distance of the nearest registered sex offender and sexual predator within 0.2 of a mile and census block disorder social disorganization and residential instability - produced mostly negative relationships. There was a significant negative correlation between the distance of the nearest registered sex offender within 0.2 of a mile and social disorganization, $r(551),=-.090, p<.05$. This correlation indicated that as the distance decreased between the sold home and the nearest registered sex 
offender the greater likelihood the sold home was located in an area with high rates of femaleheaded households and children under the age of 19. There was a significant negative correlation between the distance of the nearest registered sex offender and residential instability, $r(551)=-.148, p<.001$. This relationship indicated that as the distance between a sold home and the nearest registered sex offender it increases the probability that the sold home is nearby renter occupied housing units and vacant homes. Notably, a significant correlation did not exist between the distance of the nearest sexual predator and social disorganization, $r(376)=.026$, and residential instability, $r(376)=-.080$.

\section{Regression between Dependent and Independent Variables}

The bivariate correlation produced some significant correlations between the variables within the distance question, the current study conducted an additional analysis, an OLS regression. Such reasons for the OLS regression analysis is that 1) it can predict whether or not the model is meaningful, and 2) which variables within the model are most meaningful. A multiple regression analysis was piloted to test if the distance of the nearest registered sex offender within 0.2 of a mile (Model 3 ) and the distance of the nearest sexual predator within 0.2 of a mile (Model 4) predicted home sale prices, after controlling for home and community characteristics.

In Table 9, the distance of the nearest registered sex offender within 0.2 of a mile (Model 3) significantly predicted home selling price $(b=.072, \mathrm{p}<.01)$. Several of the control variables also predicted home selling price, including: home sale age $(b=-.335, \mathrm{p}<.001)$, building square feet $(b=.534, \mathrm{p}<.001)$, social disorganization $(b=-.082, \mathrm{p}<.01)$, and residential instability $(b=-$ $.182, p<.001)$. The overall model fit was $R^{2}=.64, F(5,545)=194.21, p<.001$, thus, Model 1 
explained $64 \%$ of a sold home's selling price if the home's property characteristics and neighborhood conditions are known. The predictive regression equation developed by the unstandardized coefficients is $Y=54,035+(18.92)$ (Dist. RSO) $+(-724.63)$ (Age) + (69.41)(Building Sq. Ft. $)+(-9598.30)($ Soc. Disorg. $)+(-16126.58)($ Res. Instab.). Using the unstandardized coefficient, the distance of the nearest registered sex offender can be interpreted to mean that for every additional foot away the sold home is from the residence of a registered sex offender there is an $\$ 18.92$ increase in home selling price. This independent variable produced the lowest beta in the model, therefore, may not be as influential upon selling price as the control variables were within the model.

In regards to Model 4, the distance of the nearest sexual predator within 0.2 of a mile significantly predicted home selling price $(b=.076, p<.05)$. A number of the control variables also predicted home selling price including: home sale age $(b=-.328, \mathrm{p}<.001)$, building square feet $(b=.531, \mathrm{p}<.001)$, social disorganization $(b=-.087, \mathrm{p}<.01)$, and residential instability $(b=-$ $.215, p<.001)$. All of the variables within the model were significant predicators. The overall model fit was $R^{2}=.63, F(5,370)=124.37, p<.001$, therefore, Model 4 explained $63 \%$ of a sold home's selling price, if a sold home's property characteristics and neighborhood conditions are known. The predictive regression equation developed by the unstandardized coefficients is $Y=$ $55,225+(18.53)($ Dist. SP) + (-671.34)(Age) + (65.01)(Building Sq. Ft.) + (-9749.06)(So. Disorg.) + (16427.24)(Res. Instab.). Using the unstandardized coefficient, the distance from a sexual predator can be interpreted to mean that for each additional foot away the sold home's from a sexual predator there is an $\$ 18.53$ increase in home selling price. To note, this is a slightly lower drop in selling price compared to the distance of the nearest registered sex offender unstandardized coefficient, which is an indication that the presence of a sexual predator can 
produce a slight, but greater financial influence upon a sold home's selling price. Similarly to the beta produced from the distance of the nearest registered sex offender (Model 3), the distance of the nearest sexual predator produced the lowest beta in the model, which is an indication that the variable distance of the nearest sexual predator within 0.2 of a mile may not be as influential as the other variables upon home selling price.

Similarly to the concentration question, an additional investigation was conducted in order to isolate the predicted financial influence of the nearest registered sex offenders and sexual predators produced onto a sold home's selling price. The averages of the present study's variables, age, building square feet, social disorganization, and residential instability were inserted into the regression equation. These means are collected from the sample of sold homes that were afflicted by the nearest registered sex offender and sexual predator. As a reminder, both groups afflicted a different number of sold homes; therefore the appropriate means of each variable for both groups were inserted into the equation. The regression equation created is used to ultimately isolate the predicted financial influence of the distance of the nearest of registered sex offender within 0.2 of a mile became, $Y=54,035+(18.92)$ (Dist. RSO) $+(-45144.45$ [Age] $)+(94675.24$ [Building Sq. Ft.]) + (-281.13 [Soc. Disorg.]) + (-20642.02 [Res. Instab.]). The regression equation created to determine the predicted home selling price and the nearest sexual predators within 0.2 of a mile became, $Y=55,225+(18.53)($ Dist. SP $)+(-43194.02$ [Age] $)+$ (87438.45 [Building Sq. Ft.]) + (-285.55 [So. Disorg.]) + (-21026.87 [Res. Instab.]). The predicted financial outcomes are given in increments of 50 feet up to 500 feet, the residency restriction for child registered sex offenders and the loitering restriction for sexual predators for the state of Illinois. These predicted financial outcomes are displayed in Table 10. To describe the results, a sold home 50 feet from a registered sex offender is predicted to sell for $\$ 83,589$, on average, compared to the $\$ 79,084$, on average, predicted by a sexual predator. Additionally, on average, 
when the impact produced by the registered sex offender was isolated a \$946 monetary gain was experienced for every 50 feet the sold home is away from a registered sex offender compared to the lower $\$ 927$ gain in selling price of a sold home by the nearest sexual predator.

Table 9

Distance of the Nearest Registered Sex Offender (RSO) and Nearest Sexual Predator (SP) Within 0.2 of a Mile Predicting Sold Homes' Selling Prices

\begin{tabular}{|c|c|c|c|c|c|c|}
\hline \multirow[b]{3}{*}{ Variable } & \multicolumn{2}{|l|}{$N=550$} & \multicolumn{4}{|c|}{$N=375$} \\
\hline & \multicolumn{3}{|c|}{ Model 3} & \multicolumn{3}{|c|}{ Model 4} \\
\hline & $b$ & S.E. & $\beta$ & $b$ & S.E. & $\beta$ \\
\hline $\begin{array}{l}\text { Dist. RSO } \\
(\mathrm{ft})\end{array}$ & $18.92 * *$ & 6.815 & .072 & ------------- & ----------- & ------------ \\
\hline Dist. SP (ft) & --------------------- & ------------ & ------------ & $18.53^{*}$ & 7.76 & .076 \\
\hline Age & $-724.63 * * *$ & 64.04 & -.335 & $-671.34 * * *$ & 73.90 & -.328 \\
\hline $\begin{array}{l}\text { Building Sq. } \\
\text { Ft. }\end{array}$ & $69.41^{* * *}$ & 3.45 & .534 & $65.01 * * *$ & 3.99 & .531 \\
\hline Soc. Disorg. & $-9598.30 * *$ & 3018.60 & -.082 & $-9749.06 * *$ & 3556.02 & -.087 \\
\hline Res. Instab. & $-16126.58 * * *$ & 2626.82 & -.182 & $-16427.24 * * *$ & 2777.00 & -.215 \\
\hline Constant & $54035.17 * * *$ & 4177.99 & & $55225.36 * * *$ & 9410.43 & \\
\hline & & & $.64 * * *$ & & & $.63 * * *$ \\
\hline Adjusted $\mathrm{R}^{2}$ & & & $.64^{* * *}$ & & & $.62 * * *$ \\
\hline $\mathrm{F}$ & & & $194.21 * * *$ & & & $124.37 * * *$ \\
\hline$d f$ & & & 5 & & & 5 \\
\hline
\end{tabular}


Table 10

Calculated Isolated Financial Effect Onto Selling Price Produced by the Nearest Registered Sex Offender (RSO) and Nearest Sexual Predator (SP) Within 0.2 of a Mile

\begin{tabular}{|c|c|c|c|c|}
\hline Distance & $\begin{array}{l}\text { RSO Predicted } \\
\text { Financial Outcome }\end{array}$ & $\begin{array}{l}\text { Isolated Financial } \\
\text { Impact of } \\
\text { Nearest RSO }\end{array}$ & $\begin{array}{l}\text { SP Predicted } \\
\text { Financial } \\
\text { Outcome }\end{array}$ & $\begin{array}{l}\text { Isolated Financial } \\
\text { Impact of Nearest } \\
\text { SP }\end{array}$ \\
\hline 0 feet & $\$ 82,642.64$ & $+\$ 0$ & $\$ 78,157.01$ & $+\$ 0$ \\
\hline 50 feet & $\$ 83,558.64$ & $+\$ 946$ & $\$ 79,083.51$ & $+\$ 926.5$ \\
\hline 100 feet & $\$ 84,534.64$ & $+\$ 1,892$ & $\$ 80,010.01$ & $+\$ 1,853$ \\
\hline 150 feet & $\$ 85,480.64$ & $+\$ 2,838$ & $\$ 80,936.51$ & $+\$ 2,779.5$ \\
\hline 200 feet & $\$ 86,426.64$ & $+\$ 3,784$ & $\$ 81,863.01$ & $+\$ 3,706$ \\
\hline 250 feet & $\$ 87,372.64$ & $+\$ 4,730$ & $\$ 82,789.51$ & $+\$ 4,632.5$ \\
\hline 300 feet & $\$ 88,318.64$ & $+\$ 5,676$ & $\$ 83,716.01$ & $+\$ 5,559$ \\
\hline 350 feet & $\$ 89,264.64$ & $+\$ 6,622$ & $\$ 84,642.51$ & $+\$ 6,485.5$ \\
\hline 400 feet & $\$ 90,210.64$ & $+\$ 7,568$ & $\$ 85,569.01$ & $+\$ 7,412$ \\
\hline 450 feet & $\$ 91,156.64$ & $+\$ 8,514$ & $\$ 86,495.51$ & $+\$ 8,338.5$ \\
\hline 500 feet & $\$ 92,102.64$ & $+\$ 9,460$ & $\$ 87,422.01$ & $+\$ 9,265$ \\
\hline
\end{tabular}

The bivariate correlations and multiple regression analyses determined that the concentrations of registered sex offenders and sexual predators and the distance to the nearest registered sex offender and sexual predators within 0.2 of a mile were related and predicted home sale selling price. A more thorough interpretation of the results is discussed in the subsequent section and related with previous studies that have examined the financial phenomenon produced by the nearby presence of a registered sex offender onto home selling price. Moreover, several limitations are noted together with recommendations for future research and the implications of the findings from the present study. 
CHAPTER V

DISCUSSION

Introduction

Sex offender legislation has produced unforeseen repercussions upon communities and registered sex offenders, which have created multiple controversies in the validity of the stated purposes behind these laws (Levenson \& Cotter, 2005; Tewksbury, 2002; Tewksbury \& Higgins, 2005). Registered sex offenders are forced into unfavorable neighborhoods by law (Suresh et al., 2010; Tewksbury \& Mustaine, 2006) and have potentially produced a cycle, in which community members have decided to move out due to the nearby presence of a registered sex offender (Zevitz, 2003, 2004) with some that stated a concern of a depreciation in their property value (Zevitz, 2004). The residence of one registered sex offender has exhibited the potential to destabilize a neighborhood (Zevitz, 2003). This sequence mirrors the broken windows theory, in which sex offender legislation relegated registered sex offenders to reside in socially disorganized areas that have promoted citizens to withdraw from the community, thereby created a perception that the area is unfavorable, which has been exhibited in the reactions in home sale prices (Bian et al., 2013; Larsen et al., 2003; Linden \& Rockoff, 2008; Pope, 2008; Wentland et al., 2013).

A number of studies have investigated and exhibited how the presence of registered sex offenders have created household reactions via selling price in various U.S. states (Bian et al., 2013; Larsen et al., 2003; Linden \& Rockoff, 2008; Pope, 2008; Wentland et al., 2013). Clusters 
of registered sex offenders have produced an additional monetary impact onto selling price (Bian et al., 2013; Wentland et al., 2013). In particular, Bian et al. (2013) established that clusters of four or more registered sex offenders produced the greatest financial impact upon the selling price of homes, whereas Larsen et al. (2003), Linden and Rockoff (2008), Pope (2008), and Wentland et al. (2013) discovered that the further a sold home is from a registered sex offender's residence the lesser the financial impact on its selling price. Additionally, when registered sex offenders moved out, selling prices rebounded, which strengthened the causal link between registered sex offenders and home sale prices (Pope, 2008; Wentland et al., 2013). Moreover, an examination of a subset of registered sex offenders, sexual predators, which were labeled as limited disclosure in Larsen's et al. (2013) and violent registered sex offenders (Wentland et al., 2013), who are deemed more dangerous, produced a greater financial impact upon home sale prices than offenders without that classification.

The purpose of this quantitative study was to confirm and extend the research on the financial phenomenon produced by the nearby presence of registered sex offenders onto home selling price. The present study sought to investigate whether or not the concentration and distance of a registered sex offender within 0.2 of a mile after controlling for disorder and property characteristics affected home sale values in McLean County, Illinois. Previous research has not investigated in a community that is largely rural, in the state of Illinois that has enforced different residency restrictions, and the concentrations of registered sex offenders considered more dangerous; therefore, the intent of this study was to fill in multiple gaps not addressed by similar research studies and offer future study in this area. 


\section{Discussion}

In the following section, the major findings are related to previous studies that have examined the financial repercussions produced by the nearby presence of registered sex offenders onto a sold home, which are organized in the order the current study's research questions were presented. Next, a discussion of the broken windows theory and its fit for the current study will follow. Finally, implications and limitations are identified with recommendations for future research.

\section{Concentrations of Registered Sex Offenders Within 0.2 of a Mile}

Previous research determined that concentrations of registered sex offenders inflicted an influence upon the selling price of a sold home in (Bian et al., 2013; Wentland et al., 2013). Although the proposed focus behind Wentland's et al. (2013) study was to investigate whether distance from a registered sex offender played a role onto the observed home's selling price rather than concentration, the researchers discovered that for each additional registered sex offender within a mile of the observed home there was a $\$ 695$ financial loss onto the selling price. Whereas the purpose behind Bian's et al. (2013) study, which is an extension of Wentland's et al. (2013) research, was to investigate how many registered sex offenders was needed to represent the tipping point of a neighborhood's financial equilibrium. Their findings indicated that a concentration of four or more registered sex offenders within less than or equal to a quarter mile produced the greatest financial reduction upon a home's selling price. Also producing a significant result was the presence of one registered sex offender, but the nearby residence of two and three registered sex offenders did not produce a significant result. These results provide credence to the current study's findings found in McLean County, Illinois of the financial phenomenon produced by the concentrations of registered sex offenders within 0.2 of 
a mile, especially when taken in consideration that both researchers investigated central Virginia, which was described as maintaining suburban and rural surroundings.

In the current study, the selling price of a sold home in McLean County, Illinois was affected by concentrations of registered sex offenders within 0.2 of a mile. A significant negative relationship existed between the concentrations of registered sex offenders and the sale price of a sold home. For every additional registered sex offender within 0.2 of a mile the home selling price was predicted to reduce by nearly $\$ 6,586$. The financial impact of concentrations of registered sex offenders was isolated in order to determine the predicted sole financial impact of such concentrations onto any home in McLean County. The averages of the present study's variables were inserted into the equation except for the offender's information, in order to determine the sole effect produced by the offender. It was determined the presence of one registered sex offender within 0.2 of a mile of any home would reduce the selling price by $\$ 3,978$, on average. A buffer zone that maintained two registered sex offenders was predicted to reduce the selling price by $\$ 10,564$, on average.

\section{Concentrations of Sexual Predators Within 0.2 of a Mile}

No one study has yet to have examined the financial influence of a concentrated effect of a more dangerous group of registered sex offenders onto home sale price. Although Bian et al. (2013) did not directly examine a certain subset of registered sex offenders and how clusters of such group may afflict home sale price; Bian et al. (2013) coded homes that maintained three or more bedrooms as family homes. Their assumption was that family homes would experience a greater depreciation in selling price because: 1) these households have children and 2) families with children are more so aware of nearby registered sex offenders. A significant finding was revealed within the concentrations of four or more registered sex offenders within a quarter 
mile of a family home where a greater financial loss was experienced compared to non-family homes. It is apparent in their findings, that families with children are more likely to be aware of nearby registered sex offenders due to the greater reduction in selling price, possibly due to the unwillingness to reside near such predators with children.

Results produced by the present study predicted concentrations of sexual predators created a greater reduction in selling price of a sold home than concentrations of registered sex offenders. A significant negative relationship existed between concentrations of sexual predators within 0.2 of a mile and home selling price. For every additional sexual predator within 0.2 of a mile, home sale price decreased by approximately $\$ 9,098$, a greater financial loss compared to registered sex offenders. The financial impact of concentrations of sexual predators was isolated in order to determine the predicted sole financial impact of such concentrations onto any home in McLean County. It was determined the presence of one sexual predator within 0.2 of a mile of any home would reduce the selling price by $\$ 7,174$, on average. A buffer zone that maintained two sexual predators was predicted to reduce the selling price by $\$ 16,272$, on average.

Under the Illinois definition of sexual predators, a subset of registered sex offenders, are deemed more dangerous due to their possible subsequent convictions/attempts, convicted of/attempted heinous crimes, subjected to a 500 foot loitering restriction, and a lifetime registration. As a result of these strict requirements a sexual predator must submit to it conveys a message of dangerousness. Perhaps the image that is conjured by the term sexual predator is one that possibly divulges greater fear than a registered sex offender, which as a result, impacted selling prices at a greater level than a registered sex offender. 


\section{Distance to the Nearest Registered Sex Offender Within 0.2 of a Mile}

Literature has determined the closer a registered sex offender is to a home being sold or has sold the greater the financial repercussion (Larsen et al., 2003; Linden \& Rockoff, 2008; Pope, 2008; Wentland et al., 2013). Four research studies examined a concentric zone of 0.1 of a mile with the home as the epicenter and yielded a financial loss as a result of the presence of a registered sex offender. Two studies examined between 0.1 and 0.2 of a mile radius, which produced no impact for Pope (2008), but Larsen et al. (2003) yielded a financial impact. Linden and Rockoff (2008) observed a radius from 0.1 of a mile to 0.3 of a mile, in which there was no financial impact created by the presence of a registered sex offender. Wentland et al. (2013) examined a distance less or equal to a quarter mile and uncovered a financial impact upon the sale price of a home. All in all, the financial effect was strongest the closer the registered sex offender's residence is to the home and either disappeared or diminished the further away the home was from the registered sex offender.

In regards to distance of the nearest registered sex offender within 0.2 of a mile of a sold home, the present study confirmed that selling prices of the sold homes were affected. There was a significant positive relationship, and a significant prediction where every foot away the sold home is from the nearest registered sex offender the home sale price increased by \$18.92. To illustrate, for every additional 50 feet between a sold home within 0.2 of a mile of a registered sex offender, it was predicted a $\$ 946$ increase in selling price would be experienced. The present study's finding confirmed that the sale price is: 1) affected and 2) the effect is diminished the further away the sold home is from the registered sex offender. 


\section{Distance of the Nearest Sexual Predator Within 0.2 of a Mile}

Three studies examined whether or not a registered sex offender deemed more dangerous would produce a greater financial impact upon the selling price of a home with mixed findings. Keep in mind that all three studies were conducted in three different U.S. states that have contained diverse classifications of these types of registered sex offenders. Larsen et al. (2003) determined registered sex offenders in Ohio with a limited disclosure classification produced a significant financial effect upon the selling price of sold homes within 0.1 of a mile, which was lessened within the concentric ring of 0.1 to 0.2 of a mile. On the other hand, when Pope (2008) set out to investigate whether a financial impact would be produced by the nearby residence of sexual predators in Hillsborough County, Florida it was determined that there was no significant effect by their presence in the Florida U.S. county. In contrast, Wentland's et al. (2013) Virginian sample of violent registered sex offenders produced a significant effect upon a selling price of a home within 0.1 of a mile, but no significant effect was experienced within a quarter mile. Although there was mixed results with the effect of the nearby presence of a subset of registered sex offenders, that by law are more dangerous, they exhibited three notable themes. First, there is a greater financial impact produced by the presence of a more dangerous registered sex offender. Second, the closer a sold home is to a more dangerous registered sex offender the greater financial impact is experienced, which diminishes or is nonexistent the further away the sold home. Third, each U.S. state experienced different results by the presence of a dangerous registered sex offender, which may be contributed by the different classifications or the residency restrictions imposed in their U.S. state.

A look at the present study's results indicated that the distance of the nearest sexual predator within 0.2 of a mile of a sold home uncovered a near significant positive relationship, 
but a significant effect was present that determined the predictive effect upon home selling price. For every foot the sold home is away from the nearest sexual predator the selling price increased by $\$ 18.53$. To demonstrate, for every additional 50 feet between a sold home within 0.2 of a mile of a sexual predator, there was a predicted $\$ 927$ increase in selling price. A $\$ 927$ gain in selling price as a result of the presence of the nearest sexual predator is a slightly lower increase when compared to the financial impact of the nearest registered sex offender. Such a finding confirmed previous literature that determined registered sex offenders deemed more dangerous created a greater financial impact onto the selling prices of homes. Additionally, it cemented the idea that the financial impact is diminished the further distance is placed between the sold home and sexual predator.

Theory

Findings from the present study determined that the broken windows theory was an appropriate theory to be utilized, and a good measurement of social disorganization. The sequence described by the broken windows theory resembled the community reaction of McLean County, Illinois to a registered sex offender, in which resided in areas with forms of social and physical disorder. Ultimately, the reaction to elements of disarray and disorder affected the wish for future investment in such neighborhoods demarcated with unfavorable features.

To begin, the neighborhood conditions involved four 2010 decennial U.S. Census Bureau elements within census blocks. These four types of data were grouped into two factors, which were subsequently labeled as social disorganization (female-headed households and children under the age of 19) and residential instability (renter occupied housing units and vacant homes). These two factors became the indicators of census block disorder. Each sold home in 
McLean County corresponded to their respective census block, thus, each home was assigned their indicator of that particular blocks' disorder ${ }^{32}$.

Concentrations of registered sex offenders and sexual predators produced significant positive relationships between the indicators of census block disorder. Within these 0.2 of a mile buffer zones of concentrated registered sex offenders and sexual predators relationships were stronger with residential instability than they were with social disorganization. Further, concentrations of registered sex offenders were more likely to reside near census blocks with a sold home that contained variables of social disorganization and residential instability than sexual predators. In regards to the financial losses, concentrations of sexual predators were predicted to decrease the selling price of a sold home more so with every increase of social disorganization and residential instability than registered sex offenders. Although these forms of census block disorder created the largest financial losses they were both weak predictors for a sold home's selling price.

The relationships between the indicators of census block disorder and the nearest registered sex offender and sexual predator produced analogous results compared to the concentrations of these offenders. Similar to the relationships between concentration and indicators of census block disorder, sold homes to the nearest registered sex offenders were more likely to be located in a census block that included high levels of social disorganization and residential instability. This is a sensible result, taken in consideration the low sample number of the nearest sexual predator compared to the nearest registered sex offender, thereby, which

\footnotetext{
${ }^{32}$ It was predicted at a significant level that a sold home's selling price was more likely to be influenced by their respective census block that maintained renter occupied housing units and vacant homes (residential instability) than female-headed households and children under the age of 19 (social disorganization).
} 
may have affected the potential to produce a significant effect. Predicted reductions in selling prices were more distinct than in the concentration question. Census blocks that contained a sold home and renter occupied homes and vacant homes with a nearby registered sex offender or sexual predator greatly decreased the selling price of a sold home, more so than the variables in social disorganization. Important to note, the predictive values of residential instability in the distance question were more robust than in the concentration research question. The nearest sexual predator appeared to have produced greater deductions in the selling price of a sold home than the nearest registered sex offender. Moreover, the distance predicted values of the indicators of census disorder were stronger than in the concentration research question, and the explanation of the selling price of a sold home was increased. Meaning, the distance question represented a sturdier response to the influences of a sold home's selling price.

Notably, the present study confirmed literature between the presence of elements of social disorganization and registered sex offenders locations. It is known that concentrations of registered sex offenders reside in areas with increased levels of social disorganization (Hughes \& Burchfield, 2008; Hughes \& Kadleck, 2008; Linden \& Rockoff, 2008; Mustaine \& Tewksbury, 2008; Mustaine et al., 2006a; Mustaine et al., 2006b; Suresh et al., 2010; Tewksbury \& Mustaine, 2008; Tewksbury et al., 2007). Further, past literature stated that registered sex offenders reside in areas demarcated with female-headed households (Mustaine \& Tewksbury, 2008; Mustaine et al., 2006a), children under the age of 19 (Mustaine \& Tewksbury, 2008; Mustaine et al., 2006a), renter occupied housing units (Mustaine \& Tewksbury, 2008; Mustaine et al., 2006a; Mustaine et al., 2006b; Mustaine \& Tewksbury, 2011), and vacant homes (Mustaine \& Tewksbury, 2008; Mustaine et al., 2006a; Mustaine et al., 2006b; Suresh et al., 2010). The study's findings extended the literature in the manner that concentrations of 
registered sex offenders reside near certain forms of disorder via census block in different community settings.

Results from the present study reflected the heart of the broken windows theory, being the unrepaired broken window; where if one window is broken, more will soon be broken (Kelling \& Wilson, 1982). This idea where disorder will invite more disorder was evident in the stronger relationships between indicators of census block disorder and the concentrations of registered sex offenders and sexual predators when matched to the nearest. The residence of one registered sex offender can be recognized as a broken window, therefore imply the message of the level of care of the community. The broken windows theory indicated it invites more deviant characters, therefore more disorder, resulting in citizens withdrawing from the community (Kelling \& Wilson, 1982). Disorder, an element that is specified by Skogan (1990) as physical and social disorder, were prevalent in the present study's clusters of registered sex offenders, clusters of sexual predators, and the nearest registered sex offender and nearest sexual predator. A community riddled with elements of social and physical disorder can motivate citizens to move out and produce a lack of investment into such areas that has resulted negatively in home prices (Skogan, 1990), which was evident in the decreases in selling prices to the presence of registered sex offenders and sexual predators. Generally speaking, the broken windows theory and the elements of disorder were a suitable theoretical framework that matched with the effects evidently produced by the presence of registered sex offenders.

\section{Implications}

In light of the present study's findings, there is an introduction of the financial implications of the presence of registered sex offenders, which has been exposed in various U.S. states, but now it includes an additional U.S. state. Their presence has introduced major 
financial repercussions upon urban areas (Bian et al., 2013; Larsen et al., 2003; Linden \&

Rockoff, 2008; Pope, 2008; Wentland et al., 2013), and now a rural setting in terms of home sale prices. Furthermore, the greater financial losses by the presence of a subset of registered sex offenders deemed more dangerous, which was evident in previous studies (Larsen et al., 2003; Wentland et al., 2013). As highlighted by Cowan et al. (2001) there is a paradoxical outcome to the presence of registered sex offenders and the protection offered by sex offender legislation. All in all, the financial repercussions are evident in various U.S. states, in different community settings, with different sex offender legislation enforced upon those convicted of sexual crimes, which has ostensibly created a need to balance sex offender legislation for public protection and a community's financial well-being.

Change of Population and Setting

The findings of the present study suggested that financial reactions can occur in the selling prices of homes outside of a heavily populated U.S. county that contains a major metropolitan city. Previous studies examined U.S. counties that consisted of an enormous population that paled in comparison to McLean County, Illinois. There is an absence of research that has observed whether or not the presence of registered sex offenders can influence the selling prices of homes in rural areas as they do in urban environments. The present study's findings indicated that the presence of registered sex offenders do influence a sold home's selling price. Ultimately, not only has this financial phenomenon produced by the presence of registered sex offenders been evident in urban areas, but the present study indicated that it may be apparent in a rural and agricultural setting with a much lesser population.

As there were three studies that examined a U.S. county (Larsen et al., 2003; Linden \& Rockoff, 2008; Pope, 2008), two other studies observed an independent city and not U.S. 
counties of the financial implications of the presence of registered sex offenders (Bian et al., 2013; Wentland et al., 2013), therefore, a further examination of population via persons per square mile was required and revealed that there were distinct differences in population density when compared to McLean County, Illinois. Each setting observed in previous work maintained extremely high population densities, whereas McLean County maintained a significantly lesser persons per square mile. Regardless of the major disparity between previous literature's settings of population density, which exhibited the financial phenomenon produced by the presence of registered sex offenders, it continued to be present in the current study and afflicted communities with lower population densities.

Given these points of the differences in community settings, population size, and population density, the presence of registered sex offenders persisted to expose an influence on the selling prices of sold homes. Considering that research indicated a majority of land available for the relocation of registered sex offenders is located in rural and/or agricultural areas due to residency restrictions (Chajewski \& Mercado, 2009; Turley \& Hutzel, 2001; Zandbergen \& Hart, 2006), there should be a cause of concern the effect the presence registered sex offenders might create in these settings. Even though the state of Illinois has enforced a lenient residency restriction and loitering restriction, it continued to produce significant financial consequences onto selling prices of sold homes in a rural, agricultural U.S. county.

\section{Different Residency Restrictions}

This present study not only examined a different community setting, but also a different U.S. state that mandated different sex offender legislation of dissimilar residency restriction 
lengths. Compared to similar previous studies ${ }^{33}$, Illinois has enforced lenient state-wide residency restrictions. Child registered sex offenders have a 500 foot residency restrictions (720 ILCS § 5/11-9.3 (LexisNexis 2014)), whereas, sexual predators have a 500 foot loitering restriction applied to them (720 ILCS $\S 5 / 11-9.4-1$ (LexisNexis 2014)). As a result of residency restrictions, rural areas are predominantly becoming the only remaining legal areas for registered sex offenders to reside in compared other community settings (Chajewski \& Mercado, 2009; Zandbergen \& Hart, 2006), and it is ostensible registered sex offenders are moving toward rural environments (Turley \& Hutzel, 2001). It is also apparent that regardless of the residency restriction applied by each U.S. state toward registered sex offenders, a negative financial effect is still produced. Perhaps this is an indication that regardless of the residency restrictions enforced upon these offenders, the mere presence of a registered sex offender is enough to produce a financial reduction in selling price of a home. Maybe the knowledge of a registered sex offender within their midst produced fear amongst community members to the extent where investment in that particular neighborhood is less desirable, thus, home selling price is lowered in order to attract other buyers.

\section{Different Reactions between Registered Sex Offenders and Sexual Predators}

There are many differences between a criminal sex offender and one that has been classified as a sexual predator in accordance to Illinois sex offender legislation, which may explain the different financial impacts created by registered sex offenders and sexual predators. A registered sex offender is not required to register for life, whereas a sexual predator is required. Therefore, the presence of a sexual predator in a neighborhood will always be known,

\footnotetext{
${ }^{33}$ The state of Virginia has not yet mandated a residency restriction. Although those convicted of sexual crimes are restricted from school related areas (Va. Code Ann. § 18.2-370.5, 2013).
} 
which may be enhanced by their residence in a rural area. Wentland et al. (2013) discussed how the perception of a neighbor in a suburban/rural community may differ from an urban setting. Then again, if one was familiar with their neighbor's would they be more likely to sympathize with the offender, especially considering 'everybody knows everybody' concept in rural areas? The identity of someone in a big city is minimized according to Zimbardo's belief (Diary of a vandalized car, 1969). In other words, the identity of an individual of a lesser population must be more pronounced, especially in an area like McLean County, Illinois. The potential for the offender to be related to someone in a rural surrounding may be increased than registered sex offenders who reside in or near urban areas. Here, the study suggested that the sexual predator's presence might be more known in a rural setting than in an urban environment, due to the substantially increased depreciation in selling price. Additionally, since 2011 , sexual predators are to abide by a 500 foot loitering restriction from public parks where children frequent (720 ILCS § 5/11-9.4-1 (LexisNexis 2014)). A restriction that is not applied to criminal sex offenders. In order to avoid these public parks, which may be placed in safer areas, the homes away from these areas are most likely not desirable than those closer to public parks. All in all, a sexual predator in a rural, agricultural U.S. county in Illinois produced greater financial consequences on selling prices than a registered sex offender.

Concentrations of Registered Sex Offenders and Sexual Predators

This is a novel finding, in the manner that, no previous study has observed the financial reactions upon sale price by the nearby presence of the concentrations of sexual predators in any setting. The present study is the first to directly question whether or not a certain subset of concentrated registered sex offenders located in a largely rural area deemed more dangerous would produce a greater impact on sale price. Research is limited in the examination of the 
financial impacts produced by concentrations of registered sex offenders, but the current study's findings indicated that concentrations of registered sex offenders and sexual predators in rural Illinois yielded reductions in home selling price. In particular, concentrations of sexual predators were predicted to produce greater monetary impacts than concentrations of registered sex offenders. It was known that in rural areas are more at risk of clusters of registered sex offenders than urban areas when controlled for population (Grubesic, 2010). The present study confirmed that concentrations of individuals convicted of sexual crimes do exist in rural areas. Further, those deemed more dangerous yielded greater financial impacts. Again, this is not only an urban issue, but a rural issue.

\section{Broken Windows Theory}

The broken windows theory has been demonstrated in urban areas across the country, but it is unknown whether crime and disorder are perceived differently by residents of rural communities. The present findings exposed that relationships existed between the location of registered sex offenders and indicators of census block disorder. Meaning, perhaps the broken windows theory could be applicable to rural areas and not only to urban areas. Concentrations of registered sex offenders and sexual predators were more likely to reside near census blocks that contained disorder. This is an indication that perhaps the more concentrated registered sex offenders are the more disorder, which is an extension of past literature as this is an observation of a rural U.S. county via census blocks. On the other hand, mixed results were produced in the nearest registered sex offender and sexual predator. Registered sex offenders were more likely to reside near census blocks that contained renter occupied housing units and vacant homes than sexual predators, but this may be related to the lower sample size of sexual predators. It appears as if rural registered sex offenders and sexual predators resided nearby disorder as do 
urban offenders. Two questions remain. First, do these results confirm Kelling and Wilson's (1982) assumption that the broken windows theory can be applied to rural or small and mid-city surroundings? Second, whether registered sex offenders should be viewed as a social disorder?

\section{Limitations}

There are several limitations that the present study has come across that could assist future researchers. Beginning with issues that were present in the study, followed by other variables that limited the current study.

The present study's results should be taken with some caution. The predictor values that included concentration and the nearest of registered sex offenders and sexual predators produced the lowest predictors. In other words, these variables did not play a large role in the influence of a sold home's selling price compared to the control variables used. However, due to the significance and predictor value, there is still an indication that the presence of registered sex offenders and sexual predators in some way in this study influenced home sale price. Furthermore, the variables explained a bit more than half or two-thirds of the influence on the selling price of a sold home in McLean County, which was similar to the previous studies that detailed how much their study explained the home's selling price.

The present study attempted to acquire move-in and move-out dates to include a temporal variable in order to establish a causal link between the present study's registered sex offenders and a sold home's selling price. Unfortunately, an extremely small portion of the McLean County registered sex offenders had such records kept. Larsen and Rockoff (2008) had the luxury of acquiring move-in dates of registered sex offenders and Pope (2008) obtained move-in and move-out dates due to their U.S. state that maintained such records. Larsen and 
Rockoff (2008) noted that the known presence of a registered sex offender could produce two reactions within a neighborhood. If the registered sex offender is well-known by the public it could increase the risk and potentially inhibit future investment and development of new housing. On the other hand, if the registered sex offender has lived there for quite a while, the risk has decreased as their presence is no longer alarming. Ultimately, without a causal link and the present study's findings established indeterminate financial reactions potentially created by the presence of registered sex offenders.

Another type of information that was lacking was the Inconsistent housing property characteristics that occurred during data collection. Since four different tax assessor's offices' supplied the housing property characteristics the information was not constant. In the end, only year built/age and building square footage were utilized as property characteristics of the sold homes in the present study as they were consistently reported. When taken in consideration the strength of the beta values produced by the property characteristics variables in the present study were the strongest predictors. The insertion of more housing variables could have potentially either influenced the strength of the other variables and the explanation of the selling price of a sold home.

Also not inserted into the present study was not accounting for multiple offenders within the buffer zone for the distance question. Granted the nearest registered sex offender and sexual predator were taken in account; the other offenders within the examined buffer zone were not controlled for, as they were in Wentland's et al. (2013) study. Therefore, the influence of multiple offenders may have affected the selling price reduction for every foot away the sold home is from the registered sex offender's residence. 
Other limitations outside of the present study was whether or not the presence of a registered sex offender was known. It is unknown whether community members in McLean County, Illinois were even aware of the nearby residence of a registered sex offender and sexual predator. There is some empirical evidence that reported that a decent amount of community members are unaware of a registered sex offender in their neighborhood (Phillips, 1996; Zevitz, 2003) compounded with the lack of use of the sex offender registries (Levenson, Brannon, Fortney, \& Baker, 2007). But, if the presence of registered sex offenders and sexual predators were unknown to McLean County residents then there should be no financial repercussion onto home sale prices.

The issue of whether the presence of a registered sex offender is known is compounded with whether or not the registered sex offender and/or sexual predator were even at their listed residence. Fortunately, the state of Illinois reported a compliance rate is $93 \%$ in the year 2012 (Yeagle, 2012) and the current study removed offenders that were non-compliant, in which only six were removed due to their non-compliant status. Additionally, eight offenders in McLean County were reported as being homeless, which were effectively removed. On another note, would it matter if the registered sex offender reported a false address if the perception is what is being captured in the present study? In other words, if community members believe that a registered sex offender placed residence in their area it's the reaction of the community members that's being investigated, not whether or not they actually live at their reported address. Regardless, it would be difficult to observe the impact of nomadic registered sex offenders, especially since it is known for them to be highly transient (Hughes \& Kadleck, 2008; Pope, 2008; Suresh et al., 2010; Turley \& Hutzel, 2001). 
Elements unseen to the researcher could have played a factor in why the selling price was reduced. There could be other factors that may play a role in sale value of the property other than the fact that there is a registered sex offender nearby, such as the type of paint used for the house. Such distasteful factors, unobservable by the researcher, can influence sale cost of the home beside the nearby residence of an offender (Linden \& Rockoff, 2008). Other variables that could have been inserted into the present study are crime. Criminal activities could have been considered as being an influence and strengthened the explanation of the selling price of a sold home. It could have also affected the strength of the influence registered sex offenders played onto selling price.

The housing market economy was also not considered as a variable that may have influenced the present study's findings. The real estate market is a volatile economy, and if it was inserted as a factor for the explanation of this financial phenomenon potentially produced by registered sex offenders, it may have quelled the selling price reductions. Anecdotally, the McLean County Assessor's office reported that the year 2013 - the examined year for home sales in McLean County - was one of the best years for home sales. However, the present study only examined one year and not multiple years, therefore, would the real estate market of one year yielded enough influence onto the selling price?

As McLean County, Illinois is considered largely an agricultural and rural community, the findings in the present study should not be generalized to other U.S. counties. This was an observation of the financial impacts of just one U.S. county in the state of Illinois, which has enforced different sex offender legislation. The financial experiences may vary from other counties within the state of Illinois, as well as other U.S. states. Variables that were utilized in the present study may differ and predict differently across the nation. 
In examining a rural U.S. county like McLean County, the largest U.S. county in the state of Illinois, it forced the study to examine via census blocks, the smallest representation utilized by the U.S. Census Bureau. An examination of the census block groups would unlikely have yielded a meaningful result, as some of the census block groups in McLean County ranged from 0.1 square miles to 130.87 square miles of land area, thus an unfair representation. Under these circumstances, one is limited to the availability of information collected. The variables utilized via the 2010 decennial U.S. Census Bureau in the present study were the only variables available. Unfortunately, the factor analysis paired female-headed households and children under the age of 19. This raised a further issue due to female-headed households being standardized to households per census block, whereas children under the age of 19 were standardized to the total population per census block. Additionally, the variables within residential instability, renter occupied housing units and vacant homes were standardized by the total number of households per census block. In the final analysis, the indicator of census block disorder, social disorganization may have not been truly representative as a result of one of the variables being standardized to the population and invited the possibility of a skewed result. Ultimately, this is one of the major limitations when conducting an observation of a rural environment.

Be forewarn, this study does produce challenges in the examination of rural areas and exploration of the financial reactions by the presence of a registered sex offender and sexual predator. Information collected by the U.S. Census Bureau are limited at the census block level, whereas, they are much grander at the census block group level. Unfortunately, at the census block group level, in particular with McLean County, the largest U.S. county by size in the state of Illinois, the likelihood to produce a significant finding where the population density is 
extremely low is unlikely. Originally, the current study examined 0.1 of a mile due to tits conversation to 526 feet, near the 500 foot loitering restriction applicable to sexual predators since 2011 (720 ILCS § 5/11-9.4-1 (LexisNexis 2014)). It was deemed that not enough registered sex offenders could contribute to a significant finding within this distance. Further, related to the fact the setting is largely a rural community. Where in urbanized areas, the financial loss may immediately dissipate after the 0.1 of a mile buffer; it does not manufacture a finding in rural settings. Perhaps, this is one of the reasons rural settings are not examined enough, due to the fact it is difficult to observe an area and produce meaningful results with a low population.

\section{Recommendations for Future Research}

As a result of the findings in the current study, there are ideas for future examination. A discussion of some of the limitations and issues that presented them in the study is also mentioned as ideas for extended research. More research needs to be conducted to determine whether or not these financial reductions are exposed in other rural U.S. counties. It could be that McLean County is exhibiting unique financial repercussions due to the presence of registered sex offenders. Whereas, previous research was performed in urban areas, it seems apparent that registered sex offenders reduce selling prices of homes, but no one study has conducted in a rural setting with such a minimal population and low population density. Granted, Bian et al. (2013) and Wentland et al. (2013) stated they studied in a suburban/rural area, they did not specifically state the definition of their surroundings. Regardless, the present study's conclusions are wary. Additionally, with registered sex offenders' moving into rural areas (Chajewski \& Mercado, 2009; Turley \& Hutzel, 2001; Zandbergen \& Hart, 2006) more research needs to be conducted in order to examine the effects they are creating due to their presence. 
Additional home property characteristics are highly recommended to be inserted into future research studies. In doing so, it may clarify the financial influence between the property characteristics may have onto the selling price to the presence of a nearby registered sex offender. Unfortunately, in the present study, property characteristics were inconsistent. The present study did utilize sale date; unfortunately it yielded an extremely minimal influence on the selling price ${ }^{34}$. This is a sensible reaction considering sale date would affect the rate of sale rather than the selling price. For instance, homes sold in the winter would receive fewer buyers since snow would inhibit the view of the whole home while summer would most likely experience a greater increase in sold homes where it would be more convenient to move, especially for families with children as their children would be out of school.

A future investigation needs to be conducted to determine why there are different relationships between the concentrations of registered sex offenders and sexual predators to sold home property characteristics and forms of census block disorder. Concentrations of registered sex offenders were more likely to reside nearby old homes than sexual predators, as well as reside nearby smaller homes. Furthermore, concentrations of registered sex offenders were more likely to reside in social disorganization (female-headed households and children under 19) and residential instability (renter occupied housing units and vacant homes) than concentrations of sexual predators.

Findings from the present study revealed that the nearest sexual predator averaged a further distance from a sold home than the nearest registered sex offender. Additionally, the sexual predators observed in the study produced weaker relationships than registered sex

\footnotetext{
${ }^{34}$ When sale date was inserted into the regression analysis, the influence onto variance was less than one percent.
} 
offenders as a whole. Under those circumstances, one can infer these sexual predators are most likely located further away from the community, but this is all speculation from the results. Is this only prevalent in rural settings or is it also applicable to urban areas?

For the future, possibly examine within 0.3 of a mile in a rural environment. Such an examination can determine whether or not the financial phenomenon dissipates, disappears, or strengthens. It is unknown whether or not financial observations via home sale price of a rural setting will reproduction similar reactions compared to past literature, which have examined urban areas.

In light of a discussion about urban areas, a further examination can be conducted in a myriad of communities to determine whether or not this financial phenomenon produced by sex offenders exists in another U.S. county in Illinois, particularly Cook County - home of Chicago, Illinois. It would be able to distinguish the differences between a rural and urban U.S. county in the same U.S. state. Furthermore, an examination whether or not the difference of more dangerous registered sex offenders yielded greater financial impacts onto sold homes.

It was beyond the scope of the study to determine whether or not a registered sex offender was actually at their listed residence. Additionally, it does create an interesting question regarding the differences between compliance rates between rural, suburban, and urban settings. Linden and Rockoff (2008) and Pope (2008) had the luxury of obtaining move-in and/or move-out dates for their registered sex offender list. Do U.S. counties differ in their procedures of keeping such records? Take in consideration, each of the researchers U.S. county's maintained a major metropolitan city, whereas, McLean County is not as highly populated. 
If a number of neighborhood residents are unaware of a registered sex offender in their neighborhood, is there a reason? What reasons are attributed to their lack of knowledge of registered sex offenders within their community? Linden and Rockoff (2008) mentioned that the closer a non-offenders home is to a registered sex offender, the more likely their presence is known. So does proximity influence a neighbor's knowledge of nearby registered sex offenders? One can investigate why non-offenders are unaware of a registered sex offender in their community and whether their awareness is influenced by the proximity of the registered sex offender. Furthermore, whether their awareness is changed due to the level of dangerousness of the registered sex offender?

In different community settings, does the awareness of registered sex offenders change? The definition of neighbor may be quite different in a rural setting than in an urban setting. Noted in Wentland's et al. (2013) study, that the perception of a neighbor is different in rural and suburban settings, therefore, may have explained the drastic differences between their financial impacts to previous literature. Websdale (1995, p. 102) stated "rural to refer to certain types of communities where people know each other's business, come into more regular contract with each other, and share a larger core of values than is true of people in urban areas". In other words, traits like low population and low densities produced a level of familiarity with everybody compared to urban areas which lack such features. On one hand, rural environments contain an atmosphere where everybody knows everything, but on the other side of the spectrum, it can offer anonymity due to the sparse population spread out of vast amounts of land. Research has already confirmed that registered sex offender prefer anonymity (Burchfield \& Mingus, 2008; Levenson \& Cotter, 2005; Mustaine et al., 2006a; Norman-Eady, 2007). Future research must be conducted in order to see which perspective 
holds true in rural areas and whether it will confirm or conflict with the stereotypical belief of rural areas.

Once the presence of a registered sex offender is known are community members surprised that a registered sex offender has a residential location in their neighborhood or consider them a form of disorder? With regard to the broken windows theory, the perception of safety was influenced by the element of disorder (Kelling \& Wilson, 1982). Furthermore, are areas with different levels of social disorganization experience differences in awareness? Areas that registered sex offenders choose are generally socially disorganized (Mustaine et al., 2006a). These locations can encourage re-offending (Levenson \& Cotter, 2005; Mustaine et al., 2006a) or offer escape from their criminal sexual history (Burchfield \& Mingus, 2008; Mustaine et al., 2006a). Such areas generally lacked investment and interest by community members, as well as increased levels of economic disadvantage. As a result, these communities may not have the amenities offered by sex offender legislation in order to protect themselves, proper access to the Internet (Tewksbury \& Mustaine, 2008).

\section{Conclusion}

The present study identified several financial effects produced by the presence of registered sex offenders in a community.

First, the financial phenomenon of the presence of registered sex offenders occurred in not only urban areas, but also in rural settings. Important to note, this study examined a U.S. state not yet to be examined for the monetary losses in selling price of sold homes that still produced similar results as the previous literature. Furthermore, a U.S. county that is home to a much lesser population with a lower population density. Examination of a rural U.S. county 
exhibited decreased selling prices, which may be as a result of a nearby registered sex offender. Previous literature displayed that this phenomenon occurred in urban area, if this is evident in a different U.S. state and in a rural area with a lesser population, is this a nation-wide phenomenon?

The second conclusion is that concentrations of sexual predators, a subset of registered sex offenders predicted greater financial losses in terms of selling prices than registered sex offenders as a whole. Granted, each U.S. state has different definitions for registered sex offenders deemed more dangerous, which may have resulted in different financial reactions produced by this subset, the level of dangerousness by a registered sex offender has the possibility to yield a greater financial impact. In other words, the residence of a more dangerous sex offender in an area produced greater monetary losses, therefore are more harmful to the financial stability of the surrounding areas.

The third conclusion is that sex offender legislation may need to be rethought in light of these findings due to the conflict between public protection and the financial livelihood of the publics' surroundings. Sex offender legislation has produced unintended financial consequences onto communities located in urban areas and the present findings suggested such financial harm has occurred in a rural area. An indication that there are wider implications from the legal mandates enforced onto registered sex offenders than previously thought. Specifically, residency restrictions, which appear to have no explanation for their chosen length from the areas where registered sex offenders are restricted to be near, as well as a discord of U.S. state and jurisdiction agreement in the chosen lengths. Moreover, not every U.S. state has mandated a residency restriction and yet financial harm is predicted to occur onto a neighborhood regardless of an enforced residency restriction. It is unlikely a policymaker will combat these 
forms of sex offender legislation and commit political suicide and be seen as an advocate for registered sex offenders in the eyes of the public, regardless of the evidence of the financial damage produced by the presence of registered sex offenders. Further, the stated purpose of sex offender legislation is to protect the public, yet it is laid upon the shoulders of the community members to utilize the legislation to their benefit and become aware of their surroundings, of which some may not know the locations of registered sex offenders near them. This massive public outcry for the protection against individuals that committed sexual crimes has created a fortuitous effect that relegated registered sex offenders into disordered neighborhoods and one unexpected outcome are depreciated home selling prices. Ultimately, sex offender legislation intended on public protection from such individuals, but also created a paradox where the public has experienced financial harm by the residences of registered sex offenders in their community. 


\section{REFERENCES}

720 ILL. COMP. STAT. ANN. 5/11-9.3 (LexisNexis 2014)

720 ILL. COMP. STAT. ANN. 5/11-9.1(b) (LexisNexis 2014)

720 ILL. COMP. STAT. ANN. 5/11-9.4-1 (LexisNexis 2014)

725 ILL. COMP. STAT. 205/1-01 (LexisNexis 2013)

725 ILL. COMP. STAT. 205/4.01 (LexisNexis 2013)

725 ILL. COMP. STAT. 205/10 (LexisNexis 2013)

725 ILL. COMP. STAT. 207/5(f) (LexisNexis 2013)

730 ILL. COMP. STAT. 150/ (LexisNexis 2013)

730 ILL. COMP. STAT. 150/2 (LexisNexis 2013)

730 ILL. COMP. STAT. 150/3 (LexisNexis 2013)

730 ILL. COMP. STAT. 150/6 (LexisNexis 2013)

730 ILL. COMP. STAT. 150/7 (LexisNexis 2013)

730 ILL. COMP. STAT. 152/101 (LexisNexis 2013)

730 ILL. COMP. STAT. 152/120 (LexisNexis 2013)

730 ILL. COMP. STAT. 152/122 (LexisNexis 2013)

Adam Walsh Child Protection Act, 2006, Pub. L. No. 109-248, 120 Stat. 587 (2013).

Adam Walsh Child Protection and Safety Act (2013, February 25). National Conference of State Legislatures. Retrieved April $2^{\text {nd }}, 2013$, from http://www.ncsl.org/issuesresearch/justice/adam-walsh-child-protection-and-safety-act.aspx

Bian, X., Brastow, R., Stoll, M., Waller, B., \& Wentland, S. (2013). Neighborhood tipping and sorting dynamics in real estate: Evidence from the Virginia sex offender registry. 
Burchfield, K. B., \& Mingus, W. (2008). Not in my neighborhood: Assessing registered sex offenders' experiences with local social capital and social control. Criminal Justice and Behavior, 35(3), 356-374. doi: 10.1177/00938548073113

Chajewski, M., \& Mercado, C. C. (2009). An evaluation of sex offender residency restriction functioning in town, county, and city-wide jurisdictions. Criminal Justice Policy Review, 20(1), 44-61. doi: 10.1177/0887403408320845

Cook, P. J. (2008). Assessing urban crime and its control: An overview. National Bureau of Economic Research Working paper Series No. 13781.

Cowan, D., Pantazis, C., \& Gilroy, R. (2001). Social housing as crime control: An examination of the role of housing management in policing sex offenders. Social \& Legal Studies, 10(4), 435-457.

Davey, M. (2006, March 15). lowa's residency rules drive sex offenders underground. New York Times. Retrieved April $5^{\text {th }}, 2013$, from http://classes.maxwell.syr.edu/psc202_s05/Kristi/sex\%20offenders\%20in\%20iowa.pdf

Diary of an abandoned car. (1969, February 28). Times, 93(9), 68. Retrieved from http://ehis.ebscohost.com.libproxy.lib.ilstu.edu/eds/detail?sid=991f42a1-90c8-41818 eab-

20184a1154a5\%40sessionmgr110\&vid=1\&hid=107\&bdata=JnNpdGU9ZWRzLWxpdmUm c2NvcGU9c2I0ZQ\%3d\%3d\#db=a9h\&AN=54042882

Edward Byrne Memorial Justice Assistance Grant Program of 1968, 42 U.S.C.S. § 3750 (LexisNexis 2013).

Fact sheet: What you need to know about sex offenders. (2008). Center for Sex Offender Management. Retrieved April $2^{\text {nd }}, 2013$, from http://www.csom.org/pubs/needtoknow_fs.pdf

Fla. Stat. Ann. § 947.1405 (LexisNexis 2013)

Frequently Asked Questions. (2014). Retrieved January $8^{\text {th }}, 2014$, at http://www.isp.state.il.us/sor/faq.cfm

Gau, J. M., \& Pratt, T. C. (2008). Broken windows or window dressing? Citizens' (in)ability to tell the difference between disorder and crime. Criminology \& Public Policy, 7(2), 163-194. doi: 10.1111/j.1745-9133.2008.00500.x

Grubesic, T. H. (2010). Sex offender clusters. Applied Geography, 30(1), 2-18. doi: 10.1016/j.apgeog.2009.06.002 
Grubesic, T. H., Murray, A. T., \& Mack, E. A. (2011). Sex offenders, residence, restrictions, housing, and urban morphology: A review and synthesis. Cityscape: A Journal of Policy Development and Research, 13(3), 7-31.

Guide to sex offender registration in Illinois/prepared for Illinois Criminal Justice Agencies. (2006). Springfield, IL: Illinois State Police.

Hughes, L. A., \& Burchfield, K. B. (2008). Sex offender residence restrictions in Chicago: An environmental injustice? Justice Quarterly, 25(4), 647-673. doi: 10.1080/07418820802119976

Hughes, L. A., \& Kadleck, C. (2008). Sex offender community notification and community stratification. Justice Quarterly, 25(3), 469-495. doi: 10.1080/07418820701710941

Illinois Voices for Reform, Inc. (2012). The term "sexual predator" and what it means in Illinois. Retrieved October 17, 2013, at http://www.ilvoices.com/media/cc240e1817464761ffff8aeeffffe415.pdf

Jacob Wetterling Crimes Against Children and Sexually Violent Offender Registration Program of 1994, 42 U.S.C. § 14071 (2013).

Kelling, G. L., \& Wilson, J. Q. (1982). 'Broken Windows'. Atlantic Monthly. March, pp. 29-38.

Larsen, J. E., Lowrey, K. J., \& Coleman, J. W. (2003). The effect of proximity to a registered sex offender's residence on a single-family house selling price. The Appraisal Journal, 71(3), 253-265.

Levenson, J. S., \& Cotter, L. P. (2005). The effect of Megan's Law on sex offender reintegration. Journal of Contemporary Criminal Justice, 21(1), 49-66. doi: $10.1177 / 1043986204271676$

Levenson, J. S., Brannon, Y. N., Fortney, T., \& Baker, J. (2007). Public perceptions about sex offenders and community protection policies. Analyses of Social Issues and Public Policy, 7(1), 1-25. doi: 10.1111/j.1530-2415.2007.00119.x

Linden, L., \& Rockoff, J. E. (2008). Estimates of the impact of crime risk on property values from Megan's Laws. American Economic Review, 98(3), 1103-1127. doi: 10.1257/aer.98.3.1103

Lovett, I. (2013, March 9). Neighborhoods seek to banish sex offenders by building parks. The New York Times. Retrieved May $30^{\text {th }}, 2013$, from http://www.nytimes.com/2013/03/10/us/building-tiny-parks-to-drive-sex-offendersaway.html?pagewanted=all\&_r=0 
Matson, S., \& Lieb, R. (1996). Community notification in Washington State: A 1996 survey of law enforcement. Olympia, WA: Washington State Institute for Public Policy.

Megan's Law of 1996, Pub. L. No. 104-145, 110 Stat. 1345 (2013).

Meloy, M. L., Miller, S. L., \& Curtis, K. M. (2008). Making sense out of nonsense: The deconstruction of state-level sex offender residence restrictions. American Journal of Criminal Justice, 33(2), 209-222. doi: 10.1007/s12103-008-9042-2

Mustaine, E. E., \& Tewksbury, R. (2008). Registered sex offenders, residence, and the influence of race. Journal of Ethnicity in Criminal Justice, 6(1), 65-82. doi: 10.1300/J222v06n01_05

Mustaine, E. E., Tewksbury, R., Stengel, K. M. (2006a). Social disorganization and residential locations of registered sex offenders: Is this a collateral consequence? Deviant Behavior, 27(3), 329-350. doi: 10.1080/01639620600605606

Mustaine, E. E., Tewksbury, R., \& Stengel, K. M. (2006b). Residential location and mobility of registered sex offenders. American Journal of Criminal Justice, 30(2), 177-192.

Mustaine, E. E., \& Tewksbury, R. (2011). Residential relegation of registered sex offenders. American Journal of Criminal Justice, 36(1), 44-57. doi: 10.1007/s12103-010-9102-2

N.C. Gen. Stat. § 14-208.16 (2013)

$\mathrm{Ng}, \mathrm{C}$. (2013, March 20). Family sues to force sex offender neighbor to buy its house. ABCNews.com. Retrieved March 20, 2013, from http://abcnews.go.com/US/pa-familysues-force-sex-offender-neighbor-buy/story?id=18773177

Norman-Eady, S. (2007). Sex offenders' residency restrictions (2007-R-0380). http://www.cga.ct.gov/2007/rpt/2007-R-0380.htm.

Ohio Rev. Code Ann. § 1950.034 (LexisNexis 2013)

Olson, M. (2010). Putting the brakes on the preventive state: Challenging residency restrictions on child sex offenders in Illinois under the Ex Post Facto Clause. Northwestern Journal of Law \& Social Policy, 5(2), 403-436.

Parks, W. (2001, March 13). Racine residents voice concerns over sex offender's release. Racine Journal Times. Retrieved April 5, 2013, from http://journaltimes.com/news/local/racineresidents-voice-concerns-over-sex-offender-s-release/article_3f3f98ec-3e6c-53b9-b1fa8878b8fc6e91.html

Perkins, D. D., Florin, P., Rich, R. C., Wandersman, A., \& Chavis, D. M. (1990). Participation and the social and physical environment of residential blocks: Crime and community context. American Journal of Community Psychology, 18(1), 83-115. doi: 10.1007/BF00922690 
Perkins, D. D., Meeks, J. W., \& Taylor, R. B. (1992). The physical environment of street blocks and resident perceptions of crime and disorder: Implications for theory and measurement. Journal of Environmental Psychology, 12(1), 21-34. doi: 10.1016S0272-4944(05)80294-4

Perkins, D. D., \& Taylor, R. B. (1996). Ecological assessments of community disorder: Their relationship to fear of crime and theoretical implications. American Journal of Community Psychology, 24(1), 63-107.

Pope, J. C. (2008). Fear of crime and housing prices: Household reactions to sex offender registries. Journal of Urban Economics, 64(3), 601-614. doi: 10.1016/j.jue.2008.07.001

Prentky, R. A. (1996). Community notification and constructive risk reduction. Journal of Interpersonal Violence, 11(2), 295-298. doi: 10.1177/088626096011002012

Price-Spratlen, T., \& Santoro, W. A. (2011). Neighborhood disorder and individual community capacity: how incivilities inform three domains of psychosocial assessment. Sociological Spectrum, 31(5), 579-605. doi: 10.1080/02732173.2011.589785

"Qualifying Urban Areas for the 2010 Census." Federal Register 70:59 (27 March 2012) p. 1865218669.

Rudin, J. B. (1996). Megan's law: Can it stop sexual predators - and at what cost to constitutional rights? Criminal Justice, 11(3), 3-10, 60-63.

Sample, L. L., \& Bray, T. M. (2003). Are sex offenders dangerous? Criminology \& Public Policy, 3(1), 59-82. doi: 10.1111/j.1745-9133.2003.tb00024.x

Sample, L. L., \& Kadleck, C. (2008). Sex offender laws: Legislators' accounts of the need for policy. Criminal Justice Policy Review, 19(1), 40-62. doi: 10.1177/0887407308292

Sampson, R. J., \& Raudenbush, S. W. (1999). Systematic social observation of public spaces: A new look at disorder in urban neighborhoods. American Journal of Sociology, 105(3), 603-651. doi: 10.1086/210356

Seo, W., \& Rabenau, B. V. (2011). Spatial impacts of microneighborhood physical disorder on property resale values in Columbus, Ohio. Journal of Urban Planning and Development, 137(3). doi: 10.1061/(ASCE)UP.1943-5444.0000067

Sex offender registration: Policy overview and comprehensive practices (2012, March 30). Center for Sex Offender Management. Retrieved April 2nd, 2013, from http://www.csom.org/pubs/sexreg.html

Skogan, W. G. (1990). Disorder and decline: Crime and the spiral decay in American neighborhoods. New York, NY: The Free Press. 
Skogan, W. G., \& Hartnett, S. M. (1997). Community policing, Chicago style. New York, NY: Oxford University Press.

Skogan, W. G., \& Maxfield, M. (1981). Coping with crime: Individual and neighborhood reactions. Newbury Park, CA: Sage Publications Inc.

Skogan, W. G. (1999). Measuring what matters: Crime, disorder, and fear. In R. H. Langworthy (Ed.), Measuring what matters: Proceedings from the policing research institute meetings. Washington, D. C.: National Institute of Justice.

Socia, K. M., \& Stamatel, J. P. (2012). Neighborhood characteristics and the social control of registered sex offenders. Crime \& Delinquency, 58(4), 565-587. doi: 10.1177/0011128711420111.

Suresh, G., Mustaine, E. E., Tewksbury, R., \& Higgins, G. E. (2010). Social disorganization and registered sex offenders: An exploratory spatial analysis. Southwest Journal of Criminal Justice, $7(2), 180-213$.

Taylor, R. B. (1999a). Crime, grime, fear, and decline: A longitudinal look. Washington, D.C.: National Institute of Justice.

Taylor, R. B. (1999b). The incivilities thesis: Theory, measurement, and policy [NCJ 170610]. In R. H. Langworthy (Ed.), Measuring what matters: Proceedings from the policing research institute meetings (pp. 65-88). Washington, D. C.: National Institute of Justice.

Tewksbury, R. (2002). Validity and utility of the Kentucky sex offender registry. Federal Probation, 66(1), 21-26.

Tewksbury, R. (2005). Collateral consequences of sex offender registration. Journal of Contemporary Criminal Justice, 21(1), 67-81. doi: 10.1177/1043986204271704

Tewksbury, R., \& Higgins, G. (2005). What can be learned from an online sex offender registry site? Journal of Community Corrections, 14(3), 9-16.

Tewksbury, R., \& Lees, M. B. (2006). Perceptions of sex offender registration: Collateral consequences and community experiences. Sociological Spectrum, 26(3), 309-334. doi: $10.1080 / 02732170500524246$

Tewksbury, R., \& Mustaine, E. E. (2006). Where to find sex offenders: An examination of residential locations and neighborhood conditions. Criminal Justice Studies, 19(1), 61-75. doi: 10.1080/14786010600615991

Tewksbury, R., Mustaine, E. E., \& Stengel, K. M. (2007). Residential concentrations of rural registered sex offenders. American Journal of Criminal Justice, 31(2), 49-63. doi: 10.1007/s12103-007-9004-0 
Tewksbury, R., \& Mustaine, E. E. (2008). Where registered sex offenders live: Community characteristics and proximity to possible victims. Victims and Offenders, 3(1), 86-98. doi: $10.1080 / 15564880701752371$

The Newark foot patrol experiment. (2013). Police Foundation. Retrieved March 16, 2013, from http://www.policefoundation.org/content/newark-foot-patrol-experiment

Turley, E., \& Hutzel, L. (2001). West Virginia sex offender study. Charleston, WV: Division of Criminal Justice Sciences. Retrieved April $6^{\text {th }} 2013$, from, http://www.djcs.wv.gov/SAC/Documents/WVSAC_SexOffender01_Report.pdf

U.S. Census Bureau State \& County QuickFacts. (2012). State and county quick facts: McLean County, Illinois. Retrieved August 1, 2013, from http://quickfacts.census.gov/qfd/states/17/17113.html

U.S. Census Bureau State \& County QuickFacts. (2013a). State and county quick facts: Hillsborough County, Florida. Retrieved October 30, 2013, from http://quickfacts.census.gov/qfd/states/12/12057.html

U.S. Census Bureau State \& County QuickFacts. (2013b). State and county quick facts: Mecklenburg County, North Carolina. Retrieved October 30, 2013, from http://quickfacts.census.gov/qfd/states/37/37119.html

U.S. Census Bureau State \& County QuickFacts. (2013c). State and county quick facts: Montgomery County, Ohio. Retrieved October 30, 2013, from http://quickfacts.census.gov/qfd/states/39/39113.html

U.S. Census Bureau State \& County QuickFacts. (2013d). State and county quick facts: Lynchburg (city), Virginia. Retrieved October 30, 2013, from http://quickfacts.census.gov/qfd/states/51/5147672.html

U.S. Census Bureau State \& County QuickFacts. (2014). State and county quick facts: Rhode Island. Retrieved April 20, 2014, from http://quickfacts.census.gov/qfd/states/44000.html

U.S. Census Bureau. (2007a). Annual estimates of the population for counties of Florida: April 1, 2000 to July 1, 2006 (CO-EST2006-01-12). Retrieved July 11, 2013, from http://www.census.gov/popest/data/counties/totals/2006/CO-EST2006-01.html

U.S. Census Bureau. (2007b). Annual estimates of the population for counties of North Carolina: April 1, 2000 to July 1, 2006 (CO-EST2006-01-37). Retrieved July 11, 2013, from http://www.census.gov/popest/data/counties/totals/2006/CO-EST2006-01.html 
U.S. Census Bureau. (2010). USA counties: Population estimates. Retrieved August 1, 2013, from http://censtats.census.gov/cgi-bin/usac/usatable.pl

U.S. Department of Justice. Office of Justice Programs. (2008, July). Sex offender residency restrictions: How mapping can inform policy (NCJ 222759). Washington, DC: Author.

Wentland, S., Waller, B., \& Brastow, R. (2013) Estimating the effect of crime risk on property values and time on market: Evidence from Megan's Law in Virginia. Property, Land Use and Real Estate Law, 41(3), 1-40.

Yeagle, P. (2012, April 19). Reformers: Sex offender mandate would hurt Illinois. IllinoisTimes. Retrieved September $9^{\text {th }}, 2012$, from http://www.illinoistimes.com/Springfield/article9911-reformers-sex-offend.html

Zandbergen, P. A., \& Hart, T. C. (2006). Reducing housing options for convicted sex offenders: Investigating the impact of residency restriction laws using GIS. Justice Research and Policy, 8(2), 1-24.

Zandbergen, P. A., \& Hart, T. C. (2009). Availability and spatial distribution of affordable housing in Miami-Dad County and implications of residency restriction zone for registered sex offenders. Miami, FL: Miami Capitation for the Homeless.

Zevitz, R. G. (2003). Sex offender community notification and its impact on neighborhood life. Crime Prevention and Community Safety: An International Journal, 5(4), 41-61. doi: 10.5555/crpr.2003.5.4.41

Zevitz, R. G. (2004). Sex offender placement and neighborhood social integration: The making of a scarlet letter community. Criminal Justice Studies, 17(2), 203-222. doi: 10.1080/0888431042000235039

Zevitz, R. G. (2006). Sex offender community notification: Its role in recidivism and offender reintegration. Criminal Justice Studies, 19(2), 193-208. doi: 10.1080/14786010600764567

Zevitz, R. G., \& Farkas, M. A. (2000a). Sex offender community notification: Examining the importance of neighborhood meetings. Behavioral Sciences and the Law, 18(2-3), 393408.

Zevitz, R. G., \& Farkas, M. A. (2000b). Sex offender community notification: Managing high risk criminals or exacting further vengeance? Behavioral Sciences and the Law, 18(2-3), 375391.

Zimbardo, P. (2007). The Lucifer effect: Understanding how good people turn evil. New York, NY: Random House Inc. 